\title{
TRATAMENTO QUÍMICO DO SOLO VISANDO AO CONTROLE DO CUPIM COPTOTERMES GESTROI (WASMANN, 1896), (ISOPTERA: RHINOTERMITIDAE)
}

\author{
JOÃO FERNANDO BERNARDINI \\ Licenciado em Ciências
}

Orientador: Prof. Dr. OCTAVIO NAKANO

\author{
Dissertação apresentada à Escola Superior de \\ Agricultura "Luiz de Queiroz", Universidade de \\ São Paulo, para obtenção do título de Mestre \\ em Ciências, área de Concentração: \\ Entomologia. \\ PIRACICABA \\ Estado de São Paulo - Brasil \\ Julho - 2005
}


Dados Internacionais de Catalogação na Publicação (CIP) DIVISÃO DE BIBLIOTECA E DOCUMENTAÇÃO - ESALQ/USP

\section{Bernardini, Joāo Fernando}

Tratamento químico do solo visando ao controle do cupim Coptotermes gestroi (Wasmann, 1896), (Isoptera: Rhinotermitidae) / Joāo Fernando Bernardini. - - Piracicaba, 2005.

84 p. : il.

Dissertaçāo (Mestrado) - - Escola Superior de Agricultura Luiz de Queiroz, 2005.

Bibliografia.

1. Comportamento animal 2. Controle quimico 3. Cupim-subterraneo 4. Inseticida 5. Repelente 6. Tratamento do solo I. Titulo

CDD 632.736

"Permitida a cópia total ou parcial deste documento, desde que citada a fonte - O autor" 
Dedico este trabalho à minha família, parentes e amigos,

especialmente à:

minha esposa Roseane;

meus pais João e Lucila

e minha irmã Luciana. 


\section{AGRADECIMENTOS}

Ao Prof. Dr. Octavio Nakano, pela confiança, ensinamentos, amizade e excelente orientação;

À Universidade de São Paulo (USP), especialmente ao Departamento de Entomologia, Fitopatologia Agrícola da Escola Superior de Agricultura "Luiz de Queiroz" (ESALQ), pelo acolhimento e ensinamentos recebidos dos meus professores: Dr. Octavio Nakano, Dr. Gilberto Casadei de Baptista, Dr. Evoneo Berti Filho, Dr. José Djair Vendramim, Dr. Roberto Antonio Zucchi e Dr. Paulo Sergio Oliveira;

Ao colega Oscar R. P. Bendeck, pela amizade, oportunidade e valiosos ensinamentos;

Aos amigos da Bayer, especialmente ao Daniel D’andrea e Flávio Brandão, pela confiança, amizade e apoio;

À Bayer Environmental Science pelas oportunidades e apoio técnico que me foram oferecidos no decorrer deste trabalho;

Ao Laboratório de Resíduos de Pesticidas do Dep. de Entomologia, Fitopatologia e Zoologia Agrícola da ESALQ/USP, especialmente ao Dr. Luiz R. P. Trevizan pela amizade e apoio técnico nas análises de resíduo; 
Ao amigo Dr. Luiz R. O. Fontes, pela amizade, estímulo e auxilio na identificação do Coptotermes gestroi;

Ao colega Augusto C. Florim da Desinsecta Controle Profissional de Pragas pela amizade e pelos importantes conhecimentos compartilhados;

Ao colega Alfredo J. Rossetto Junior da Empresa Helpinsect Higienização e Controle de Pragas, pela amizade e pelas valiosas contribuições;

Ao colega Sergio B. Alves Júnior da Empresa Biomax, pela amizade e pelas fundamentais informações;

Ao colega Samuel C. Dal Porto da Controlinset S/C Ltda pela amizade e pelas valiosas contribuições técnicas;

A todos os amigos da Entomologia, especialmente a Fabiana C. B. Romano e Catia S. S. Sazaki, pela amizade e incentivo;

A Bibliotecária Silvia Zinsly, pelo auxilio na elaboração da dissertação;

A todas as pessoas que, de alguma forma, contribuíram para a realização deste trabalho. 


\section{SUMÁRIO}

Página

LISTA DE FIGURAS.............................................................. viii

LISTA DE TABELAS ..............................................................

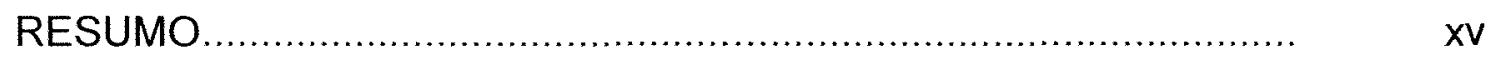

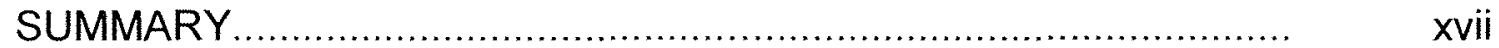

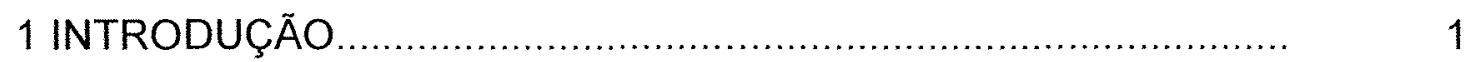

2 REVISÃO DE LITERATURA ................................................. 3

2.1 Descrição, comportamento e biologia do Coptotermes gestroi .... 3

2.2 Origem e distribuição do C. gestroi ........................................... 7

2.3 Importância econômica ............................................................. 9

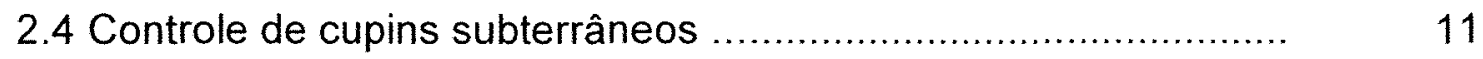

3 MATERIAL E MÉTODOS....................................................... 23

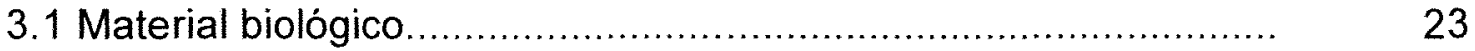

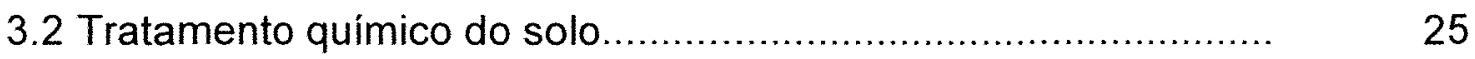

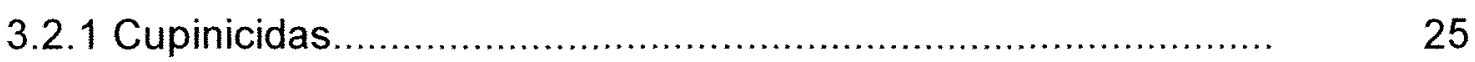

3.2.2 Descrição dos produtos utilizados..........................................

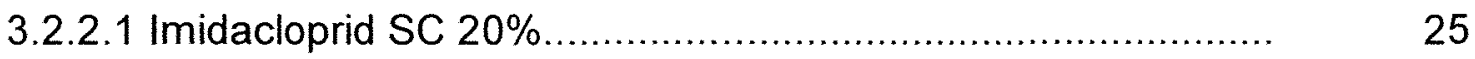

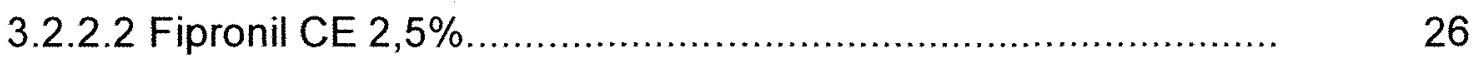

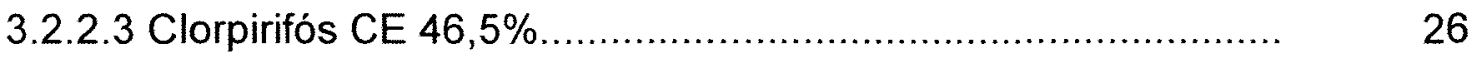

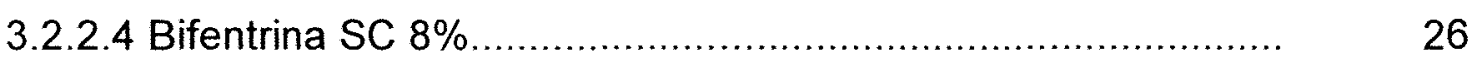

3.2.3 Aplicação dos cupinicidas no solo........................................... 27

3.3 Coleta de amostras de solo para infestação em laboratório.......... $\quad 28$

3.4 Avaliação do comportamento e mortalidade do C. gestroi........... 30 


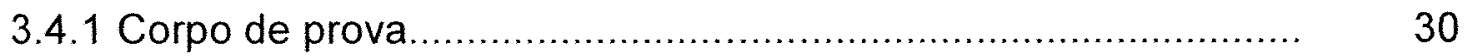

3.4.2 Infestações e avaliações dos corpos de prova........................... 30

3.5 Análise dos resíduos dos inseticidas no solo............................... 32

3.6 Análise dos resultados obtidos dos experimentos ..................... 33

4 RESULTADOS E DISCUSSÃO .............................................

4.1 Infestação realizada logo após tratamento do solo (0 DAT).......... 34

4.2 Infestação realizada 30 dias após tratamento do solo (30 DAT).... 41

4.3 Infestação realizada 60 dias após tratamento do solo (60 DAT)... 44

4.4 Infestação realizada 90 dias após tratamento do solo (90 DAT)... $\quad 47$

4.5 Infestação realizada 120 dias após tratamento do solo (120 DAT).. $\quad 51$

4.6 Infestação realizada 150 dias após tratamento do solo (150 DAT).. $\quad 54$

4.7 Infestação realizada 180 dias após tratamento do solo (180 DAT).. $\quad 57$

4.8 Análise de resíduo do solo ................................................... 61

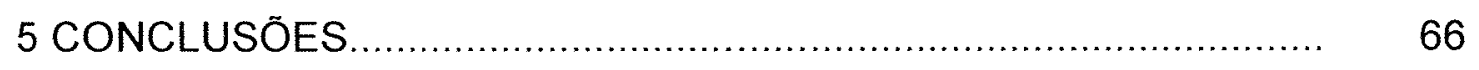

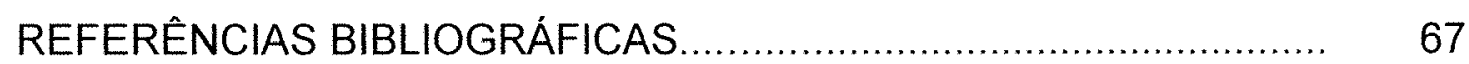




\section{LISTA DE FIGURAS}

Página

1 Isca utilizada para captura de C. gestroi, para realização dos estudos. (A) Isca não atacada pelos cupins e (B) atacada 30 dias após a sua colocação.

2 Cabeça do soldado do C. gestroi em vista dorsal. (A) Cabeça do soldado evidenciando a fontanela e (B) a excreção leitosa utilizada para defesa da colônia.

3 Faixas de solo onde foram aplicados os cupinicidas. (A) Faixas tratadas com dimensões de 4,0 × 0,30 m e 2,0 m entre as mesmas, (B) dimensões e distância entre os orifícios para aplicação de cupinicida no solo

4 Aplicação de 1,5 litros por orifício da solução cupinicida no solo com auxilio de funis plásticos

5 Trado utilizado para amostragem de solo, tendo as dimensões de $1,7 \mathrm{~cm}$ de diâmetro interno e $50 \mathrm{~cm}$ de comprimento.

6 Corpo de prova para avaliação do comportamento, mortalidade e danos dos cupins C. gestroi. (A) A primeira divisão (1 ${ }^{\text {a }}$ Div.), inicialmente infestada por 100 cupins, preenchida por solo isento de cupinicida; a segunda divisão ( $2^{\text {a }}$ Div.) preenchida por solo 
tratado, e a terceira divisão ( $3^{\mathrm{a}}$ Div.) com solo isento de cupinicida, (B) lâmina de acrílico que delimita a primeira da segunda divisão e (C) disco de madeira de Pinus sp. susceptivel ao ataque do referido cupim separando a segunda da terceira divisão

7 Distância percorrida $(\mathrm{cm})$ pelo cupim Coptotermes gestroi na $2^{\mathrm{a}}$ divisão (solo tratado), logo após o tratamento do solo com diferentes cupinicidas. Avaliações realizadas 6, 12, 24 e 48 horas após infestação.

8 C. gestroi percorrendo a $2^{\mathrm{a}}$ divisão ( $2^{\mathrm{a}}$ Div.) do tratamento testemunha, 48 horas após infestação.

9 Danos causados por C. gestroi no disco de madeira de Pinus sp. no período de 15 dias

10 Presença de fungos sobre C. gestroi mortos avaliados 15 dias após infestação em solo tratado com os cupinicidas

11 Distância percorrida $(\mathrm{cm})$ pelo cupim Coptotermes gestroi na $2^{\mathrm{a}}$ divisão (solo tratado), 30 dias após o tratamento do solo com diferentes cupinicidas. Avaliações realizadas 6, 12, 24 e 48 horas após infestação

12 Distância percorrida $(\mathrm{cm})$ pelo cupim Coptotermes gestroi na $2^{\mathrm{a}}$ divisão (solo tratado,) 60 dias após o tratamento do solo com diferentes cupinicidas. Avaliações realizadas 6, 12, 24 e 48 horas após infestação 
13 Distância percorrida $(\mathrm{cm})$ pelo cupim Coptotermes gestroi na $2^{a}$ divisão (solo tratado), 90 dias após o tratamento do solo com diferentes cupinicidas. Avaliações realizadas 6, 12, 24 e 48 horas após infestação

14 Distância percorrida $(\mathrm{cm})$ pelo cupim Coptotermes gestroi na $2^{\mathrm{a}}$ divisão (solo tratado), 120 dias após o tratamento do solo com diferentes cupinicidas. Avaliações realizadas 6, 12, 24 e 48 horas após infestação

15 Distância percorrida $(\mathrm{cm})$ pelo cupim Coptotermes gestroi na $2^{\mathrm{a}}$ divisão (solo tratado), 150 dias após o tratamento do solo com diferentes cupinicidas. Avaliações realizadas 6, 12, 24 e 48 horas após infestação

16 Distância percorrida $(\mathrm{cm})$ pelo cupim Coptotermes gestroi na $2^{\mathrm{a}}$ divisão (solo tratado), 180 dias após o tratamento do solo com diferentes cupinicidas. Avaliações realizadas 6, 12, 24 e 48 horas após infestação

17 Concentração de imidacloprid, fipronil, clorpirifós e bifentrina no solo tratado nos diferentes periodos de coleta após o tratamento 


\section{LISTA DE TABELAS}

Página

1 Tratamentos, nomes e doses dos cupinicidas utilizados no tratamento de solo

2 Dados médios obtido dos diferentes tratamentos, em centímetros acumulados $(\mathrm{cm})$, percorridos pelos cupins $C$. gestroi ao longo da

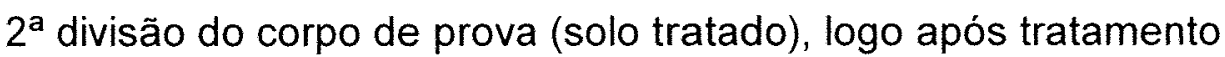
do solo, avaliando-se com 6, 12, 24 e 48 horas após a infestação (HAl) e respectivos coeficientes de variação (C.V.).

3 Dados médios para cada tratamento, número de cupins $C$. gestroi vivos $(V)$ e mortos $(M)$ na $1^{\mathrm{a}} ; 2^{\mathrm{a}}$ e $3^{\mathrm{a}}$ divisões do corpo de prova e o total de mortos, porcentagem de mortalidade (Mort. (\%)). Infestação realizada logo após o tratamento do solo e avaliação realizada 15 dias após infestação.

4 Dados médios obtidos dos diferentes tratamentos, em centímetros acumulados $(\mathrm{cm})$, percorridos pelos cupins $C$. gestroi ao longo da

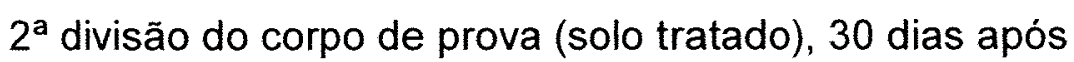
tratamento do solo, avaliando-se 6, 12, 24 e 48 horas após a infestação (HAl) e respectivos coeficientes de variação (C.V.).........

5 Dados médios para cada tratamento, número de cupins $C$. gestroi vivos $(V)$ e mortos $(M)$ na $1^{\text {a }} ; 2^{\text {a }}$ e $3^{\mathrm{a}}$ divisões do corpo de prova e o 
total de mortos (M), porcentagem de mortalidade (Mort. (\%)).

Infestação realizada 30 dias após o tratamento do solo e avaliação realizada 15 dias após infestação

6 Dados médios obtidos dos diferentes tratamentos, em centímetros acumulados $(\mathrm{cm})$, percorridos pelos cupins $C$. gestroi ao longo da

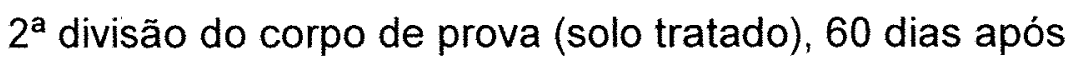
tratamento do solo, avaliando-se 6, 12, 24 e 48 horas após a infestação (HAl) e respectivos coeficientes de variação (C.V.)........

7 Dados médios para cada tratamento, número de cupins C. gestroi vivos $(V)$ e mortos $(M)$ na $1^{\text {a }} ; 2^{\text {a }}$ e $3^{\mathrm{a}}$ divisões do corpo de prova e o total de mortos $(M)$, porcentagem de mortalidade (Mort. (\%)). Infestação realizada 60 dias após o tratamento do solo e avaliação realizada 15 dias após infestação

8 Dados médios obtidos dos diferentes tratamentos, em centímetros acumulados $(\mathrm{cm})$, percorridos pelos cupins $C$. gestroi ao longo da $2^{\text {a }}$ divisão do corpo de prova (solo tratado), 90 dias após tratamento do solo, avaliando-se $6,12,24$ e 48 horas após a infestação (HAI) e respectivos coeficientes de variação (C.V.)........

9 Dados médios para cada tratamento, número de cupins $C$. gestroi vivos $(V)$ e mortos $(M)$ na $1^{a} ; 2^{a}$ e $3^{a}$ divisões do corpo de prova e o total de mortos (M), porcentagem de mortalidade (Mort. (\%)). Infestação realizada 90 dias após o tratamento do solo e avaliação realizada 15 dias após infestação.

10 Dados médios, obtidos dos diferentes tratamentos, em centímetros acumulados $(\mathrm{cm})$, percorridos pelos cupins $C$. gestroi 
ao longo da $2^{\mathrm{a}}$ divisão do corpo de prova (solo tratado), 120 dias após tratamento do solo, avaliando-se $6 ; 12 ; 24 ;$ e 48 horas após a infestação (HAI) e respectivos coeficientes de variação (C.V.)...

11 Dados médios para cada tratamento, número de cupins $C$. gestroi vivos (V) e mortos $(M)$ na $1^{a} ; 2^{a}$ e $3^{a}$ divisões do corpo de prova e o total de mortos (M), porcentagem de mortalidade (Mort. (\%)). Infestação realizada 120 dias após o tratamento do solo e avaliação realizada 15 dias após infestação

12 Dados médios obtidos dos diferentes tratamentos, em centímetros acumulados $(\mathrm{cm})$, percorridos pelos cupins $C$. gestroi ao longo da $2^{\mathrm{a}}$ divisão do corpo de prova (solo tratado), 150 dias após tratamento do solo, avaliando-se 6, 12, 24 e 48 horas após a infestação (HAI) e respectivos coeficientes de variação (C.V.)........

13 Dados médios para cada tratamento, número de cupins C. gestroi vivos $(V)$ e mortos $(M)$ na $1^{a} ; 2^{a}$ e $3^{a}$ divisões do corpo de prova e o total de mortos $(\mathrm{M})$, porcentagem de mortalidade (Mort. (\%)). Infestação realizada 150 dias após o tratamento do solo e avaliação realizada 15 dias após infestação

14 Dados médios obtidos dos diferentes tratamentos, em centímetros acumulados $(\mathrm{cm})$, percorridos pelos cupins C. gestroi ao longo da $2^{a}$ divisão do corpo de prova (solo tratado), 180 dias após tratamento do solo, avaliando-se 6, 12, 24 e 48 horas após a infestação (HAl) e respectivos coeficientes de variação (C.V.).........

15 Dados médios para cada tratamento, número de cupins $C$. gestroi vivos (V) e mortos (M) na $1^{a} ; 2^{a}$ e $3^{a}$ divisões do corpo de prova e 
o total de mortos (M), porcentagem de mortalidade (Mort. (\%)).

Infestação realizada 180 dias após o tratamento do solo e avaliação realizada 15 dias após infestação. 


\title{
TRATAMENTO QUÍMICO DO SOLO VISANDO AO CONTROLE DO CUPIM COPTOTERMES GESTROI (WASMANN, 1896),
} (ISOPTERA: RHINOTERMITIDAE)

\author{
Autor: JOÃO FERNANDO BERNARDINI \\ Orientador: Prof. Dr. OCTAVIO NAKANO
}

RESUMO

O Coptotermes gestroi foi introduzido na região sudeste do Brasil, na década de 20 , e, atualmente, causa prejuizos consideráveis em edificaçōes, principalmente em centros urbanos, havendo necessidade de intervenção. Devido a isso, a presente pesquisa, conduzida no Laboratório e Campo Experimental do Setor de Controle Químico do Departamento de Entomologia, Fitopatologia e Zoologia Agrícola, da Escola Superior de Agricultura "Luiz de Queiroz", da Universidade de São Paulo, em Piracicaba, Estado de São Paulo, objetivou avaliar a eficácia do tratamento químico do solo no controle de $C$. gestroi, observar o comportamento do cupim, ante o inseticida, com relação à repelência, e avaliar o efeito residual dos inseticidas no solo, realizando coletas mensais durante 6 meses. Cinco faixas de solo com textura média argilosa, $\mathrm{pH}$ 4,8 e $2,8 \%$ de matéria orgânica, com dimensões de $4 \mathrm{~m}$ de comprimento e 30 $\mathrm{cm}$ de largura, e $2 \mathrm{~m}$ entre elas, foram tratadas com $0,1 \%$ imidacloprid, $0,037 \%$ fipronil, $1,0 \%$ clorpirifós, $0,12 \%$ bifentrina e testemunha; o solo tratado foi protegido com lona plástica. As amostras de solo foram colocadas em tubos 
transparentes, de modo a tornar possivel a observação do $C$. gestroi, que ficou 15 dias exposto dentro desse tubo. Nas avaliaçöes com 6, 12, 24 e 48 horas após infestação, foi observada inibição do C. gestroi ao solo tratado com imidacloprid; com fipronil, o solo não apresentou repelência; com clorpirifós, apresentou forte odor, provocando possivel desorientação dos cupins; bifentrina formou uma barreira química no solo impedindo a passagem dos mesmos; os que estavam presentes na testemunha realizaram os túneis por onde transitaram naturalmente. Em todas as avaliações, os solos tratados com fipronil e clorpirifós apresentaram $100 \%$ de mortalidade dos cupins no decorrer dos 180 dias; no solo tratado com imidacloprid até 60 dias, obteve-se $100 \%$; $86,28 \%$, na avaliação com 180 dias; no entanto esses cupins não causaram dano na madeira. Com bifentrina, a mortalidade variou entre 34,82 a $88,86 \%$, mas os cupins vivos não ultrapassaram o solo tratado, portanto não causaram danos na madeira; apenas na testemunha houve dano. As concentrações de residuos no solo evidenciaram maior mobilidade do imidacloprid; fipronil, clorpirifós e bifentrina apresentaram grandes variaçōes entre as avaliaçōes, indicando desuniformidade da faixa de solo tratada ou falha na amostragem do solo. 


\title{
SOIL CHEMICAL TREATMENT AIMING TO CONTROL THE TERMITES COPTOTERMES GESTROI (WASMANN, 1896), (ISOPTERA: RHINOTERMITIDAE)
}

\author{
Author: JOÃO FERNANDO BERNARDINI \\ Adviser: Prof. Dr. OCTAVIO NAKANO
}

\section{SUMMARY}

Coptotermes gestroi was introduced in the southeast region of Brazil, in the 20s, and nowadays causes considerable damage in buildings, mainly in urban centers, making interventions necessary. Due to this fact, this research, conducted in the Laboratory and Experimental Field of the Chemical Control Sector of the Department of Entomology, Histopathology and Agricultural Zoology, of the Escola Superior de Agricultura "Luiz de Queiroz", of the University of São Paulo, in Piracicaba, Brazil, aimed to evaluate the effectiveness of soil chemical treatment in controlling $C$. gestroi, to observe the behavior of the termite when facing the insecticide regarding repellence, and evaluate the residual effect of insecticides in the soil, performing monthly collections during 6 months. Five layers of soil with average clay texture, $\mathrm{pH} 4.8$ and $2.8 \%$ of organic matter, with dimensions of $4 \mathrm{~m}$ (length) and $30 \mathrm{~cm}$ (width), and $2 \mathrm{~m}$ between them, were treated with $0.1 \%$ imidacloprid, $0.037 \%$ fipronil, $1.0 \%$ chlorpyrifos, $0.12 \%$ bifenthrin and control; the treated soil was protected with plastic canvas. The soil samples were placed in transparent tubes, in such 
a way to enable the observation of $C$. gestroi, which was exposed for 15 days inside this tube. In the evaluations within $6,12,24$ and 48 hours after infestation, C. gestroi inhibition was observed in the soil treated with imidacloprid; fipronil did not present any repellence; chlorpyrifos presented a strong odor, possibly causing termite disorientation; bifenthrin formed a chemical barrier in the soil stopping the passage of the termites; the ones present in the control made tunnels where they transited naturally. In all evaluations, the soils treated with fipronil and chlorpyrifos presented $100 \%$ termite mortality in the span of 180 days; in the soil treated with imidacloprid, $100 \%$ mortality was obtained for 60 days and $86,28 \%$ in 180 days, however these termites did not cause wood damage. With bifenthrin, the mortality rate varied between $34,82 \%$ and $88,86 \%$ but the live termites did not go over the treated soil, and therefore did not cause any damage to the wood, only in the control was the wood damaged. The residue concentration in the soil demonstrated greater mobility of imidacloprid. Fipronil, chlorpyrifos and bifenthrin presented great variations between evaluations, indicating lack of uniformity in the layer of soil treated or failure in soil sampling. 


\section{INTRODUÇÃO}

O processo de urbanização dos grandes centros sem planejamento (Milano \& Fontes, 2002), com retirada da vegetação nativa, realização de aterros, construção de galerias subterrâneas, entre outras modificações do ambiente que podem provocar desequilíbrio ambiental, favorece o desenvolvimento de algumas pragas (Fontes, 2004).

Um dos grandes problemas em áreas urbanas são os cupins, principalmente os subterrâneos (Fontes \& Berti Filho, 1998; Fontes \& Milano, 2002; Milano \& Fontes, 2002). Atualmente, estão catalogadas 2869 espécies em 287 gêneros (Constantino, 2005), mas apenas 40 são consideradas pragas urbanas (Constantino, 2002), que, com a eliminação dos competidores e predadores feita pelo homem, passaram a infestar áreas urbanas (Waller \& La Fage, 1986).

Dentre muitas espécies, destaca-se o Coptotermes gestroi, que foi introduzido na região sudeste do Brasil no início do século passado (Araújo, 1958, 1980; Milano \& Fontes, 2002). Segundo Fontes \& Berti Filho (1998), em edificações e vegetação urbana o ataque é voraz, embora com pouco ou nenhum sinal de sua presença, exceto quando o nivel de infestação é alto.

O C. gestroi é a espécie mais importante economicamente em áreas urbanas do Brasil, por ter maior poder destrutivo entre os cupins subterrâneos urbanos (Milano \& Fontes, 2002). Uma colônia adulta dessa espécie pode causar severos danos às estruturas de madeira em poucos meses após o início de seu forrageamento. 
Estima-se que, em todo o mundo, haja gastos da ordem de US\$ 5 a 10 bilhões anuais, com tratamento, reparos e substituições de peças atacadas por cupins. No Brasil, apenas na cidade de São Paulo, os prejuizos atingem cerca de US\$10 a 20 milhões anuais (Milano \& Fontes, 2002).

As empresas especializadas no ramo de controle de pragas urbanas deparam com dificuldades no controle de cupins subterrâneos, devido à escassez de pesquisa para a região sudeste do Brasil, sobre as condições e características das construções.

Os métodos utilizados para controle preventivo e curativo dos cupins subterrâneos consistem na realização de barreiras físicas, não permitindo a passagem dos cupins (Ewart, 2001); tratamento de madeira com inseticidas de longo residual para a ação preventiva; utilização de iscas com agentes de controle biológico como nematóides, fungos e bactérias (Costa-Leonardo, 2002); iscas com inibição do metabolismo dos cupins (Su et al., 1995a); hormônios reguladores de crescimento de insetos, como os juvenóides e os inibidores de sintese de quitina, também utilizados em forma de iscas (Su \& Scheffrahn, 1990, 1993), e a barreira química no solo, consistindo em proteger quimicamente a edificação contra o ataque de cupins, de modo preventivo e curativo.

Grande parte dos tratamentos das edificações infestadas pelo C. gestroi na região sudeste é realizado com o tratamento de solo, que consiste em tentar fazer uma barreira de inseticida no solo, o mais contínua possivel, junto às paredes das edificações, evitando assim a passagem dos insetos e protegendo o imóvel e móveis.

Tendo em vista o alto potencial do C. gestroi para causar danos em edificações, principalmente em centros urbanos do sudeste brasileiro, foi realizado este trabalho com os seguintes objetivos: 1) Avaliar a eficácia do tratamento químico do solo, no seu controle; 2) Observar o comportamento dessa espécie, ante o inseticida, com relação ao fator repelência e 3) Avaliar o efeito residual dos inseticidas no solo em diferentes períodos. 


\section{REVISÃO DE LITERATURA}

\subsection{Descrição, comportamento e biologia do Coptotermes gestroi}

Estudos recentes realizados por Constantino, (2005) constataram a ocorrência de 2869 espécies; 40 espécies representam prejuizo econômico para edificações humanas (Constantino, 2002). Na região Neotrópica, estão registrados 83 gêneros e 534 espécies. Segundo Constantino (1998), 6 dessas espécies foram introduzidas, destacando-se a espécie Coptotermes gestroi (Wasmann) pertencente à Ordem Isoptera, Família Rhinotermitidae e subfamília Coptotermitinae, sendo insetos eussociais (Costa-Leonardo, 2002).

Os cupins subterrâneos, por apresentarem colônias no solo de difícil localização, não sofrem freqüente ataque de inimigos naturais, o que também dificulta o controle realizado pelo homem. (Culleny \& Grace, 2000).

Segundo as observações de Grassé (1986), a família Rhinotermitidae é bastante heterogênea, e várias espécies são consideradas cupins subterrâneos; apesar de seus ninhos não serem conhecidos, imagina-se que sejam difusos no solo, havendo várias espécies consideradas pragas. Segundo Milano \& Fontes (2002) o C. gestroi, é de maior importância em áreas urbanas no sudeste brasileiro.

Kirton \& Brown (2003), determinaram que o C. havilandi Holmgren é sinônimo de C. gestroi (Wasmann), sendo assim denominado na atualidade.

No trabalho de Shellman-Reeve (1997), sobre eussocialidade na Ordem Isoptera, o autor caracterizou fatores como nidificação, habitat, parentesco 
intracolonial e comportamentos sociais dos grupos dentro dessa ordem. Embora os cupins sejam hemimetábolos, os termitólogos utilizam alguns termos comuns para insetos holometábolos; o termo "larva" designa os imaturos sem broto alar, e "ninfa" é o termo usado para designar imaturos alar, ainda pouco pigmentados; o termo "soldados brancos" ou "pré-soldados" para imaturos pouco pigmentados, pouco esclerotizados e com características de soldados.

Através da casta de soldado torna-se fácil a identificação do cupim $C$. gestroi, que apresenta uma cápsula cefálica oval de cor amarelada, onde se encontra uma grande fontanela arredondada (Costa-Leonardo, 2002).

Segundo Berti Filho et al. (1993), os operários são as castas mais numerosas da colônia. São incumbidos de todas as funções vitais da colônia, como forrageamento, construção, consertos, aumento e profilaxia do ninho e túneis a ele associados, cuidados com a prole, fornecimento de alimento para os soldados e reprodutores e eliminação de cupins doentes ou mortos.

As castas de operários do C. gestroi possuem coloração amarela esbranquiçada, mandíbulas esclerotizadas ou com princípio de esclerotização, antenas de 11 a 14 antenômeros e são cegos (Costa-Leonardo, 2002).

Nas colônias do C. gestroi podem-se encontrar castas de reprodutores alados, reprodutores imaginais ou primários e reprodutores neotênicos (Pearce, 1997).

Os reprodutores alados geralmente realizam a revoada entre os meses de agosto e setembro, assim estabelecendo novas colônias. Os alados dão origem ao casal real primário ou imaginal. Na ausência ou não do casal real primário, pode ocorrer a presença de reprodutores neotênicos, podendo ser imaturos ou funcionais (Costa-Leonardo, 2002).

Com a ocorrência de reprodutores neotênicos em colônias ou subcolonias do C. gestroi (Lelis, 1995), quando grupos de cupins ficam fora do alcance do controle químico, pode ocorrer formação de novas colônias com reprodutores neotênicos (Lelis, 1999). 
Segundo Mariconi et al. (1999) os cupins são considerados xilófagos, pois sua dieta está baseada em material celulósico, no entanto, os cupins podem perfurar isolantes de cabos elétricos, produtos têxteis sintéticos, couro, gesso, betume e, até mesmo, abrir passagem dentro do reboco de paredes de alvenaria, cuja matéria prima não é celulose.

Costa-Leonardo \& Camargo-Dietrich (1999) estimaram que a população de uma colônia de C. gestroi, localizada em Rio Claro, São Paulo, possuía cerca de $729.918 \pm 33.740$ indivíduos, valor superior quando se compara a outra espécie como o Heterotermes tenuis (Hagen) (Isoptera: Rhinotermitidae) com $134.583 \pm 5.803$ individuos verificado por Camargo-Dietrich \& CostaLeonardo (2003).

A distância percorrida pelo C. gestroi para forrageamento chega a 33 metros (Costa-Leonardo \& Camargo-Dietrich, 1999).

No estudo realizado em laboratório por Costa-Leonardo et al. (2002), pode-se verificar que o consumo diário do cupim C. gestroi foi de $0,046 \mathrm{mg}$ de madeira de Pinus sp., e 0,022 mg de eucaliptos. Bennett et al. (1988) concluiram que as principais espécies de cupins que atacam edificações, consomem diariamente de 2 a 3 vezes o seu peso.

Em infestações naturais pelo $C$. gestroi, onde foram dispostas estacas de Eucalyptus sp. e Pinus sp., Peralta et al. (2004) avaliaram o consumo diário máximo, após 45 dias de exposição, em 21,62 g em ambas as madeiras.

Su \& Fage (1986), observaram, em colônia de cupins Coptotermes formosanus, em condições de laboratório, que, na ausência de alimento para as colônias, os operários se alimentam dos soldados, ocorrendo canibalismo. Nas colônias que, inicialmente, possuiam aproximadamente $11 \%$ de soldados, às quais estava disponivel dieta celulósica, a proporção de soldados permaneceu a mesma, no entanto, nas colônias que foram desprovidas de dieta, os soltados estavam em proporções de $2 \%$.

O cupim C. gestroi é chamado de "cupim de solo" ou "cupim subterrâneo", mas o ataque e a presença da colônia podem estar restritos a 
andares de altos edifícios sem o contato com o solo (Zorzenon \& Potenza, 1998). Não é raro encontrar ninhos nos pavimentos mais altos dos edifícios, com ou sem nenhum contato direto com o solo (Mariconi et al., 1999).

O ninho do C. gestroi é denominado do tipo composto, sendo constituído de várias unidades interligadas por túneis, que podem ser encontradas em vãos das edificações (Mariconi et al., 1999), porões, poços de ventilação e de elevadores, paredes e lajes duplas, caixas de eletricidade, caixões perdidos, entre outras galerias, em árvores e no solo (Milano et al., 1996). Segundo Milano et al. (1996), os ninhos de C. gestroi geralmente são superiores a $0,5 \mathrm{~m}^{3}$.

Estudos realizados por Diogo et al. (2002), nas cidades do Rio de Janeiro, São Gonçalo, Niterói, São João do Meriti e Nova Iguaçu, no período de 1994 a 2001, dos 133 edifícios que estavam sendo atacados pelo C. gestroi $78 \%$ apresentavam ninhos secundários com destaque para apartamentos de cobertura. Em 21 residências térreas avaliadas apenas 17\% apresentaram ninhos secundários para a espécie referida.

Os ninhos de cupins subterrâneos, quando não possuem contato com o solo, mas há umidade suficiente, têm atividade maior, causando grandes prejuizos (Bennett et al., 1988).

Romagnano (2002) relata que embarcação ancorada no Municipio de Guarujá, litoral do estado de São Paulo, foi vistoriada em 1998 e toda a estrutura de madeira estava preservada; dois anos após, foi constatado ataque pelo cupim C. gestroi na proa de madeira de ipê e, no entanto a embarcação não tinha tido contato com o solo.

Em uma amostragem de 420 edificações infestadas pelo C. gestroi, $57,3 \%$ da localização dos ninhos eram no solo; $21,7 \%$ ninhos com localização aérea e $21 \%$ com ninhos no solo e aéreo ao mesmo tempo (Milano \& Fontes, 2002). 
De acordo com Florim. ${ }^{1}$ das 37 ocorrências de C. gestroi em 2004, 2 foram infestação aérea.

\subsection{Origem e distribuição do C. gestroi}

O C. gestroi é originário do Oriente, comum na Indonésia, Malásia e Tailândia. Na primeira metade do século passado, foi introduzido e aclimatado em outros locais do mundo, como nas Ilhas Reunião, Mauricio, em Barbado, na Jamaica e no Brasil. No Brasil, os primeiros casos de infestações ocorreram em cidades portuárias do sudeste, principalmente nos Estados de São Paulo e Rio de Janeiro (Araujo, 1977).

Fontes \& Milano (2002), mencionam que Lima identificou, pela primeira vez, o C. gestroi como C. vastator, em 1939, na cidade do Rio de Janeiro.

Os primeiros C. gestroi foram coletados no Rio de Janeiro, em 1923, e no estado de São Paulo na cidade de Santos, em 1934 (Araujo, 1958). A espécie se destacou entre as pragas introduzidas, pela notável disseminação no continente sul-americano e pelos danos causados em áreas urbanas (Fontes, 2004).

Segundo Milano \& Fontes (2002), a propagação do C. gestroi dá-se sentido oeste do Estado de São Paulo, infestando as cidades litorâneas como Santos, São Vicente, Guarujá, posteriormente a capital, São Paulo e cidades do interior como Campinas, Piracicaba, Porto Ferreira, Rio Claro, Limeira, Ribeirão Preto, Jacareí e Taubaté. No estado do Rio de Janeiro, foram registradas infestações na Capital, Niterói, Cabo Frio e Seropédica.

De acordo com Fontes \& Milano (2002), não foram relatadas infestações de $C$. gestroi em vegetação nativa preservada e áreas rurais, o que evidencia que a disseminação para outras cidades tem ocorrido por transporte humano.

\footnotetext{
${ }^{1}$ FLORIM, A.C. Desinsecta Controle Profissional de Pragas Ltda. Piracicaba, SP, comunicação pessoal, 2005.
} 
Segundo Fontes (2004), a mudança do processo de urbanização na metade do século $X X$ é seguida por aumento significativo de infestação de cupins.

Levantamento realizado por Eleotério \& Berti Filho (2000) no bairro São Dimas da cidade de Piracicaba, evidencia que quanto maior a idade das edificações, maior o risco de infestações de cupins, devido a maior exposição às revoadas.

Os dois primeiros registros de introdução da espécie $C$. gestroi em Miami, Florida, foram constatados em 1996 (Su et al., 1997). A localização e história dessas infestações, indicam recente infestação pelo comércio marítimo. Com isso, o cupim continua a expandir sua distribuição pelo mundo.

O conhecimento da data de infestação de $C$. gestroi em edificios na cidade de São Paulo, permitiu a Milano \& Fontes (2002) estimar que a dispersão da infestação, através das revoadas, é da razão de 250 a 300 metros por ano da infestação inicial.

Segundo Rossetto Junior ${ }^{2}$, em Piracicaba, estado de São Paulo, no decorrer do ano de 2004, houve 52 ocorrências de edificaçōes infestadas por cupins, sendo $59 \%$ cupim de madeira seca, e $41 \%$ de cupim subterrâneo, dentre estes $70 \%$ C. gestroi e 30 do gênero Nasutitermes.

Alves Junior ${ }^{3}$ relata que das 104 edificações infestadas por cupins no ano de $2004,70 \%$ deveram-se a cupins subterrâneos, sendo $90 \%$ C. gestroi e $10 \%$ do gênero Nasutitermes.

Das 128 edificações danificadas por cupins inspecionadas, $28,90 \%$ foram por cupins subterrâneos sendo todos C. gestroi, diz Florim ${ }^{4}$.

\footnotetext{
${ }^{2}$ ROSSETTO JUNIOR, A.J. Empresa Helpinsect Higienização e Controle de Pragas. Piracicaba, SP, comunicação Pessoal, 2005.

${ }^{3}$ ALVES JUNIOR, S.B. Empresa Biomax Manejo Ecológico de Pragas S/C Ltda. Piracicaba, SP, comunicação pessoal, 2005.

${ }^{4}$ FLORIM, A.C. Desinsecta Controle Profissional de Pragas Ltda. Piracicaba, SP, comunicação pessoal, 2005.
} 
Segundo Porto ${ }^{5}$, no ano de 2004 houve 232 chamados referentes a infestações de edificações por cupins, sendo $55,60 \%$ por cupins de madeira seca, e $44,40 \%$ por cupins subterrâneos, dentre esses, $70 \%$ pelo C. gestroi e as demais infestações, pelo Nasutitermes spp.

Das 40 edificações inspecionadas no bairro São Dimas em Piracicaba, 1 estava infestada pelo C. gestroi (Eleotério \& Berti Filho, 2000).

\subsection{Importância econômica}

Segundo Menezes (2004), os cupins são os insetos que causam maior dano em áreas urbanas e rurais, e a espécie que assola o pais e que causa maior problema em centros urbanos, é o C. gestroi.

Os gêneros Reticulitermes e Coptotermes, possuem maior importância econômica em edificações na área urbana. Devido a isso, amplos estudos estão sendo realizados visando ao conhecimento do comportamento e controle desses cupins (Logan et al., 1990).

Para identificar se as edificações estão sendo atacadas por cupins subterrâneos, Fontes \& Berti Filho (1998), descreveram alguns sintomas típicos do grupo: cupins subterrâneos raramente produzem orificios na superfície das peças atacadas, constroem galerias com aspecto de solo em paredes, tetos, caixas de tomada de luz, interruptores e interiores de armários; superficies por onde caminham ou atacam, apresentam pontilhado castanho claro que pode ser denso ou esparso e quando danificados os fundos de armários atacados, produzem som característico de escorrimento de material particulado.

Segundo Paiva (1997), os cupins são os grandes responsáveis pela destruição e descaracterizarão de edificações antigas, consideradas patrimônios históricos. Peças originais (tábuas de forro e de sobrados, paus a pique, laços de embira e outros) são severamente atacadas e são substituídas por novas desvirtuando sua função pelo restaurador, por desconhecimento.

\footnotetext{
${ }^{5}$ PORTO, S.C.D. Controlinset S/C Ltda. Piracicaba, SP, comunicação pessoal, 2005.
} 
O centro histórico de Porto Rico foi drasticamente atacado pelos cupins C. gestroi e Heterotermes sp., comprometendo toda a estrutura e peças com valor histórico (Su et al., 2002).

Pesquisa realizada pela empresa PPV Controle Integrado de Pragas em 500 edificações infestadas na cidade de São Paulo, revelou um perfil de $10,2 \%$ infestadas por brocas, $11,8 \%$ por cupim de madeira seca e $84 \%$ por cupins subterrâneos, prevalecendo $C$. gestroi; apenas três edificações estavam infestadas por Heterotermes assu (Fontes \& Milano, 2002).

$\mathrm{Na}$ cidade de São Paulo, edifícios são infestados por C. gestroi, danificando e nidificando no interior dos eletrodutos elevando o risco de curtocircuitos e maiores prejuízos (Mariconi et al., 1999).

Milano \& Fontes (2002) descreveram infestações em edificações e arborização na prefeitura da Universidade de São Paulo, localizada no bairro Butantã na cidade de São Paulo, causando sérios danos à estrutura e móveis dos edifícios.

Segundo Milano \& Fontes (2002), no ano de 2001 foram registradas algumas infestações em galpões no Recife, estado de Pernambuco, onde os cupins $C$. gestroi e duas espécies do gênero Nasutitermes estavam consumindo pilhas de paletes de madeira.

Amaral (2002) avaliou árvores urbanas do bairro Higienópolis da cidade de São Paulo, e constatou que 28,6\% estavam infestadas por cupins prevalecendo C. gestroi.

Grandes variedades de materiais vêm sendo danificados pelo $C$. gestroi, como estruturas de madeira, papel, papelão, cabos elétricos e telefônicos, plásticos, couro, estruturas de alvenaria, tecidos, metal, borracha, isopor, gesso, betume e árvores vivas (Costa-Leonardo, 2002; Costa-Leonardo et al., 1999; Costa-Leonardo \& Barsotti, 1998; Fontes, 1995).

O fato de os cupins danificarem materiais não celulósicos, não significa que se alimentam dos mesmos. Isso ocorre para chegarem até o alimento que contenha celulose, ou simplesmente para expansão da colônia (Pearce, 1997). 
De acordo com observações realizadas por Pearce (1997), Coptotermes pode causar sérios danos a estruturas de madeiras assim comprometendo as edificações.

A estimativa realizada por Edwards \& Mill (1986), em todo mundo há prejuízos que chegam próximos a US $\$ 2$ bilhões, causados pelos cupins. Nos Estados Unidos, os prejuizos excedem US $\$ 5$ bilhões, causados diretamente ou indiretamente, com reparações, e tratamentos, para tentar eliminar as infestações (Su \& Scheffrahn, 2000).

Baskaran et al. (1999), citam que, na Austrália, os prejuízos causados por ataque de cupins chegam a mais de US $\$ 100$ milhões.

Lelis (1994) estima que para controlar e solucionar problemas causados por cupins em 240 edificações da cidade de São Paulo, o gasto é de US $\$ 1,3$ milhões.

Como citado anteriormente (Fontes \& Milano, 2002), no Brasil na cidade de São Paulo, os prejuízos com controle e reposição de material danificado atingem cerca de US\$10 a 20 milhões ao ano.

\subsection{Controle de cupins subterrâneos}

Construções concluídas, independente do tempo, estão sujeitas ao ataque de cupins subterrâneos (Potenza et al.,1998). Para Fontes \& Milano (2002), padrões americanos e europeus para o controle de cupins são adotados no Brasil: tratamento de solo, tratamento de madeira, tratamento de fundações, iscas e alterações mecânicas.

Os métodos mais usuais no controle preventivo e curativo dos cupins subterrâneos, principalmente em edificações urbanas e rurais, é a utilização de barreiras físicas, utilização de iscas com controle biológico, inibidores de metabolismo ou hormônios de crescimento, tratamento de madeira e barreira química no solo (Costa-Leonardo, 2002; Pearce, 1997; Su \& Scheffrahn, 1998). 
Segundo Costa-Leonardo (2002) e Su \& Scheffrahn (1992), a barreira física formada por partículas uniformes de areia fina impede a passagem dos cupins, e se forem grandes eles não conseguem remover. Além da areia, vidro moído e basalto são usados. O cascalho e terra diatomácea são utilizados também como barreira (French, 1993; Grace \& Yamamoto, 1993; Tamashiro et al., 1991). Entretanto, Grace \& Yamamoto (1993) concluíram que a barreira formada por terra diatomácea não é eficaz no controle de cupins subterrâneos.

Testes realizados por Su \& Scheffrahn (1992), com barreira física composta por partículas de areia de 2,0 a $2,8 \mathrm{~mm}$ de diâmetro foram eficientes no controle de Reticulitermes e Coptotermes.

Barreiras físicas com partículas de pedra de 1,7 a 2,4 mm de diâmetro, compactadas em torno de residências da Austrália, tiveram eficaz prevenção, impedindo a penetração do Coptotermes spp. (Peter et al., 2001)

A barreira física por meio de lâminas sintéticas impregnadas com inseticida químico (Lenz et al., 1998), e polímeros misturados com cupinicidas (Yoshimura \& Tsunoda, 1994) proporcionam bons resultados para prevenção do ataque de cupins. A barreira física deve ser impenetrável aos cupins, impedindo sua chegada às edificações (Ewart, 2001).

Métodos de controle como o uso de Iscas, que são distribuidas na área de forrageamento dos cupins, provocam a redução da colônia, lentamente (Costa-Leonardo, 2002), até sua eliminação por completo, não havendo mais danos (Costa-Leonardo, 1996).

Segundo Costa-Leonardo, (2002), as iscas são impregnadas com agentes biológicos como nematóides, fungos ou bactérias e produtos tóxicos. As ocorrências de infestações por cupins subterrâneos foram tratadas com iscas tóxicas como relata Alves Junior ${ }^{6}$.

Devido às condições inadequadas para o desenvolvimento dos fungos, bactérias e nematóides no controle de cupins em condições de campo, não

\footnotetext{
${ }^{6}$ ALVES JUNIOR, S.B. Empresa Biomax Manejo Ecológico de Pragas S/C Ltda. Piracicaba, SP, comunicação pessoal, 2005.
} 
houve eficácia satisfatória (Costa-Leonardo, 2002; Costa-Leonardo \& Thorne, 1995; Su \& Scheffrahn, 2000).

Isca de celulose contaminada pelo fungo Metarhizium anisopliae em condições de laboratório foi satisfatória para o controle dos cupins $C$. formosanus e $R$. flavipes chegando a $100 \%$ de controle, não sendo repelente (Wang \& Powell, 2004).

Os entomopatógenos isolados $M$. anisopliae e Beauveria bassiana, associados ou não a inseticidas (Almeida \& Alves, 1996; Almeida et al., 1998; Alves et al., 1998) em iscas com papelão corrugado (Termitrap $\AA$ ) apresentam controle de Heterotermes tenuis na cultura da cana-de-açúcar.

Inibidores metabólicos como hidrametilnona (Logan \& Abood, 1990), boratos e sulfluramida, são apropriados para iscas. Segundo Su et al. (1995a), é difícil a eliminação por completo da atividade de forrageamento. Indivíduos que ingerem quantidade adequada contribuem para a redução populacional da colônia, no entanto os cupins que ingerem grande quantidade morrem rapidamente e não contribuem para a transferência do ativo para outros cupins.

Para Su \& Scheffrahn (1990) e Pearce (1997) iscas com substâncias análogas ao homônimo juvenil como o fenoxicarbe, hidroprene e metoprene aumentam a quantidade de soldados na colônia e podem causar desequilibrio nutricional e afetar as atividades dos cupins, sendo mais eficientes para espécies com baixa proporção de soldados.

Iscas contaminadas com inibidores de síntese de quitina, como o diflubenzuron, lufenuron e hexaflumuron (Costa-Leonardo, 2002), para o controle de cupins subterrâneos também são empregadas. O hexaflumuron está sendo pesquisado, e com sucesso, no controle dos cupins (Su \& Scheffrahn, 1993, 1996, 2000) e Su, (1994); usado comercialmente inclusive no Brasil (Costa-Leonardo, 2002) e Su et al. (2000) obtiveram $80 \%$ de controle do C. gestroi.

No controle de C. gestroi na região histórica de Porto Rico, por meio do do uso de iscas com hexaflumuron, 3 colônias foram eliminadas no período de 
2 a 8 meses após tratamento; no entanto, 4 colônias de Heterotermes sp., na mesma região levaram de 13 a 15 meses para total eliminação (Su et al., 2002).

Infestações com $C$, formosanus tratadas com iscas contaminadas com fipronil 0,1 a $10 \mathrm{mg} / \mathrm{kg}$ mostrou controle, mas a eliminação da colônia nem sempre foi obtida (Henderson \& Forschler, 1997).

Segundo $\mathrm{Nakano}^{7}$, edifício infestado pelo C. gestroi na cidade de São Paulo, em estudo experimental, visando ao controle por meio de iscas de papelão contaminadas com fipronil, não foi obtido sucesso porque não houve consumo das iscas tóxicas, inclusive iscas contendo apenas o papelão.

Formulação comercial de extrato vegetal de Azadirachta inidica a 0,3\% na concentração de $100 \mathrm{mg} / \mathrm{kg}$, causa mortalidade significativa em $C$. formosanus. Em estudos mais demorados, com chance de escolha, apresentou repelência aos operários (Grace \& Yates, 1992).

Segundo Chen et al. (2004), extrato de Larix leptolepis apresentou resultados satisfatórios, como deterrente alimentar em operários de C. formosanus.

Tratamento de madeira através de inseticidas de ação residual dissolvido em querosene, isoparafina, álcool ou aguarrás (Costa-Leonardo, 2002) é mais uma medida de controle preventivo ao ataque de cupins subterrâneos.

$\mathrm{Na}$ metade da década de 50 , com o surgimento dos ciclodienos (clorados), o método de controle de cupim subterrâneo mais comum era a barreira química, pois tinha longo residual e custo reduzido (Su, 2002).

A infestação e danos causados pelos cupins subterrâneos está sendo crescente em centros urbanos, e se tornando ordinário o controle através de tratamento de solo pelas empresas especializadas (Bennett et al., 1988).

A técnica mais utilizada para proteger edifícios contra cupins de subterrâneos, na Austrália, é o tratamento de solo com inseticidas persistentes

\footnotetext{
${ }^{7}$ NAKANO, O. Professor titular do Departamento de Entomologia, Fitopatologia e Zoologia Agrícola, ESALQ/USP, comunicação pessoal, 2005.
} 
que formam uma barreira impedindo a passagem dos cupins (Lenz et al., 1988). Milano et al. (1996) indicam este tratamento apenas quando há indícios, ou riscos de futuras infestações de cupins subterrâneos provenientes do solo.

Segundo relatos de Florim $^{8}$, Porto $^{9}$ e Rossetto ${ }^{10}$, nos controles preventivos e curativos para o ataque do C. gestroi, com acesso às edificações exclusivamente pelo solo, o método de tratamento de solo, oferece bom resultado.

O ideal para barreira química no solo é o momento em que o imóvel está sendo construído, quando a cobertura está pronta e o solo desnudo, mas pronto para o contrapiso (Mariconi et al., 1999).

Potenza et al. (1998) e Peter et al. (2001), indicam como um dos métodos de controle do $C$. gestroi: o tratamento quimico do solo com cupinicidas de ação residual, permitindo a formação de uma barreira eficiente contra cupins, protegendo as fundações, paredes, muros, pisos, entre outras estruturas contornadas interna e externamente (Johnston et al., 1979). Em locais com vulnerabilidade ao ataque dos cupins, deve-se intensificar as aplicações (Beal, 1980). Edwards \& Mill (1986), deixam evidente que, para controlar o ataque de cupins subterrâneos, o tratamento deve ser de maneira mais uniforme e contínua, formando uma barreira de solo protegido.

Para Su \& Scheffrahn (1998), a aplicação de cupinicidas líquidos no solo formando uma barreira, embora de duração não permanente, é de grande importância, pois tem efeito imediato, cessando o ataque dos cupins e, assim, diminuindo os prejuízos.

\footnotetext{
${ }^{8}$ FLORIM, A.C. Desinsecta Controle Profissional de Pragas Ltda. Piracicaba, SP, comunicação pessoal, 2005.

${ }^{9}$ PORTO, S.C.D. Controlinset S/C Ltda. Piracicaba, SP, comunicação pessoal, 2005.

${ }^{10}$ ROSSETTO JUNIOR, A.J. Empresa Helpinsect Higienização e Controle de Pragas.

Piracicaba, SP, comunicação Pessoal, 2005.
} 
Além de a calda do cupinicida se encontrar entre os furos, é de suma importância que entre em contato com a parede, não permitindo o acesso dos cupins (Thomas \& Robinson, 1991). Isso é também indicado por Potenza et al. (1998).

Para Thomas \& Robinson (1991), o distanciamento é fator fundamental para o sucesso da barreira resultante da aplicação de defensivo químico no solo para controle de cupins subterrâneos. Quando o solo estiver coberto por piso, deve-se perfurar $10 \mathrm{~cm}$ distante das paredes e espaçamentos de 20 a 50 $\mathrm{cm}$ entre furos dependendo do tipo de solo. Distâncias semelhantes são indicadas por Edwards \& Mill, (1986), Milano et al. (1996) e Moein (2000).

Em construções onde o solo está exposto, pode-se realizar o tratamento abrindo valetas (Edwards \& Mill, 1986 e Johnston et al., 1979); com dimensões de 15 a $20 \mathrm{~cm}$ de largura e de 15 a $30 \mathrm{~cm}$ de profundidade ao lado das paredes (Milano et al., 1996).

Para atingir maior uniformidade da barreira, Milano et al. (1996) destacam a importância de distribuir homogeneamente a solução do cupinicida pelos furos abertos no piso, aplicando um volume de 5 a 6 litros por metro linear. O volume de calda recomendado, é geralmente, de 4 a 6 litros por metro linear, como observado em Edwards \& Mill, (1886), Johnston et al. (1979), Mariconi et al. (1999) e Moein (2000).

Para Milano et al. (1996), a distância entre furos pode variar de 20 a 60 $\mathrm{cm}$ dependendo do tipo de solo. Quanto mais argiloso e rico em matéria orgânica, menor o espaçamento.

Edificações com infestação aérea ou mista pelo C. gestroi, que forem tratadas com cupinicidas através do tratamento de solo, poderão não obter controle eficaz (Fontes \& Milano, 2002).

Gay et al. (1957) realizaram testes de eficácia de produtos destinados a tratamento de solo para proteção das edificações contra o ataque dos cupins. Os locais do experimento tinham infestação natural. O solo foi tratado com o volume de calda e dose recomendada no rótulo, utilizando como corpo de 
prova, madeira altamente susceptível ao ataque dos cupins. Pôde-se avaliar a eficácia e repelência do solo tratado.

$\mathrm{Na}$ Austrália, os inseticidas aldrin, dieldrin, chlordane e heptacloro eram muito utilizados no tratamento de solo, visando ao controle de cupins. Com a proibição destes, atualmente, recomenda-se o clorpirifós, bifentrina e imidacloprid (Peter et al., 2001). Esses inseticidas são indicados, também, por Wiseman \& Eggleton (1994) e eles acrescentam fipronil para tratamento de solo. Grace et al. (2002) consideram como um dos mais utilizados e menos tóxicos, além do imidacloprid.

Mariconi et al. (1999) citaram os defensivos químicos, clorpirifós, permetrina e fipronil para uso domissanitário no país, para o controle e prevenção de infestações de cupins subterrâneos através do tratamento de solo; Menezes (2004) acrescenta o diclorvos, ciflutina e bifentrina para controle da referida praga.

Segundo Su \& Scheffrahn (2005), os cupinicidas utilizados para tratamento de solo, visando ao controle de cupim subterrâneo, são os repelentes; como a permetrina, cipermetrina, bifentrina e fenvalerate e outros não repelentes que contaminam os insetos como o clorpirifós, fipronil e imidacloprid, podendo realizar aplicação pré-construção através de trincheiras ou pós-construção, através de trincheiras ou injetando o cupinicida no solo da fundação.

O imidacloprid e o fipronil são as moléculas mais recentes para tratamento de solo, com finalidade de proteger as construções do ataque e cupins. O clorpirifós, utilizado a mais tempo, possui característica de não repelência e a bifentrina, utilizada para tratamento de solo, é bastante repelente (Forschler, 2005).

Segundo Thorne \& Breisch (2001), os cupins Reticulitermes virginicus em contato com areia tratada com o inseticida imidacloprid a $100 \mathrm{mg} / \mathrm{kg}$ atingiram até $95 \%$ de mortalidade, e operários que entraram em contato com 
areia tratada com apenas $10 \mathrm{mg} / \mathrm{kg}$ de imidacloprid apresentaram desorientação, afetando as atividades da colônia.

Osbrink \& Lax (2003), realizaram tratamento em 57 árvores infestadas por C. formosanus adjacentes a 7 construções, com imidacloprid $0,1 \%$, inicialmente reduziu o forrageamento e o número de cupins. Os que eram encontrados aparentavam estar intoxicados, no entanto, 6 meses após a aplicação, parte da população de cupins voltou à atividade e 15 meses após houve recuperação de toda população de cupins.

Wei et al. (2000), realizaram tratamento de solo, em condições de laboratório, com 0,05 e $0,20 \%$ de imidacloprid, 6 dias após obteve $100 \%$ de mortalidade do $C$. formosanus. Nesse período, os cupins não realizaram túneis no solo tratado.

Estudos de $\mathrm{CL}_{50}$ realizados por Gatti \& Henderson (1996) concluíram que os operários do $C$. formosanus são mais susceptiveis comparados aos soldados, em relação ao uso dos inseticidas imidacloprid e clorpirifós a 11,42 e $2,86 \mathrm{mg} / \mathrm{kg}$ respectivamente.

Segundo Shelton \& Grace (2003), imidacloprid e fipronil na concentração de $100 \mathrm{mg} / \mathrm{kg}$ não são repelentes aos operários do $C$. formosanus, sendo transmitidos de um operário contaminado para outro não contaminado sem haver percepção; areia tratada com fipronil nas doses de $0,01 \%$ e $0,06 \%$ apresentaram mortalidade acima de $90 \%$ e não apresentaram repelência aos cupins; entretanto, na dose de $0,125 \%$, apresentou repelência aos operários desta espécie (Ibrahim et al., 2003).

Segundo Osbrink \& Lax (2002), C. formosanus, 10 dias exposto em solo tratado com $5 \mathrm{mg} / \mathrm{kg}$ de fipronil, penetrou um total de $5 \mathrm{~cm}$ em $100 \%$ de mortalidade. Waite (2003) conclui que as edificações tratadas nos perímetros internos e externos das paredes com fipronil, usando volume de calda de $5 \mathrm{~L} / \mathrm{m}$, obtêm resultados $100 \%$ de controle. 
Ibrahim et al. (2003) relatam que quanto menor o número de soldados em uma colônia de $C$. formosanus, maior será a transmissão lateral do fipronil aos operários, provocando maior mortalidade.

Su et al. (1997) comparam a distância percorrida pelos cupins C. formosanus e Reticulitermes flavipes em diferentes tubos tratados com diferentes concentrações de clorpirifós, cipermetrina e permetrina. Os resultados foram semelhantes nos tratamentos. Nos três produtos com concentrações de $0,1,1$ e $10 \mathrm{mg} / \mathrm{kg}$, eles caminharam 5,2 e $0 \mathrm{~cm}$ respectivamente nos tubos com o solo tratado.

Loeck (1985) observou que, em tubos com solo tratado com inseticidas piretróides, os cupins Cornitermes cumulans, após 24 horas de exposição, tentaram escavar, mas voltaram assim que houve a percepção do inseticida. No tratamento testemunha, os cupins escavam $2,60 \mathrm{~cm}$ em 24 horas, enquanto nos tratamentos com piretróides, escavam, em média $0,15 \mathrm{~cm}$. Houve mortalidade de $7,1 \%$ dos cupins.

A bifentrina, mesmo em dose sub-letal para os cupins $C$. formosanus $e$ Reticulitermes flavipes, tem ação de repelência, pois não penetram no solo tratado (Su et al., 1989); entretanto Su et al. (1999) observaram que, logo após o tratamento de areia com bifentrina, os cupins $C$. formosanus caminharam verticalmente $4,6 \mathrm{~cm}$ e o $R$. flavipes $4,9 \mathrm{~cm}$. No tratamento com clorpirifós, as distâncias percorridas foram de 4,6 e $5,0 \mathrm{~cm}$ respectivamente.

No teste de laboratório realizado por Nunes et al. (2002), visando à mortalidade do C. gestroi, com soluções de $0,02,0,03,0,04$, e $0,06 \%$ de bifentrina, $0,46 \%$ de clorpirifós e água destilada no tratamento testemunha, a taxa de sobrevivência da testemunha foi de $98 \%$; com exceção do tratamento bifentrina $0,02 \%$, que atingiu $75 \%$ de mortalidade. Os demais chegaram a $100 \%, 24$ horas após infestação.

Su et al. (1999) deixaram os cupins $C$. formosanus 1 semana expostos a areia tratada com bifentrina $0,031 \%$. Logo após, e 12 meses após o tratamento, obtiveram 17,9 e $12,1 \%$ de mortalidade respectivamente. No 
tratamento com clorpirifós, $0,1 \%$ nas mesmas condições, os resultados foram de 79,8 e $82,7 \%$ de mortalidade respectivamente. Os mesmos tratamentos, nas mesmas condições foram realizados com o $R$. flavipes obtendo-se 17,7 e $22,5 \%$ de mortalidade com 0 e 12 meses após tratamento com bifentrina, e 91,9 e $96,7 \%$ com clorpirifós. Su et al. (1993) avaliaram, 1 ano após, os tratamentos de bifentrina e clorpirifós, em solo arenoso que se manteve eficaz contra $C$. formosanus e R. flavipes.

Em solo tratado com $5 \mathrm{mg} / \mathrm{kg}$ de clorpirifós, C. formosanus, 10 dias após exposição, penetraram em todo o percurso $(5 \mathrm{~cm})$, havendo baixa mortalidade (Osbrink \& Lax, 2002). Su et al. (1989) relataram a realização de túneis pelos cupins $C$. formosanus e $R$. flavipes na areia tratada com clorpirifós. Os que entraram em contato com a areia morreram.

$\mathrm{Na}$ areia tratada com clorpirifós, ocorre maior penetração dos cupins $C$. formosanus e $R$. flavipes. Há maior mortalidade, quando comparados aos piretróides testados, entre eles a bifentrina (Su et al., 1993; Su et al., 1995b).

Segundo Wei et al. (2000), no solo tratado com 0,05\% clorpirifós, em condições de laboratório, houve $100 \%$ de mortalidade dos C. formosanus, os quais realizaram túneis no solo tratado.

Segundo Osbrink et al. (2001), operários de C. formosanus contaminados por clorpirifós morrem em, aproximadamente, 30 minutos; piretróides, em 2 horas, e em fipronil, 5 horas.

Forschler \& Townsend (1996), demonstraram que os ativos cipermetrina, permetrina, fenvalerate e clorpirifós utilizados para tratamento de solo, visando ao controle do cupim $R$. flavipes, apresentam diferença na $C_{50}$ com relação à composição do solo. Em solos arenosos, a $\mathrm{CL}_{50}$ é sete vezes menor do que em solo argiloso; Pearce (1997) indica que o clorpirifós, dependendo do tipo de solo e condições climáticas, pode proteger as construções contra o ataque de cupins durante 1 a 25 anos, mas em condições tropicais, a proteção pode cair de 1 a 5 anos. Cypermetrina, bifentrina, 
permetrina e fenvalerate podem ser efetivos no solo de 5 a 15 anos, também dependendo do clima e tipo de solo.

Gold et al. (1996), realizaram estudos em diferentes solos, utilizando organofosforados e piretróides, e observaram que pode haver proteção contra ataques de cupins entre o período de 1 a 19 anos, dependendo do tipo de solo, havendo grande variabilidade.

Lenz et al. (1988) relataram que tratamento realizado com clorpirifós, no sudeste da Austrália, foi eficiente contra ataque de cupins durante 9 anos e 12 anos no solo protegido da ação direta do sol e águas pluviais. Já no trabalho realizado na região dos trópicos, em Townsville, o residual no solo foi de 4 anos para área não protegida e de 7 anos para o solo protegido.

Tratamento de solo arenoso e argiloso no Hawaii, por meio de cipermetrina para controle do $\mathrm{C}$. formosanus evidenciou grande diferença no residual; após 3 anos da aplicação, o controle estava sendo de $80 \%$ em solo argiloso e $40 \%$ em solo arenoso (Grace et al., 2002).

Estudos, em laboratório, da degradação de bifentrina, clorpirifós e imidacloprid aplicados em dose comercial para proteção de edificações contra ataques de cupins realizados por Baskaran et al. (1999), permitiram calcular a meia vida dos cupinicidas estudados. O solo tratado apresentava $59 \%$ de areia, $\mathrm{pH} 7,1$ e $1,2 \%$ de carbono orgânico, com temperatura de $25 \%$ e umidade do solo de $60 \%$ constantes durante 2 anos, estipularam a meia vida da bifentrina em 1332 dias; clorpirifós, em 462 dias, e 990 dias a meia vida do imidacloprid. Esse mesmo estudo, mas realizado em solo composto de areia e dolomita com $\mathrm{pH} 9,6,55 \%$ de areia e $0,2 \%$ de carbono orgânico a meia vida da bifentrina ficou em 1386 dias; clorpirifós, em 315 dias e o imidacloprid, 1230 dias. No tratamento com clorpirifós, os autores atribuem a alta degradação ao acúmulo do metabólico TCP (3,5,6-trichlro-2-pyridinol), que pode ter ocorrido por hidrólise alcalina.

Su et al. (1999), realizaram estudos em solo arenoso da Flórida, avaliado durante 5 anos. Aplicaram vários inseticidas, entre eles bifentrina. 
Nessas condições, a meia vida foi estipulada em 5,27 meses, inicialmente com $10,9 \mathrm{mg} / \mathrm{kg}$ e, após um ano, 2,1 mg/kg, e o clorpirifós 4,22 meses de meia vida, iniciando com $744,7 \mathrm{mg} / \mathrm{kg}$ e, após um ano, $225,6 \mathrm{mg} / \mathrm{kg}$.

O fipronil protegido da ação da luz solar e em condições de $\mathrm{pH} 7,1$ e temperatura em torno de $22^{\circ} \mathrm{C}$, a meia vida foi estipulada em 1390 dias (Bobe et al., 1998).

Segundo Pearce (1997), é de suma importância realizar avaliação prévia do local onde será realizado tratamento de solo para combater o ataque de cupim à edificação, como o histórico do local, tipo do solo, melhor forma de realizar a aplicação do cupinicida e definições do produto mais adequado para determinada infestação. Além das condições físicas do local, faz-se necessário considerar a espécie do cupim, e se o acesso para o ataque está sendo restrito ao solo ou parcialmente, ou totalmente aérea, o que pode interferir no método de controle utilizado (Bennett et al., 1988; Fontes \& Milano, 2002; Milano \& Fontes, 2002). 


\section{MATERIAL E MÉTODOS}

O presente trabalho foi conduzido no Campo Experimental e no Laboratório do Setor de Defensivos Agrícolas do Departamento de Entomologia, Fitopatologia e Zoologia Agrícola da Escola Superior de Agricultura "Luiz de Queiroz", Universidade de São Paulo, Piracicaba, SP, iniciado em Julho de 2004 e finalizado em Janeiro de 2005.

\subsection{Material biológico}

O material biológico (operários de Coptotermes gestroi) utilizado neste trabalho foi obtido utilizando armadilhas, iscas compostas de material celulósico, formadas por cilindros de papelão ondulado com dimensões de $30 \mathrm{x}$ $10 \mathrm{~cm}$ (Figura 1), altamente susceptiveis ao ataque dos cupins (CostaLeonardo, 2002) e dispostos próximos a túneis e artefatos de madeira que estavam sendo atacados pelo cupim. A infestação localizava-se em um depósito de água no Bairro Alto do município de Piracicaba, SP. Após 30 dias da distribuição das iscas, houve alta infestação de operários (Figura 1), que foram coletados e levados ao laboratório para infestação dos corpos de prova e realização dos estudos.

A identificação do, C. gestroi, confirmada por Fontes ${ }^{11}$, foi realizada com auxílio de binocular com aumento de $40 x$, e Chaves para identificação de Famílias e Gêneros de cupins que ocorrem no Brasil, de Constantino (1999). Foram utilizados de soldados, que apresentam mandibulas grandes e

\footnotetext{
${ }^{11}$ FONTES, L.R.O. Doutor em Ciências. São Paulo, SP, comunicação pessoal, 2005.
} 
funcionais, sendo a direita com a margem interna lisa e a esquerda serrilhada próxima à base, sem loco anterior definido, esporões tibiais com a fórmula 3:2:2, antenas com 15 antenômeros, lobo estreito, olhos ausentes, poro frontal ou fontanela exageradamente grande voltado anteriormente, por onde secretam um fluido para defesa com característica leitosa assemelhando-se a cola, produzida pela glândula frontal (Figura 2). E um único par de pêlos na base da fontanela voltado lateralmente (Costa-Leonardo, 2002).
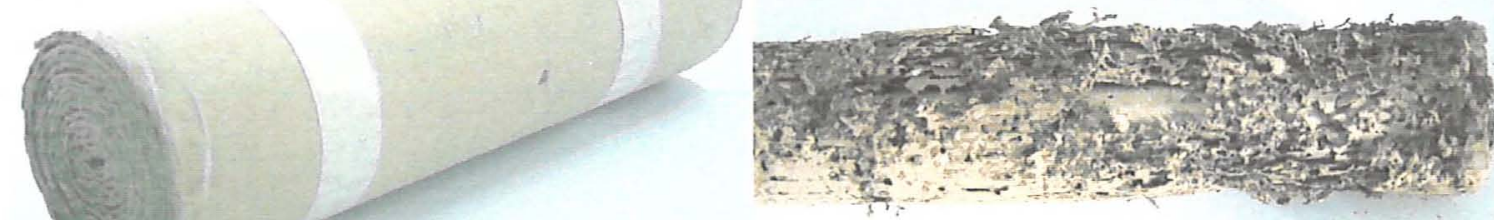

A

B

Figura 1 - Isca utilizada para captura de C. gestroi, para realização dos estudos. (A) Isca não atacada pelos cupins e (B) atacada 30 dias após a sua colocação
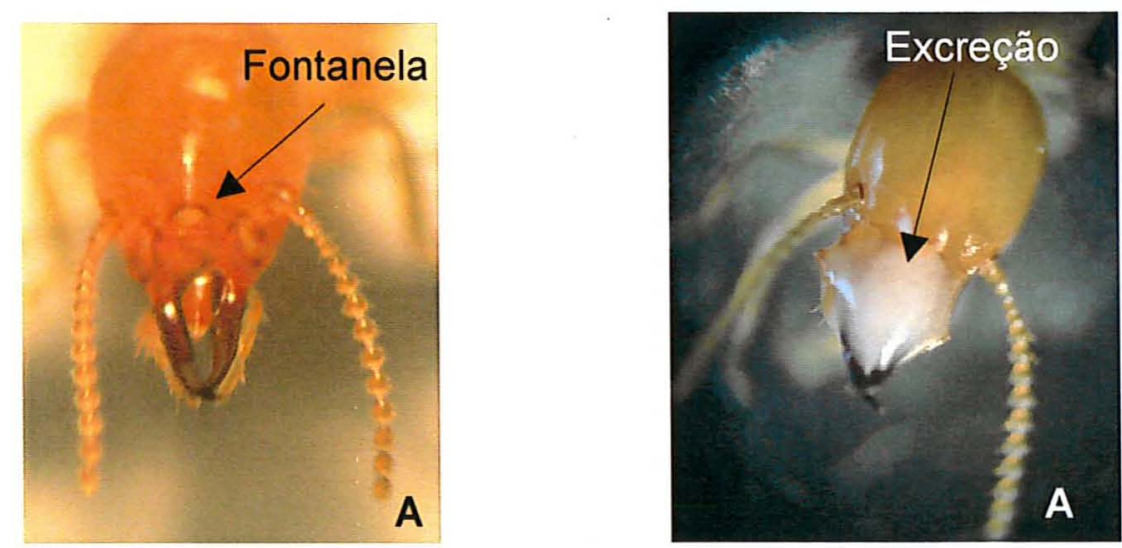

Figura 2 - Cabeça do soldado do C. gestroi em vista dorsal. (A) Cabeça do soldado evidenciando a fontanela e (B) a excreção leitosa utilizada para defesa da colônia 


\subsection{Tratamento químico do solo}

\subsubsection{Cupinicidas}

Para realização do tratamento de solo, foram definidos os inseticidas químicos com registro no Brasil junto ao Ministério da Saúde para o controle de cupins subterrâneos, através da aplicação no solo, utilizados com maior freqüência por pesquisadores e pelas empresas especializadas no controle da praga. Indicados e utilizados em outros estudos para controle de cupins subterrâneos (Baskoran et al., 1999; Forschler, 2005; Mariconi et al., 1999; Menezes, 2004; Wiseman \& Eggleton, 1994). Os cupinicidas utilizados no estudo constam na Tabela 1.

Tabela 1. Tratamentos, nomes e doses dos cupinicidas utilizados no tratamento de solo

\begin{tabular}{lll}
\hline Tratamentos & Nomenclatura & Doses $^{\mathbf{1}}$ \\
\hline 1. Imidacloprid SC 20\% & IMID & $0,100 \%$ \\
2. Fipronil CE 2,5\% & FIPR & $0,037 \%$ \\
3. Clorpirifós CE 46\% & CLOR & $1,000 \%$ \\
4. Bifentrina SC 80\% & BIFEN & $0,120 \%$ \\
5. Testemunha & TEST & $--^{2}$ \\
\hline
\end{tabular}

${ }^{1}$ Concentração de ingrediente ativo na solução.

${ }^{2}$ Aplicação de água isenta de contaminação de inseticidas.

\subsubsection{Descrição dos produtos utilizados}

\subsubsection{Imidacloprid SC $20 \%$}

A molécula imidacloprid com a composição de 1-(6-cloro-3-piridimetil)$\mathrm{N}$-nitroimidazolidim-2-ilideamino, classifica-se como inseticida com ação de contato e ingestão, pertencente ao grupo químico dos cloronicotinil, sendo 
agonista de acetilcolina (Andrei, 1999). A solubilidade é de $510 \mathrm{mg} / \mathrm{L}$ de água a $20^{\circ} \mathrm{C}$ (Tomlin, 1994). Comercialmente, é conhecido por Premise $\circledast$ registrado para controle de cupins subterrâneos, na concentração de $20 \%$ de ingrediente ativo, formulação suspensão concentrada; a dose recomendada é aplicação de 5 litros de solução a $0,1 \%$ por metro linear.

\subsubsection{Fipronil CE 2,5\%}

O fipronil tem a composição molecular de 5-amino-1-(2,6-dicloro- $\alpha, \alpha, \alpha,-$ trifluor-p-tolil)-4-trifluormetilsulfinil pirazole-3-carbonitrila. É um inseticida com ação de contato e ingestão, pertencente ao grupo químico fenil pirazol, sendo inibidor do GABA (Andrei, 1999). Possui solubilidade de $2 \mathrm{mg} / \mathrm{L}$ de água a $20^{\circ} \mathrm{C}$ (Tomlin, 1994). Termidor ${ }^{\circledR}$ é o nome comercial registrado para controle de cupins subterrâneos, $2,5 \%$ de concentração do ingrediente ativo. Formulação é concentrado emulsionável; a dose recomendada para aplicação é de 5 litros de solução a $0,037 \%$ por metro linear.

\subsubsection{Clorpirifós CE 46,5\%}

A composição molecular do clorpirifós é tiofosfato de 0,0 -dietil-0,3,5,6tricloro-2-piridila, classificado como inseticida e acaricida de contato. Pertence ao grupo quimico organofosforado. A ação tóxica ocorre devido à inibição da colinesterase (Andrei, 1999). A solubilidade é de $1,4 \mathrm{mg} / \mathrm{L}$ de água a $25^{\circ} \mathrm{C}$ (Tomlin, 1994). Comercializado para controle de cupins subterrâneos como Dursban $\circledast$, concentração de $46,5 \%$ de ingrediente ativo, formulação concentrado emulsionável. A dose recomendada é aplicação de 5 litros de solução a $1,0 \%$ por metro linear.

\subsubsection{Bifentrina SC $8 \%$}


Bifentrina pertence ao grupo químico dos piretróides sintéticos, composta de (2-metil (1,1-bifenil) -3-il) metil-3- (2-cloro-3,3,3-trifluoro-1propenil) -2,2-dimetilciclopropanocarboxilato, sendo inseticida com ação de contato, atuando como modulador dos canais de $\mathrm{Na}^{+}$(Andrei, 1999). A solubilidade é de $0,1 \mathrm{mg} / \mathrm{L}$ de água a $25^{\circ} \mathrm{C}$ (Tomlin, 1994). Biflex® é o nome comercial que está registrado para controle de cupins subterrâneos, à concentração de $8 \%$ de ingrediente ativo, formulação suspensão concentrada; a dose recomendada é aplicação de 5 litros de solução a $0,12 \%$ por metro linear.

\subsubsection{Aplicação dos cupinicidas no solo}

Em cada tratamento, foi utilizada uma faixa contínua de solo de $4,0 \mathrm{x}$ $0,30 \mathrm{~m}$ e $2 \mathrm{~m}$ de distância entre os diferentes tratamentos. Com auxílio de trado, foram realizadas perfurações de orifícios para aplicação dos cupinicidas com dimensões de $1 \mathrm{~cm}$ de diâmetro por $20 \mathrm{~cm}$ de profundidade e $30 \mathrm{~cm}$ entre os mesmos (Figura 3) (Milano et al., 1996; Thomas \& Robinson, 1991).
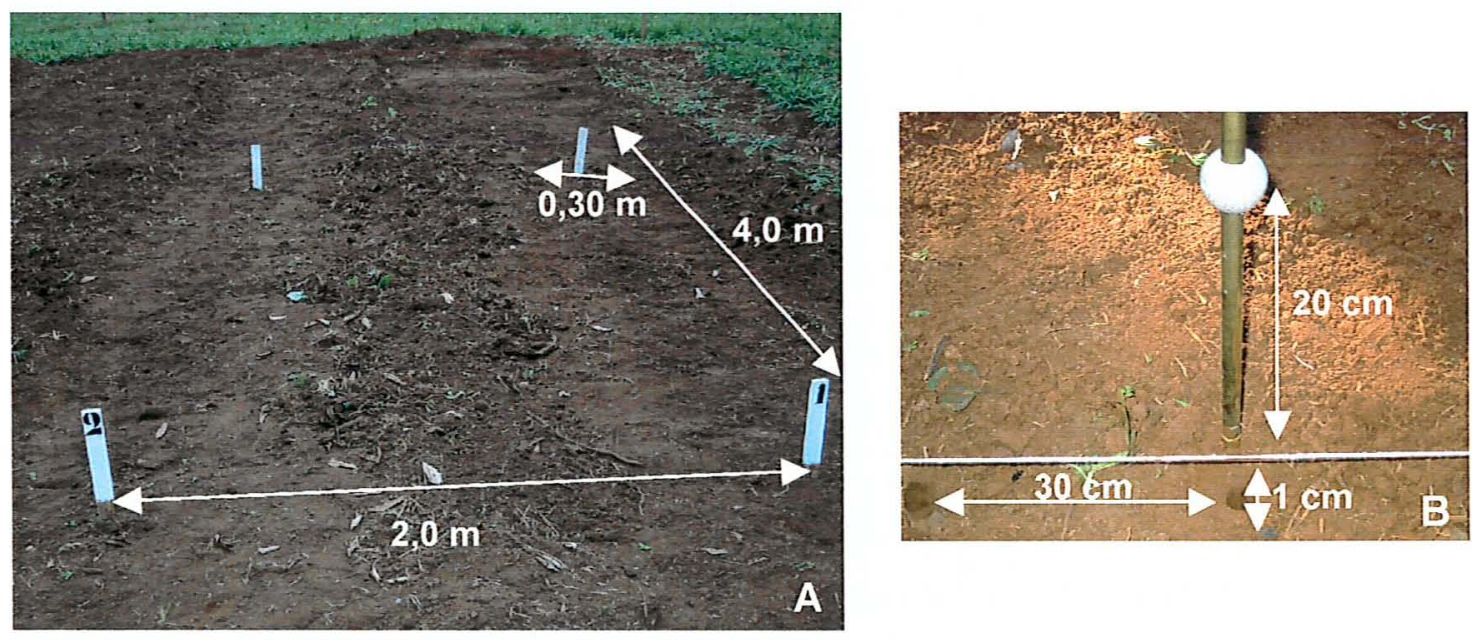

Figura 3 - Faixas de solo onde foram aplicados os cupinicidas. (A) Faixas tratadas com dimensões de 4,0 x 0,30 m e 2,0 m entre as mesmas, (B) dimensões e distância entre os orifícios para aplicação de cupinicida no solo 
Para a aplicação dos cupinicidas no solo, foram utilizados funis plásticos com capacidade para $700 \mathrm{ml}$, permitindo que a calda diluída na dose desejada pudesse ser uniformemente absorvida pelo solo de forma passiva, (Figura 4). Conforme ocorria a absorção pelo solo, foi-se adicionando a calda no funil até completar a vazão de 1,5 litros por orifício totalizando 5 litros por metro linear (Fontes \& Berti Filho, 1998; Johnston et al., 1979; Mariconi et al., 1999). Após aplicação do cupinicida no solo, este foi coberto com lona plástica de cor preta, evitando assim, a ação direta da luz solar e águas pluviais, favorecendo um maior período residual dos inseticidas utilizados (Lenz et al., 1988).

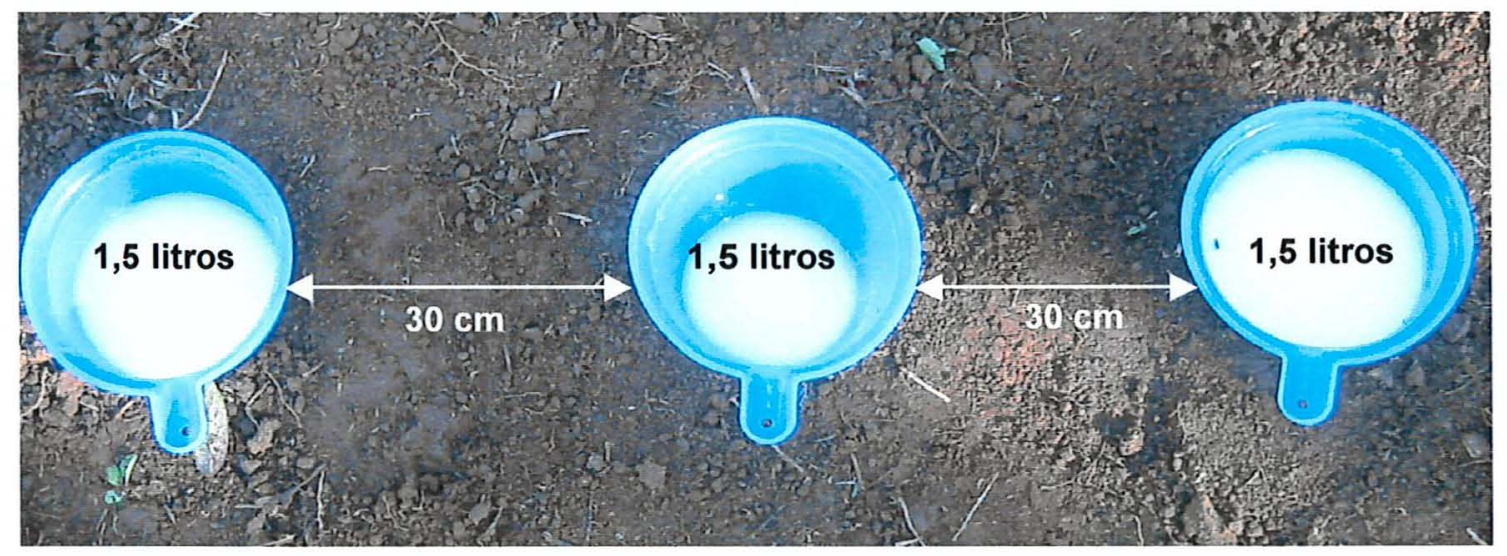

Figura 4 - Aplicação de 1,5 litros por orifício da solução cupinicida no solo com auxílio de funis plásticos

\subsection{Coleta de amostras de solo para infestação em laboratório}

Antecedendo a realização da aplicação dos cupinicidas no solo, com auxílio de um trado com dimensões de $1,7 \mathrm{~cm}$ de diâmetro interno e $50 \mathrm{~cm}$ de comprimento (Figura 5), foram coletadas, aleatoriamente, no perfil de 0 a $30 \mathrm{~cm}$ de profundidade, 10 amostras de 100 gramas, homogeneizadas e encaminhadas ao Departamento de Solos e Nutrição de Plantas da Escola Superior de Agricultura "Luiz de Queiroz", Universidade de São Paulo, Piracicaba, SP, para a realização de análises químicas e granulométrica. O solo 
no qual se realizou o estudo apresenta $34 \%$ de argila, caracterizando textura média-argilosa, com 2,8\% de matéria orgânica e pH de 4,8.

Para cada tratamento, foram realizadas 8 coletas, aleatoriamente, de solo dentro da faixa tratada com auxílio de trado, até a profundidade de $30 \mathrm{~cm}$ (Figura 5), posteriormente levadas ao laboratório. Com auxílio de embalagens plásticas, as amostras foram agitadas, possibilitando a homogeneização para realização das infestações de cupim.

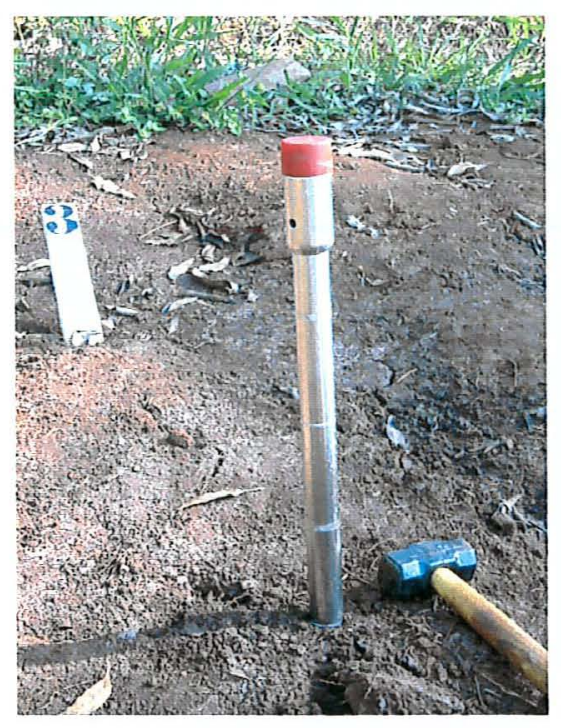

Figura 5 - Trado utilizado para amostragem de solo, tendo as dimensões de 1,7 $\mathrm{cm}$ de diâmetro interno e $50 \mathrm{~cm}$ de comprimento

As amostras de solo foram umedecidas com água destilada até a saturação, para calcular a porcentagem de saturação do solo, ou seja, a porcentagem de água a adicionar nas amostras de solo tratado antes da infestação dos cupins, utilizando a equação de retenção de água pelo solo. Em uma amostra de $100 \mathrm{~g}$ de solo seco, foi adicionada água até formar uma película, determinando, assim, a porcentagem de saturação através da equação a seguir (Designation D 3345-74, 1992): 
$\%$ Saturação $=\left\{\left[\frac{\text { peso da água adicionada no sola }}{\text { peso do solo seco }} \times 100\right\}-7\right.$

\subsection{Avaliação do comportamento e mortalidade do C. gestroi}

\subsubsection{Corpo de prova}

Para cada corpo de prova foi desenvolvido um tubo de plástico transparente com $25 \mathrm{~cm}$ de comprimento e $2,0 \mathrm{~cm}$ de diâmetro interno; o tubo foi dividido em três partes, ou seja, três divisões. As duas extremidades foram fechadas com uma lâmina de acrílico de $0,1 \mathrm{~cm}$ de espessura contendo pequenos poros para permitir troca gasosa; na primeira divisão com $5 \mathrm{~cm}$ de comprimento foram colocados 20 gramas de solo não tratado, sendo delimitada por uma lâmina de acrílico de $0,1 \mathrm{~cm}$ de espessura e com 10 orifícios de $0,5 \mathrm{~cm}$ de diâmetro, permitindo a passagens dos cupins; na segunda divisão, com 15 $\mathrm{cm}$ de comprimento, foram colocados 60 gramas de solo tratado com 0 cupinicida correspondente ao tratamento. Essa divisão foi delimitada por um pequeno disco de madeira seca de Pinus sp., não tratado com $1,5 \mathrm{~cm}$ de espessura e $2,0 \mathrm{~cm}$ de diâmetro com um orifício de $0,5 \mathrm{~cm}$ no centro, para deixar a madeira mais susceptivel ao ataque dos cupins e permitir sua passagem; na terceira e última divisão, com $5 \mathrm{~cm}$ de comprimento, foram colocadas 20 gramas de solo não tratado (Figura 6).

\subsubsection{Infestações e avaliações dos corpos de prova}

O delineamento experimental foi inteiramente casualizado, com cinco tratamentos (uma testemunha) e cinco repetiçōes, sendo que cada corpo de prova foi infestado na primeira divisão com 100 cupins, com aproximadamente 
$90 \%$ da casta operários e no máximo $10 \%$ da casta soldados (Nunes et al., 2002; Su \& Fage, 1986).

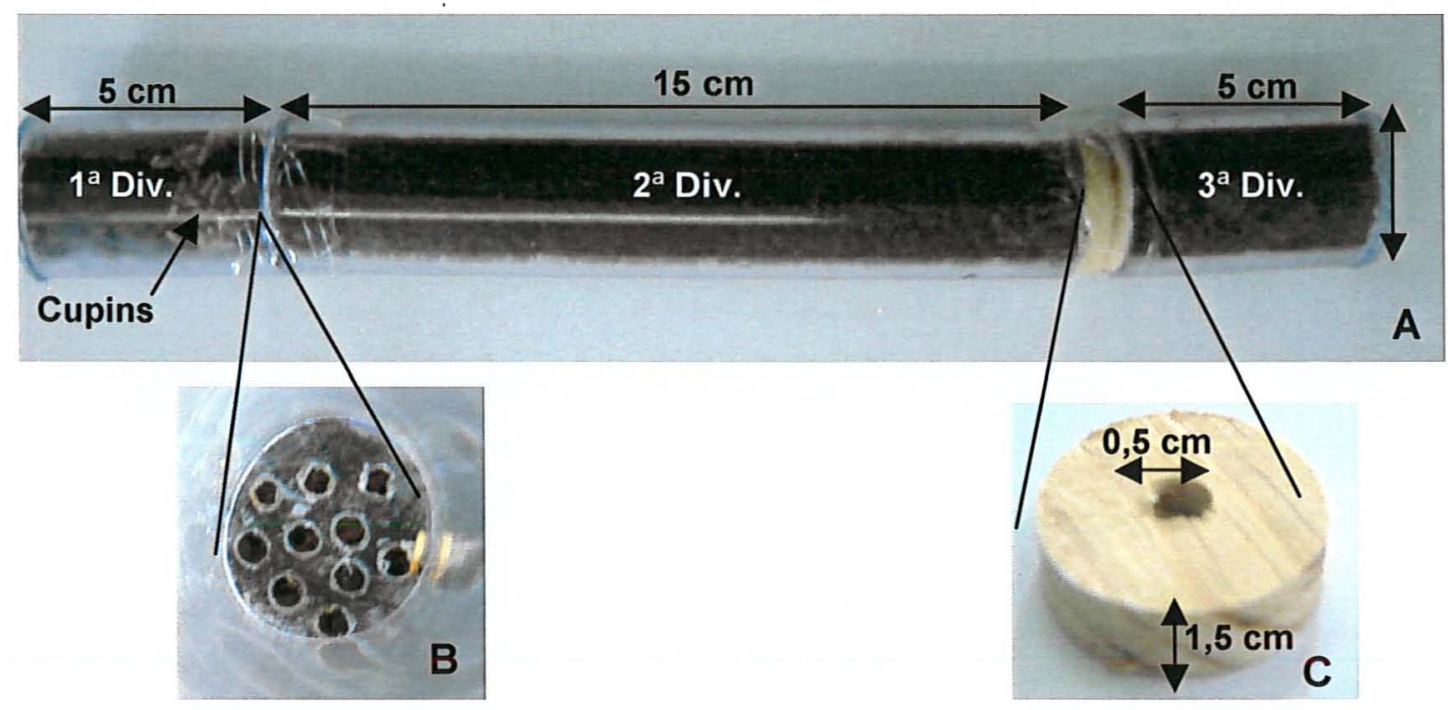

Figura 6 - Corpo de prova para avaliação do comportamento, mortalidade e danos dos cupins C. gestroi. (A) A primeira divisão (1 ${ }^{a}$ Div.), inicialmente infestada por 100 cupins, preenchida por solo isento de cupinicida; a segunda divisão ( $2^{\mathrm{a}}$ Div.) preenchida por solo tratado, e a terceira divisão ( $3^{\mathrm{a}}$ Div.) com solo isento de cupinicida, (B) lâmina de acrílico que delimita a primeira da segunda divisão e (C) disco de madeira de Pinus sp. susceptível ao ataque do referido cupim separando a segunda da terceira divisão

Os corpos de prova infestados permaneceram 15 dias em temperatura e umidade relativa do ar controladas $\left(26 \pm 2^{\circ} \mathrm{C}\right.$, umidade relativa de $80 \pm 10 \%$ e ausente de luz).

Decorridas 6, 12, 24 e 48 horas após a infestação do corpo de prova pelos cupins, foi medido, com auxílio de régua, o percurso feito por eles no solo tratado da segunda divisão, avaliando a repelência dos cupinicidas pela comparação com o tratamento testemunha.

No final do período de 15 dias, as três divisões do corpo de prova foram desconectadas, realizando-se as avaliações pelo número de cupins vivos e 
mortos em cada divisão, possibilitando, assim, avaliar a porcentagem geral de eficácia de cada cupinicida, a ocorrência ou não da formação de barreira química, impedindo a passagem dos cupins, ou se os mesmos ultrapassaram o solo tratado, possibilitando a contaminação e morte.

No disco de madeira de Pinus sp. que delimita a segunda da terceira divisão foi observado se houve ocorrência de danos.

As infestações foram realizadas com $0,30,60,90,120,150$ e 180 dias após o tratamento do solo, seguindo sempre a mesma metodologia.

\subsection{Análise dos resíduos dos inseticidas no solo}

Foram realizadas 8 amostragens de solo por tratamento, no perfil de 0 a $30 \mathrm{~cm}$ para cada tratamento, homogeneizadas e encaminhadas ao Laboratório de Resíduos de Pesticidas do Departamento de Entomologia, Fitopatologia e Zoologia Agrícola da Escola Superior de Agricultura "Luiz de Queiroz", Universidade de São Paulo, Piracicaba, SP, para realização dos estudos de resíduos dos inseticidas encontrados no solo tratado nos períodos de $0,30,60$, $90,120,150$, e 180 dias após o tratamento.

Nos solos tratados com fipronil, clorpirifós e bifentrina, o método utilizado foi adaptado a partir do Método USEPA 3545 (2005). Foram tomados $20 \mathrm{~g}$ de solo e misturados com $30 \mathrm{~g}$ de sulfato de sódio; a extração foi realizada em Dionex Accelerated Extractor (ASE 300), durante 15 minutos, à temperatura de $100^{\circ} \mathrm{C}$ e pressão de $150 \mathrm{PSI}$. Os extratos foram concentrados e submetidos à limpeza por cromatografia de permeação em gel (GPC) e, em seguida, quantificados em cromatógrafo gasoso dotado de detector de captura de elétron (GC/ECD). No solo tratado com imidacloprid, o método foi adaptado a partir de Baskaran et al. (1999), e constou da extração de $10 \mathrm{~g}$ de solo, com $50 \mathrm{ml}$ de metanol destilado, sendo retiradas alíquotas de $1 \mathrm{ml}$ e misturadas com $1 \mathrm{ml}$ de água destilada, e injetadas em cromatógrafo líquido acoplado a detector de massas (LS/MS). 
Foram realizadas análises de todos os ingredientes ativos em todas as amostras de solo nos diferentes períodos de coleta, permitindo constatar contaminação cruzada caso viesse a ocorrer.

\subsection{Análise dos resultados obtidos dos experimentos}

Os resultados foram obtidos através das observações comparadas entre indivíduos expostos ao solo tratado e não tratado.

Esses dados foram submetidos à análise de variância através do teste F de significância e as médias, comparadas pelo teste de Tukey em nivel de $5 \%$ de probabilidade e sem transformação dos dados, utilizando-se o Sistema de Análise Estatística - SANEST (Zonta \& Machado, 1984). As porcentagens de mortalidade (Mort.(\%)) foram calculadas utilizando-se a fórmula de Abbott (1925). 


\section{RESULTADOS E DISCUSSÃO}

Os dados referentes aos períodos de: $0,30,60,90,120,150$ e 180 dias após o tratamento do solo (DAT) permitem verificar diferenças quanto ao caminhamento realizado pelo C. gestroi no solo tratado (segunda divisão), às 6 , 12, 24 e 48 horas após infestação (HAl), evidenciando repelência em alguns tratamentos quando comparados à testemunha (Figura 8). No final do período de 15 dias da infestação dos cupins, os valores de mortalidade (Mort. (\%)) para os diferentes tratamentos e periodos após tratamento ficaram entre $34,82 \%$ e $100 \%$.

\subsection{Infestação realizada logo após tratamento do solo (0 DAT)}

As avaliaçōes da distância percorrida permitiram observar que o sistema do corpo de prova desenvolvido atingiu os objetivos esperados (Figura 7 e Tabela 2); os cupins na testemunha, $6 \mathrm{HAl}$, percorreram 3,60 $\pm 1,14 \mathrm{~cm}$ no solo da segunda divisão. Nesse período, houve possivel adaptação ao corpo de prova, sendo que, nas avaliações com 12, 24 e $48 \mathrm{HAl}$ os cupins caminharam praticamente toda a extensão da segunda divisão. Nos tratamentos com IMID e BIFEN, $6 \mathrm{HAI}$, os cupins não caminharam no solo tratado (segunda divisão). Esses dados permitem considerar que houve um possivel tempo para adaptação ao sistema, mas caracterizam repelência, quando comparados à testemunha; o FIPR não diferiu estatisticamente da testemunha, enquanto que, no CLOR, os cupins caminharam grande distância já nas $6 \mathrm{HAl}$, talvez na tentativa de fuga do odor presente no solo que causaria irritação. Nas 
avaliações com 12, 24 e 48 HAl o CLOR, não diferiu estatisticamente da testemunha; no FIPR os cupins penetraram $12,00 \pm 0,89 \mathrm{~cm}$ na segunda divisão; o IMID e o BIFEN não diferiram estatisticamente entre si. Os cupins percorreram apenas $0,60 \pm 0,70$ e $0,00 \mathrm{~cm}$, respectivamente. $\mathrm{Na}$ avaliação 24 HAI o FIPR e o CLOR não diferiram estatisticamente entre si e da testemunha; no IMID, os cupins percorreram $5,00 \pm 0,70 \mathrm{~cm}$ na segunda divisão, demonstrando inibição do C. gestroi em caminhar no solo tratado, e no BIFEN os cupins percorreram apenas $2,00 \pm 1,58 \mathrm{~cm}$ da segunda divisão, indicando maior repelência entre os cupinicidas testados. A avaliação $48 \mathrm{HAl}$ demonstrou resultados semelhantes aos obtidos $24 \mathrm{HAI}$. O clorpirifós mostrou-se perceptível ao $C$. gestroi, que procurou fugir independente da direção; no solo tratado com BIFEN ○ C. gestroi percorreu $3,60 \pm 1,14 \mathrm{~cm}$, menor distância entre os tratamentos, o que caracteriza repelência própria dos piretróides.

Nas avaliações do percurso caminhado pelo $C$. gestroi no solo tratado com imidacloprid da segunda divisão, foi possivel observar que houve uma possivel percepção do cupim caminhando mais lentamente no solo em relação à testemunha. Esse comportamento está de acordo com os resultados obtidos por Wei et al. (2000), os quais, embora trabalhando com a espécie $C$. formosanus e solo tratado com imidacloprid $0,05 \%$ e $0,20 \%$, observaram que os cupins não escavavam túneis no solo tratado. Porém, os dados discordam de Su \& Scheffrahn (2005), que indicam imidacloprid como não repelente aos cupins subterrâneos, e de Shelton \& Grace (2003) que demonstraram que solo tratado com 1, 10 e $100 \mathrm{mg} / \mathrm{kg}$ de imidacloprid não foi repelente ao $C$. formosanus nos períodos de 6, 12 e $24 \mathrm{HAl}$, e ainda dos estudos de Thorne \& Breisch (2001), que destacaram o imidacloprid como não repelente ao $R$. virginicus. No presente trabalho, os cupins no FIPR tiveram comportamento no solo tratado semelhante à testemunha, adaptando-se ao corpo de prova inicialmente e, posteriormente, percorrendo o solo tratado normalmente. Estes dados condizem com o trabalho de Shelton \& Grace (2003), que concluíram que o solo tratado com fipronil não apresenta repelência à espécie $C$. 
formosanus e com Ibrahim et al. (2003), que concluíram que fipronil 0,063\% não é perceptível ao $C$. formosanus; no solo tratado com o clorpirifós, onde foi observada maior agitação dos cupins em relação aos demais tratamentos, sugerindo ação de repelência, fato que também foi observado por Su et al. (1997), nos cupins C. formosanus e R. flavipes que não percorreram tubos com solo tratado, mesmo utilizando o clorpirifós a $10 \mathrm{mg} / \mathrm{kg}$, que é uma dose inferior à do solo aqui estudado. No entanto, não concorda com Forschler (2005), que destaca o clorpirifós com ação não repelente; o C.gestroi praticamente não percorreu o solo tratado com bifentrina, indicando repelência, característica dos piretróides e confirmada por Loeck (1985), que, estudando o cupim de montículo Cornitermes cumulans, avaliou que, após 24 horas, ele percorreu apenas $2,60 \mathrm{~cm}$ na areia tratada com piretróides e por Su et al. (1999), que trabalharam com o $C$. formosanus, observaram que percorreu $4,6 \mathrm{~cm}$ na areia logo após o tratamento com bifentrina; essas distâncias são consideradas pequenas quando comparadas à testemunha. Os estudos de Su et al. (1989), Forschler (2005) e Su \& Scheffrahn (2005) indicaram a bifentrina com ação repelente ao $C$. formosanus. 


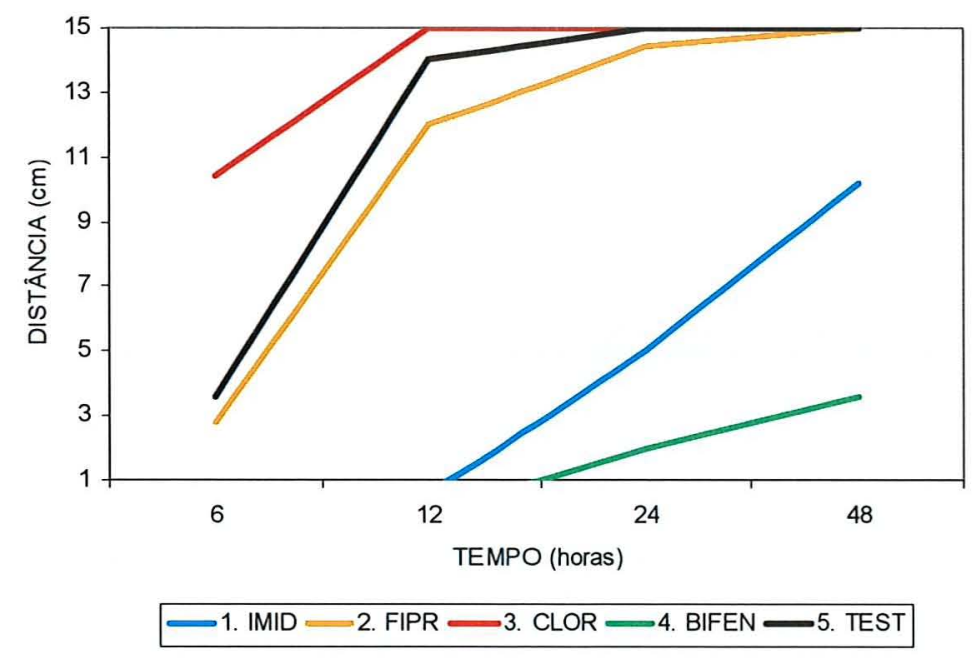

Figura 7 - Distância percorrida $(\mathrm{cm})$ pelo cupim Coptotermes gestroi na $2^{\mathrm{a}}$ divisão (solo tratado), logo após o tratamento do solo com diferentes cupinicidas. Avaliações realizadas 6, 12, 24 e 48 horas após infestação

Tabela 2. Dados médios obtidos dos diferentes tratamentos, em centímetros acumulados $(\mathrm{cm})$, percorridos pelos cupins $C$. gestroi ao longo da $2^{\mathrm{a}}$ divisão do corpo de prova (solo tratado), logo após tratamento do solo, avaliando-se 6, 12, 24 e 48 horas após a infestação (HAl) e respectivos coeficientes de variação (C.V.)

\begin{tabular}{lcccc}
\hline \multirow{2}{*}{ Tratamentos } & \multicolumn{4}{c}{ Distância acumulada percorrida em solo tratado (cm) } \\
& 6 HAl & 12 HAl & 24 HAl & 48 HAl \\
\hline 1. IMID & $0,00 \pm 0,00 \mathrm{c}^{*}$ & $0,60 \pm 0,70 \mathrm{c}$ & $5,00 \pm 0,70 \mathrm{~b}$ & $10,20 \pm 0,83 \mathrm{~b}$ \\
2. FIPR & $2,80 \pm 2,38 \mathrm{~b}$ & $12,00 \pm 0,89 \mathrm{~b}$ & $14,40 \pm 0,89 \mathrm{a}$ & $15,00 \pm 0,00 \mathrm{a}$ \\
3. CLOR & $10,40 \pm 1,14 \mathrm{a}$ & $15,00 \pm 0,00 \mathrm{a}$ & $15,00 \pm 0,00 \mathrm{a}$ & $15,00 \pm 0,00 \mathrm{a}$ \\
4. BIFEN & $0,00 \pm 0,00 \mathrm{c}$ & $0,00 \pm 0,00 \mathrm{c}$ & $2,00 \pm 1,58 \mathrm{c}$ & $3,60 \pm 1,14 \mathrm{c}$ \\
5. TEST & $3,60 \pm 1,14 \mathrm{~b}$ & $14,00 \pm 1,41 \mathrm{a}$ & $15,00 \pm 0,00 \mathrm{a}$ & $15,00 \pm 0,00 \mathrm{a}$ \\
C.V. (\%) & 38,34 & 12,37 & 8,48 & 5,37 \\
\hline
\end{tabular}

* Na coluna, médias seguidas por letras distintas diferem entre si pelo teste de Tukey em nível de $5 \%$ de probabilidade. 
Os resultados expressos na Tabela 3, obtidos após 15 dias da infestação, demonstraram que IMID, FIPR e CLOR causaram 100\% de mortalidade do C. gestroi. Embora com dose diferente, o fato está de acordo com os resultados de Wei et al. (2000), que utilizaram imidacloprid 0,05\% e $0,20 \%$ obtendo $100 \%$ de controle da espécie $C$. formosanus em 6 dias, e com os de Osbrink \& Lax (2003), que trabalharam com imidacloprid $0,1 \%$, visando ao controle do $C$. formosanus, inicialmente tendo $100 \%$ de inatividade das colônias; nos trabalhos realizados por Osbrink et al. (2001) e Osbrink \& Lax (2002), embora tenham sido empregadas doses diferentes do fipronil e a espécie $C$. formosanus, foram atingidos os mesmos resultados; Nunes et al. (2002), utilizaram o clorpirifós na dose de $0,46 \%$ e obtiveram $100 \%$ de mortalidade do C. gestro; e com BIFEN houve $88,86 \%$ de mortalidade dos cupins diferenciando estatisticamente dos demais. É importante observar que os cupins sobreviventes se encontravam na primeira divisão, não ultrapassando o solo tratado, indicando que, devido à ação repelente do cupinicida, como observado na Tabela 2, forma-se uma barreira que inibe o ataque dos cupins. Aqueles que chegaram à segunda divisão morreram; tais características são semelhantes aos resultados obtidos por Loeck (1985), que trabalhou com a espécie $C$. cumulans e Su et al. (1989) com as espécies $C$. formosanus e $R$. flavipes. Nunes et al. (2002) demonstraram que houve $100 \%$ de mortalidade do C. gestroi que ficou em contato com bifentrina 0,$03 ; 0,04$ e $0,06 \%$ durante 24 horas.

Geralmente os cupins mortos são encontrados envoltos por fungos (Figura 10), o que não foi observado na testemunha. $O$ índice de sobrevivência na testemunha foi de $95,2 \%$, assim qualificando o sistema do corpo de prova como eficaz para avaliar a mortalidade do C. gestroi em solo tratado com cupinicidas. $O$ indice de sobrevivência foi semelhante ao da testemunha do trabalho de Nunes et al. (2002), onde esse índice foi de $98 \%$, utilizando papel filtro em placas de Petri. 
No IMID e BIFEN não foram encontrados cupins vivos e/ou mortos na terceira divisão, fato ocorrido devido à possível repelência ou inibição dos produtos, como tem indicado na avaliação da distância percorrida em relação ao tempo (Figura 7 e Tabela 2).

Houve ataque do $C$. gestroi apenas na madeira de Pinus sp., presente no corpo de prova da testemunha (Figura 9); nos demais tratamentos os discos de madeira permaneceram íntegros.

Tabela 3. Dados médios para cada tratamento, número de cupins $C$. gestroi vivos $(V)$ e mortos $(M)$ na $1^{a} ; 2^{a}$ e $3^{a}$ divisões do corpo de prova e o total de mortos, porcentagem de mortalidade (Mort. (\%)). Infestação realizada logo após o tratamento do solo e avaliação realizada 15 dias após infestação

\begin{tabular}{lcccccccc}
\hline \multicolumn{1}{c}{$\begin{array}{c}\text { Mrata- } \\
\text { mentos }\end{array}$} & \multicolumn{2}{c}{$\mathbf{1}^{\mathrm{a}}$ Divisão } & \multicolumn{2}{c}{$\mathbf{2}^{\mathrm{a}}$ Divisão } & \multicolumn{2}{c}{$\mathbf{3}^{\mathrm{a}}$ Divisão } & Total & $\begin{array}{c}\text { Mort. } \\
\text { (\%) }\end{array}$ \\
& $\mathbf{V}$ & $\mathbf{M}$ & $\mathbf{V}$ & $\mathbf{M}$ & $\mathbf{V}$ & $\mathbf{M}$ & $\mathbf{M}$ & \\
\hline 1. IMID & $0,00 \mathrm{~b}^{*}$ & $11,80 \mathrm{a}$ & $0,00 \mathrm{~b}$ & $88,20 \mathrm{a}$ & $0,00 \mathrm{~b}$ & $0,00 \mathrm{~b}$ & $100 \mathrm{a}$ & 100 \\
2. FIPR & $0,00 \mathrm{~b}$ & $12,40 \mathrm{a}$ & $0,00 \mathrm{~b}$ & $74,20 \mathrm{~b}$ & $0,00 \mathrm{~b}$ & $13,60 \mathrm{a}$ & $100 \mathrm{a}$ & 100 \\
3. CLOR & $0,00 \mathrm{~b}$ & $8,80 \mathrm{a}$ & $0,00 \mathrm{~b}$ & $88,80 \mathrm{a}$ & $0,00 \mathrm{~b}$ & $2,40 \mathrm{~b}$ & $100 \mathrm{a}$ & 100 \\
4. BIFEN & $10,60 \mathrm{a}$ & $7,00 \mathrm{ab}$ & $0,00 \mathrm{~b}$ & $82,20 \mathrm{ab}$ & $0,00 \mathrm{~b}$ & $0,00 \mathrm{~b}$ & $89,40 \mathrm{~b}$ & 88,86 \\
5. TEST & $3,00 \mathrm{ab}$ & $2,40 \mathrm{~b}$ & $54,20 \mathrm{a}$ & $2,20 \mathrm{c}$ & $38,00 \mathrm{a}$ & $0,20 \mathrm{~b}$ & $4,80 \mathrm{c}$ & 0,00 \\
C.V. (\%) & 148,24 & 37,10 & 4,62 & 6,98 & 62,27 & 94,92 & 5,05 &.- \\
\hline
\end{tabular}

* $\mathrm{Na}$ coluna, médias seguidas por letras distintas diferem entre si pelo teste de Tukey em nível de $5 \%$ de probabilidade. 


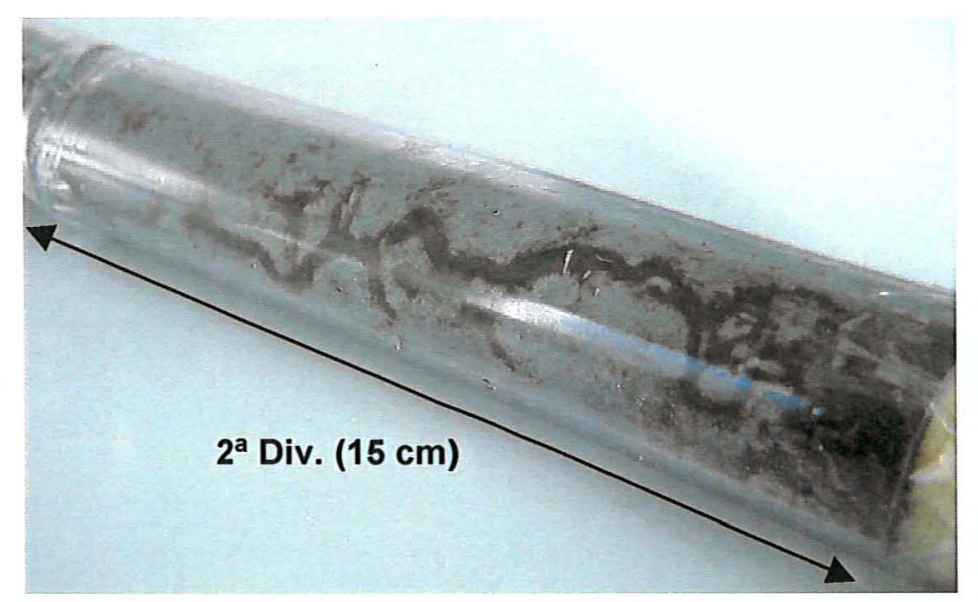

Figura 8 - C. gestroi percorrendo a $2^{\mathrm{a}}$ divisão (2a Div.) do tratamento testemunha, 48 horas após infestação
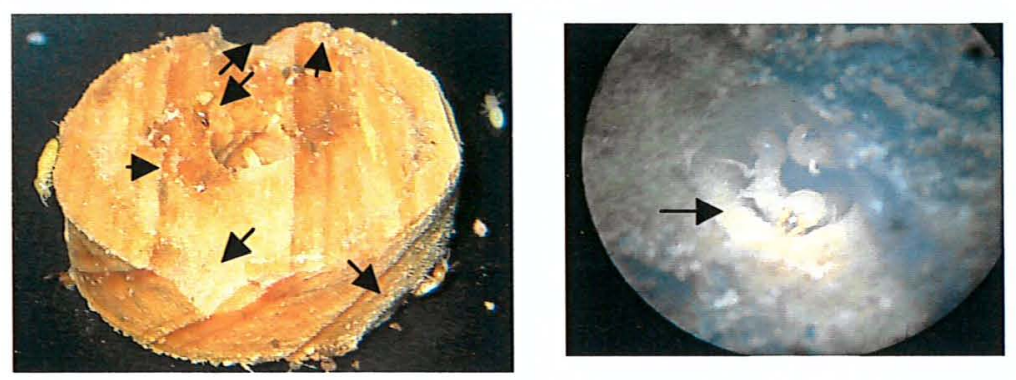

Figura 9 - Danos causados por C. gestroi no disco de madeira de Pinus sp. no período de 15 dias

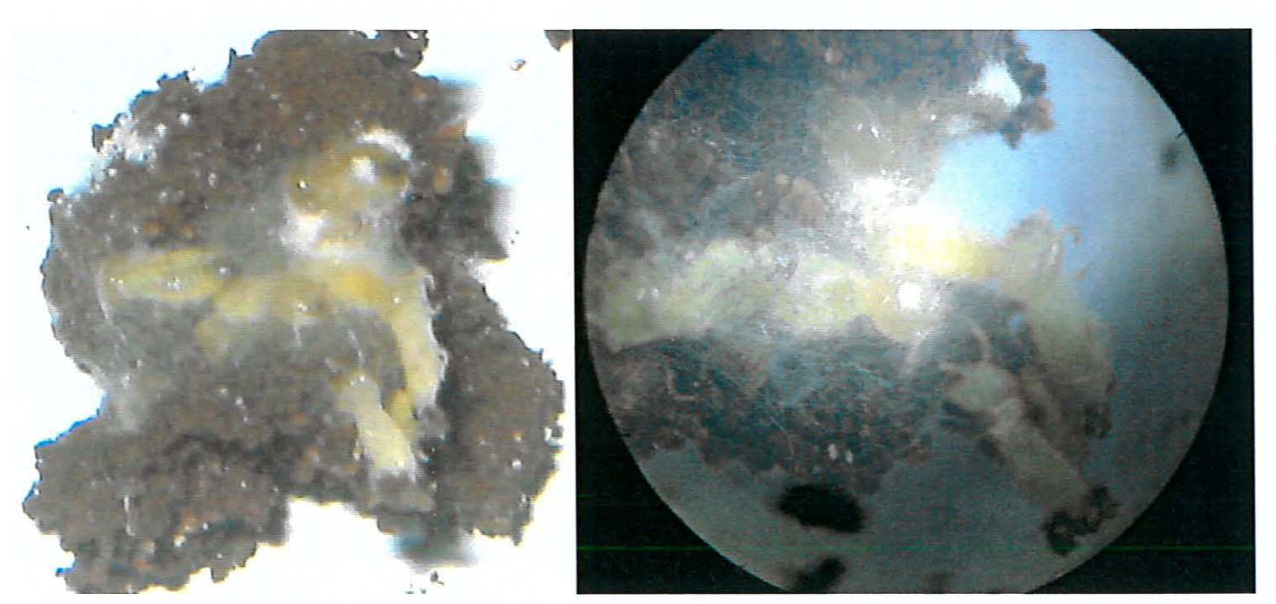

Figura 10 - Presença de fungos sobre C. gestroi mortos avaliados 15 dias após infestação em solo tratado com os cupinicidas 


\subsection{Infestação realizada 30 dias após tratamento do solo (30 DAT)}

Os resultados obtidos na avaliação da distância acumulada percorrida pelo $C$. gestroi na segunda divisão do corpo de prova (solo tratado) às $6,12,24$ e 48 horas após infestação (HAl), realizada 30 DAT, podem ser observados na Figura 11 e Tabela 4. Com $6 \mathrm{HAl}$, pode-se observar que o C. gestroi no IMID, CLOR, BIFEN e TEST apresentaram comportamento semelhante à avaliação de $6 \mathrm{HAl}$ com 0 DAT. Apenas no FIPR, o comportamento dos cupins não se manteve constante em relação à avaliação anterior, e diferiu da testemunha. Os cupins percorrendo $2,00 \pm 1,58 \mathrm{~cm}$, mostraram aparente inibição ao solo tratado, podendo esse fato não ser devido ao fipronil, pois a tendência das demais avaliações contradiz essa observação; não há referência de repelência do fipronil na dose utilizada, e os trabalhos de Ibrahim et al. (2003), Shelton \& Grace (2003), Su \& Scheffrahn (2005) e Osbrink \& Lax (2002) indicam isso; na avaliação com $12 \mathrm{HAI}$, os cupins no IMID e BIFEN continuaram a resistir, havendo baixa penetração na segunda divisão; caminharam apenas 1,00 \pm $0,70 \mathrm{~cm}$ no IMID, enquanto, na segunda divisão da testemunha os cupins percorreram $13,00 \pm 1,87 \mathrm{~cm}$; no FIPR, a distância percorrida na segunda divisão pelos cupins foi de $11,40 \pm 2,40 \mathrm{~cm}$ e, no CLOR, percorreram o percurso total de $15 \mathrm{~cm}$ da segunda divisão. Nas avaliações com 24 e $48 \mathrm{HAl}$, os cupins apresentaram comportamento semelhante ao da avaliação 0 DAT. 


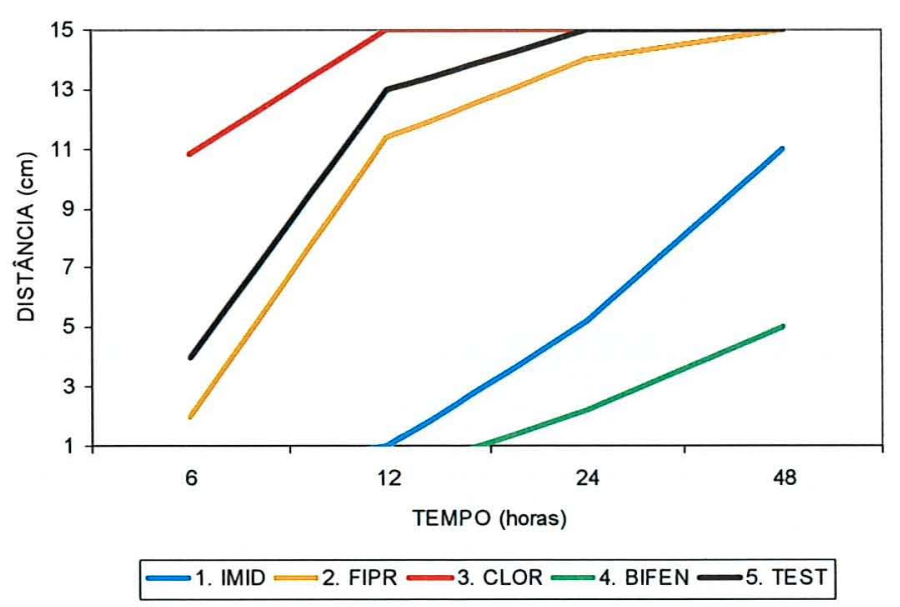

Figura 11 - Distância percorrida $(\mathrm{cm})$ pelo cupim Coptotermes gestroi na $2^{\mathrm{a}}$ divisão (solo tratado), 30 dias após o tratamento do solo com diferentes cupinicidas. Avaliações realizadas 6, 12, 24 e 48 horas após infestação

Tabela 4. Dados médios obtidos dos diferentes tratamentos, em centímetros acumulados $(\mathrm{cm})$, percorridos pelos cupins $C$. gestroi ao longo da $2^{\mathrm{a}}$ divisão do corpo de prova (solo tratado), 30 dias após tratamento do solo, avaliando-se 6, 12, 24 e 48 horas após a infestação (HAl) e respectivos coeficientes de variação (C.V.)

\begin{tabular}{lcccc}
\hline \multirow{2}{*}{ Tratamentos } & \multicolumn{4}{c}{ Distância acumulada percorrida em solo tratado (cm) } \\
& $\mathbf{6 ~ H A I}$ & $\mathbf{1 2} \mathbf{~ H A l}$ & $\mathbf{2 4} \mathrm{HAl}$ & $\mathbf{4 8} \mathbf{H A l}$ \\
\hline 1. IMID & $0,00 \pm 0,00 \mathrm{c}^{*}$ & $1,00 \pm 0,70 \mathrm{c}$ & $5,20 \pm 1,48 \mathrm{~b}$ & $11,00 \pm 1,22 \mathrm{~b}$ \\
2. FIPR & $2,00 \pm 1,58 \mathrm{bc}$ & $11,40 \pm 2,40 \mathrm{~b}$ & $14,00 \pm 1,00 \mathrm{a}$ & $15,00 \pm 0,00 \mathrm{a}$ \\
3. CLOR & $10,80 \pm 2,58 \mathrm{a}$ & $15,00 \pm 0,00 \mathrm{a}$ & $15,00 \pm 0,00 \mathrm{a}$ & $15,00 \pm 0,00 \mathrm{a}$ \\
4. BIFEN & $0,00 \pm 0,00 \mathrm{c}$ & $0,00 \pm 0,00 \mathrm{c}$ & $2,20 \pm 1,90 \mathrm{c}$ & $5,00 \pm 1,58 \mathrm{c}$ \\
5. TEST & $4,00 \pm 1,58 \mathrm{~b}$ & $13,0 \pm 1,87 \mathrm{ab}$ & $15,00 \pm 0,00 \mathrm{a}$ & $15,00 \pm 0,00 \mathrm{a}$ \\
C.V. (\%) & 45,52 & 17,32 & 11,42 & 7,33 \\
\hline
\end{tabular}

${ }^{\star} \mathrm{Na}$ coluna, médias seguidas por letras distintas diferem entre si pelo teste de Tukey em nível de $5 \%$ de probabilidade. 
Os resultados expressos na Tabela 5 correspondem à avaliação de 30 DAT, e 15 dias após infestação; observa-se que os tratamentos IMID, FIPR e CLOR permaneceram iguais aos da avaliação com 0 DAT, ou seja, demonstraram $100 \%$ de mortalidade do C. gestroi; já no tratamento 4 (BIFEN), houve $85 \%$ de mortalidade; no entanto, os cupins sobreviventes encontravamse na primeira divisão, não ultrapassaram para a segunda, indicando que os que passaram se contaminaram e morreram.

Apenas no IMID e BIFEN não foram encontrados cupins vivos e/ou mortos na terceira divisão, fato verificado também em 0 DAT, podendo considerar que existe ação de repelência dos produtos, como têm indicado as avaliações da distância percorrida em relação ao tempo, realizadas anteriormente com 0 DAT.

O índice de sobrevivência da testemunha foi de $96 \%$, semelhante à avaliação anterior e ao trabalho de Nunes et al. (2002), que obtiveram sobrevivência de $98 \%$.

No final do período de 15 dias apenas, no disco de madeira de Pinus sp. da testemunha houve dano causado pelo C. gestroi. 
Tabela 5. Dados médios para cada tratamento, número de cupins $C$. gestroi vivos $(V)$ e mortos $(M)$ na $1^{a} ; 2^{a}$ e $3^{a}$ divisões do corpo de prova e o total de mortos $(M)$, porcentagem de mortalidade (Mort. (\%)). Infestação realizada 30 dias após o tratamento do solo e avaliação realizada 15 dias após infestação

\begin{tabular}{|c|c|c|c|c|c|c|c|c|}
\hline \multirow{3}{*}{$\begin{array}{l}\text { Trata- } \\
\text { mentos }\end{array}$} & \multicolumn{7}{|c|}{ Média de cupins vivos (V) e mortos (M) } & \multirow{3}{*}{$\begin{array}{c}\text { Mort. } \\
(\%)\end{array}$} \\
\hline & \multicolumn{2}{|c|}{$1^{\text {a }}$ Divisão } & \multicolumn{2}{|c|}{$2^{\mathrm{a}}$ Divisão } & \multicolumn{2}{|c|}{$3^{a}$ Divisão } & \multirow{2}{*}{$\begin{array}{c}\text { Total } \\
\mathbf{M}\end{array}$} & \\
\hline & $\mathbf{v}$ & $\mathbf{M}$ & v & $\mathbf{M}$ & v & M & & \\
\hline 1. IMID & $0,00 \mathrm{c}$ & $12,20 \mathrm{a}$ & $0,00 \mathrm{~b}$ & $87,80 \mathrm{a}$ & $0,00 \mathrm{~b}$ & $0,00 \mathrm{c}$ & $100 \mathrm{a}$ & 100 \\
\hline 2. FIPR & $0,00 \mathrm{c}$ & $10,60 a b$ & $0,00 \mathrm{~b}$ & $75,00 \mathrm{~b}$ & $0,00 \mathrm{~b}$ & $14,40 \mathrm{~b}$ & $100 \mathrm{a}$ & 100 \\
\hline 3. CLOR & $0,00 \mathrm{c}$ & $8,40 a b c$ & $0,00 \mathrm{~b}$ & $63,00 \mathrm{c}$ & $0,00 \mathrm{~b}$ & $28,60 \mathrm{a}$ & $100 \mathrm{a}$ & 100 \\
\hline 4. BIFEN & $14,40 \mathrm{a}$ & $5,00 \mathrm{bc}$ & $0,00 \mathrm{~b}$ & $80,60 a b$ & $0,00 \mathrm{~b}$ & $0,00 \mathrm{c}$ & $85,60 \mathrm{~b}$ & 85,00 \\
\hline 5. TEST & $6,40 \mathrm{~b}$ & $2,60 \mathrm{c}$ & $54,40 a$ & $1,20 \mathrm{~d}$ & 35,20 a & $0,20 \mathrm{c}$ & $4,00 \mathrm{c}$ & 0,00 \\
\hline C.V. (\%) & 65,40 & 48,25 & 59,60 & 9,59 & 93,18 & 52,98 & 3,31 & --- \\
\hline
\end{tabular}

* Na coluna, médias seguidas por letras distintas diferem entre si pelo teste de Tukey em nível de $5 \%$ de probabilidade.

\subsection{Infestação realizada 60 dias após tratamento do solo (60 DAT)}

Dados obtidos nas avaliações da distância acumulada percorrida na segunda divisão (solo tratado) do corpo de prova pelo $C$. gestroi após 6, 12, 24 e $48 \mathrm{HAl}, 60 \mathrm{DAT}$ podem ser observados na Figura 12 e Tabela 6. Com $6 \mathrm{HAl}$, os resultados obtidos no IMID, FIPR, CLOR, BIFEN e testemunha foram semelhantes aos de $6 \mathrm{HAl}$ com 0 DAT. Na avaliação com $12 \mathrm{HAl}$, todos os tratamentos permaneceram com mesma diferenciação estatística da avaliação realizada com $6 \mathrm{HAl}$, e não houve discrepância em relação ao mesmo período em 0 DAT. Os resultados obtidos em $24 \mathrm{HAl}$ se mantiveram constantes no período observado das avaliações com 0 e 30 DAT. Com $48 \mathrm{HAl}$ apenas no BIFEN diferiu dos demais, percorrendo apenas $3,80 \pm 0,83 \mathrm{~cm}$ no solo tratado da segunda divisão, o que evidencia a formação de uma barreira, impedindo a passagem dos cupins, como observado nas avaliações de 0 e 30 DAT; no IMID 
não diferiu estatisticamente da testemunha. Houve menor concentração de resíduo do imidacloprid no solo em relação a 0 DAT (Figura 17), podendo diminuir a percepção do cupim, ocorrendo pequeno aumento da distância percorrida no solo.

Embora os cupins tenham percorrido o solo tratado com imidacloprid mais lentamente em relação à testemunha, chegaram a penetrar em quase todo o solo tratado, o que favorece a contaminação dos mesmos, que pode assim levá-los à morte.

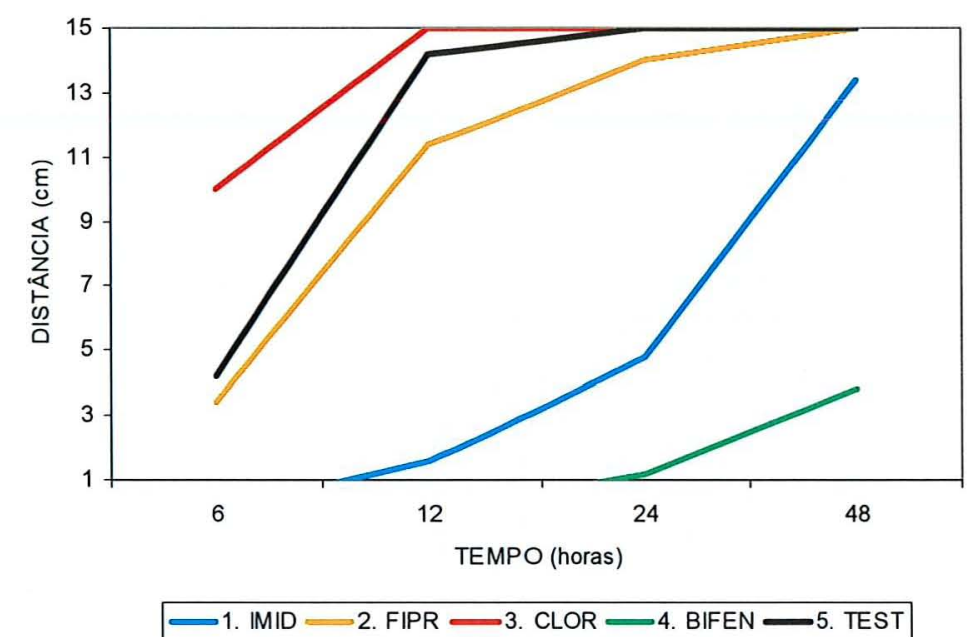

Figura 12 - Distância percorrida $(\mathrm{cm})$ pelo cupim Coptotermes gestroi, na $2^{\mathrm{a}}$ divisão (solo tratado), 60 dias após o tratamento do solo com diferentes cupinicidas. Avaliações realizadas 6, 12, 24 e 48 horas após infestação 
Tabela 6. Dados médios obtidos dos diferentes tratamentos, em centímetros acumulados $(\mathrm{cm})$, percorridos pelos cupins C. gestroi ao longo da $2^{\mathrm{a}}$ divisão do corpo de prova (solo tratado), 60 dias após tratamento do solo, avaliando-se 6, 12, 24 e 48 horas após a infestação (HAl) e respectivos coeficientes de variação (C.V.)

\begin{tabular}{lcccc}
\hline \multirow{2}{*}{ Tratamentos } & \multicolumn{4}{c}{ Distância acumulada percorrida em solo tratado (cm) } \\
& $\mathbf{6 ~ H A l}$ & $\mathbf{1 2} \mathbf{~ H A l}$ & $\mathbf{2 4} \mathbf{H A l}$ & $\mathbf{4 8 ~ H A l}$ \\
\hline 1. IMID & $0,00 \pm 0,00 \mathrm{c}^{*}$ & $1,60 \pm 1,14 \mathrm{c}$ & $4,80 \pm 0,83 \mathrm{~b}$ & $13,40 \pm 2,30 \mathrm{a}$ \\
2. FIPR & $3,40 \pm 2,70 \mathrm{~b}$ & $11,40 \pm 1,67 \mathrm{~b}$ & $14,00 \pm 1,00 \mathrm{a}$ & $15,00 \pm 0,00 \mathrm{a}$ \\
3. CLOR & $10,00 \pm 1,58 \mathrm{a}$ & $15,00 \pm 0,00 \mathrm{a}$ & $15,00 \pm 0,00 \mathrm{a}$ & $15,00 \pm 0,00 \mathrm{a}$ \\
4. BIFEN & $0,00 \pm 0,00 \mathrm{c}$ & $0,00 \pm 0,00 \mathrm{C}$ & $1,20 \pm 0,83 \mathrm{c}$ & $3,80 \pm 0,83 \mathrm{~b}$ \\
5. TEST & $4,20 \pm 1,30 \mathrm{~b}$ & $14,20 \pm 1,30 \mathrm{a}$ & $15,00 \pm 0,00 \mathrm{a}$ & $15,00 \pm 0,00 \mathrm{a}$ \\
C.V. (\%) & 43,08 & 12,76 & 6,92 & 8,80 \\
\hline
\end{tabular}

* Na coluna, médias seguidas por letras distintas diferem entre si pelo teste de Tukey em nivel de $5 \%$ de probabilidade.

Os resultados obtidos na avaliação de mortalidade do $C$. gestroi realizada 60 DAT (Tabela 7) foram de 100\% no IMID, FIPR e CLOR, como ocorrido em 0 e 30 DAT; no BIFEN que na avaliação anterior de 30 DAT apresentou $85 \%$ de mortalidade, nesta a mortalidade foi reduzida para $42,22 \%$, mas os cupins vivos permaneceram na primeira divisão, aparentando serem barrados quimicamente e não penetrando na segunda divisão; os que foram encontrados no solo tratado estavam mortos, concordando com Nunes et al. (2002), que constataram $100 \%$ de mortalidade do C. gestroi exposto ao papel filtro contaminado com bifentrina. Como os cupins vivos não atingiram o final da segunda divisão, não causaram danos no disco de madeira, como ocorreu na testemunha.

Foram encontrados alguns cupins mortos na terceira divisão do IMID, o que não havia ocorrido em avaliações anteriores, aparentando ser devido à 
maior mobilidade do $C$. gestroi no solo tratado com imidacloprid, como foi observado na avaliação de $48 \mathrm{HAl}$ com 60 DAT.

$\mathrm{Na}$ testemunha, o índice de sobrevivência do C. gestroi foi de $95,20 \%$ no final do período de 15 dias.

Tabela 7. Dados médios para cada tratamento, número de cupins $C$. gestroi vivos $(V)$ e mortos $(M)$ na $1^{\mathrm{a}} ; 2^{\mathrm{a}}$ e $3^{\mathrm{a}}$ divisōes do corpo de prova e o total de mortos (M), porcentagem de mortalidade (Mort. (\%)). Infestação realizada 60 dias após o tratamento do solo e avaliação realizada 15 dias após infestação

\begin{tabular}{|c|c|c|c|c|c|c|c|c|}
\hline \multirow{3}{*}{$\begin{array}{c}\text { Trata- } \\
\text { mentos }\end{array}$} & \multicolumn{7}{|c|}{ Média de cupins vivos (V) e mortos (M) } & \multirow{3}{*}{$\begin{array}{l}\text { Mort. } \\
(\%)\end{array}$} \\
\hline & \multicolumn{2}{|c|}{$1^{\text {a }}$ Divisão } & \multicolumn{2}{|c|}{$2^{\mathrm{a}}$ Divisão } & \multicolumn{2}{|c|}{$3^{\text {a }}$ Divisão } & \multirow{2}{*}{$\begin{array}{c}\text { Total } \\
\mathbf{M}\end{array}$} & \\
\hline & v & $\mathbf{M}$ & v & M & V & $\mathbf{M}$ & & \\
\hline 1. IMID & $0,00 \mathrm{~b}$ & $6,00 \mathrm{~b}$ & $0,00 \mathrm{~b}$ & $86,20 \mathrm{a}$ & $0,00 \mathrm{~b}$ & $7,60 \mathrm{~b}$ & $100 \mathrm{a}$ & 100 \\
\hline 2. FIPR & $0,00 \mathrm{~b}$ & $14,00 \mathrm{a}$ & $0,00 \mathrm{~b}$ & $64,00 \mathrm{~b}$ & $0,00 \mathrm{~b}$ & $22,00 \mathrm{a}$ & $100 \mathrm{a}$ & 100 \\
\hline 3. CLOR & $0,00 \mathrm{~b}$ & $11,20 \mathrm{a}$ & $0,00 \mathrm{~b}$ & $67,20 \mathrm{ab}$ & $0,00 \mathrm{~b}$ & $11,60 a b$ & $100 a$ & 100 \\
\hline 4. BIFEN & $55,00 \mathrm{a}$ & $3,80 \mathrm{bc}$ & $0,00 \mathrm{~b}$ & $46,00 \mathrm{c}$ & $0,00 \mathrm{~b}$ & $0,00 \mathrm{~b}$ & $45,00 \mathrm{~b}$ & 42,22 \\
\hline 5. TEST & $2,00 \mathrm{~b}$ & $1,40 \mathrm{c}$ & 59,40 a & $2,60 \mathrm{~d}$ & $35,80 \mathrm{a}$ & $0,80 \mathrm{~b}$ & $4,80 \mathrm{c}$ & 0,00 \\
\hline C.V. (\%) & 19,21 & 22,36 & 23,14 & 12,75 & 35,98 & 75,81 & 3,01 & -.. \\
\hline
\end{tabular}

* Na coluna, médias seguidas por letras distintas diferem entre si pelo teste de Tukey em nível de $5 \%$ de probabilidade.

\subsection{Infestação realizada 90 dias após tratamento do solo (90 DAT)}

Com 90 DAT do solo (Figura 13 e Tabela 8 ), o percurso caminhado pelo C. gestroi $6 \mathrm{HAI}$ no IMID, CLOR, BIFEN e TEST apresentaram pequenas alterações quando comparadas a 60 DAT; os cupins no FIPR percorreram 7,00 $\pm 1,58 \mathrm{~cm}$ da segunda divisão, diferindo da testemunha, que percorreu $5,60 \pm$ $1,14 \mathrm{~cm}$, possibilitando assim, a ocorrência de contaminação da amostra de solo ou algum fator que possa ter estimulado os cupins a caminharem. 
Observou-se uma similaridade no comportamento do cupim em solo tratado com fipronil ao não tratado (testemunha), concordando com Ibrahim et al. (2003), que concluiram que o fipronil no tratamento de solo não foi perceptivel ao $\mathrm{C}$. formosanus. Na avaliação com $12 \mathrm{HAI}$ no IMID os cupins percorreram $3,60 \pm 1,14 \mathrm{~cm}$ da segunda divisão, sendo superior aos resultados do mesmo período com 0,30 e 60 DAT. Foi observada redução da concentração do imidacloprid no solo (Figura 17), indicando menor percepção do C. gestroi, o que, talvez, possibilite sua maior penetração no solo. No BIFEN os cupins percorreram $1,60 \pm 1,14 \mathrm{~cm}$, sendo também, maior a penetração quando comparada à das avaliações anteriores. No entanto, a concentração de bifentrina no solo não foi reduzida quando comparada a de 0 DAT; este comportamento pode ter ocorrido por fator não avaliado. Mesmo assim, a bifentrina mostra ação repelente, pois os cupins presentes na testemunha caminharam 14,00 $\pm 1,14 \mathrm{~cm}$ na segunda divisão. Com avaliação de $24 \mathrm{HAl}$ no IMID os cupins percorreram 7,40 $\pm 1,67 \mathrm{~cm}$, diferenciando-se do BIFEN, onde os cupins percorreram $3,20 \pm 1,09 \mathrm{~cm}$ no solo da segunda divisão; esses resultados permitem supor maior tendência à repelência da bifentrina em relação ao imidacloprid para o $C$. gestroi. Nos tratamentos FIPR, CLOR e TEST os cupins percorreram os $15 \mathrm{~cm}$ da segunda divisão. Com $48 \mathrm{HAl}$ apenas o BIFEN diferiu estatisticamente dos demais; os cupins caminharam apenas 5,20 $\pm 0,83 \mathrm{~cm}$ na segunda divisão, como já observado em 60 DAT. 


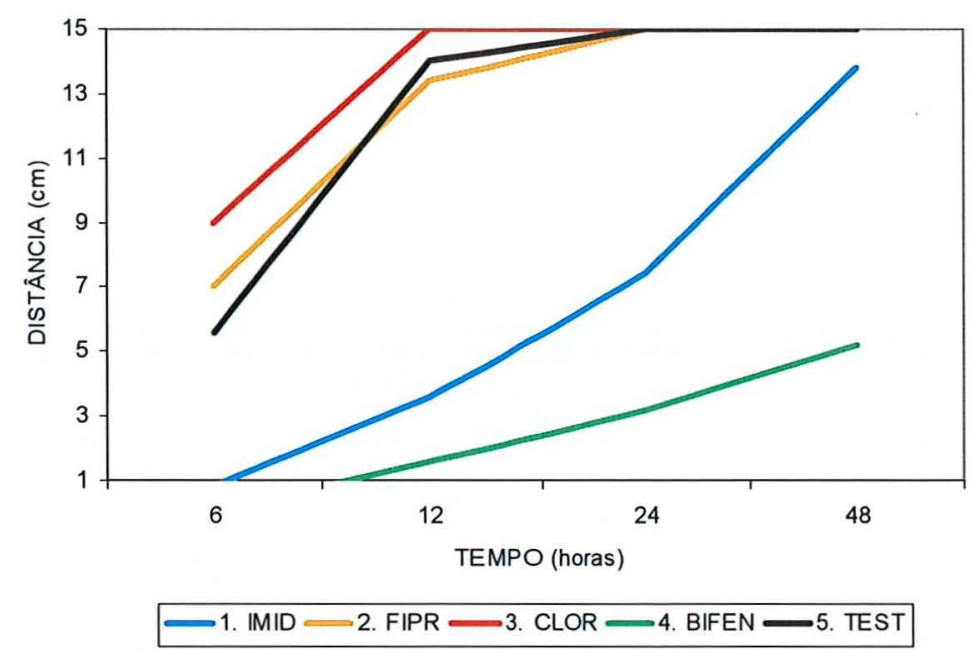

Figura 13 - Distância percorrida $(\mathrm{cm})$ pelo cupim Coptotermes gestroi, na $2^{\mathrm{a}}$ divisão (solo tratado), 90 dias após o tratamento do solo com diferentes cupinicidas. Avaliações realizadas 6, 12, 24 e 48 horas após infestação

Tabela 8. Dados médios obtidos dos diferentes tratamentos, em centímetros acumulados $(\mathrm{cm})$, percorridos pelos cupins $C$. gestroi ao longo da $2^{\mathrm{a}}$ divisão do corpo de prova (solo tratado), 90 dias após tratamento do solo, avaliando-se $6,12,24$, e 48 horas após a infestação (HAl) e respectivos coeficientes de variação (C.V.)

\begin{tabular}{lcccc}
\hline \multirow{2}{*}{ Tratamentos } & \multicolumn{4}{c}{ Distância acumulada percorrida em solo tratado $(\mathbf{c m})$} \\
& 6 HAI & 12 HAl & 24 HAI & 48 HAl \\
\hline 1. IMID & $0,80 \pm 1,30 \mathrm{c}^{*}$ & $3,60 \pm 1,14 \mathrm{~b}$ & $7,40 \pm 1,67 \mathrm{~b}$ & $13,80 \pm 1,30 \mathrm{a}$ \\
2. FIPR & $7,00 \pm 1,58 \mathrm{ab}$ & $13,40 \pm 1,81 \mathrm{a}$ & $15,00 \pm 0,00 \mathrm{a}$ & $15,00 \pm 0,00 \mathrm{a}$ \\
3. CLOR & $9,00 \pm 1,58 \mathrm{a}$ & $15,00 \pm 0,00 \mathrm{a}$ & $15,00 \pm 0,00 \mathrm{a}$ & $15,00 \pm 0,00 \mathrm{a}$ \\
4. BIFEN & $0,00 \pm 0,00 \mathrm{c}$ & $1,60 \pm 1,14 \mathrm{~b}$ & $3,20 \pm 1,09 \mathrm{c}$ & $5,20 \pm 0,83 \mathrm{~b}$ \\
5. TEST & $5,60 \pm 1,14 \mathrm{~b}$ & $14,00 \pm 1,41 \mathrm{a}$ & $15,00 \pm 0,00 \mathrm{a}$ & $15,00 \pm 0,00 \mathrm{a}$ \\
C.V. (\%) & 28,23 & 13,20 & 8,04 & 5,41 \\
\hline
\end{tabular}

* Na coluna, médias seguidas por letras distintas diferem entre si pelo teste de Tukey em nível de $5 \%$ de probabilidade. 
Na Tabela 9 observa-se que na avaliação com 90 DAT houve $95,92 \%$ de mortalidade dos cupins C. gestroi no IMID, mas os cupins sobreviventes não causaram danos ao disco de madeira, talvez devido a uma pequena quantidade de individuos. Tal comportamento pode ser discutido em relação ao estudo de Thorne \& Breisch (2001) onde os autores observaram que o $R$. virginus, entrando em contato com dose sub letal de imidacloprid, apresentou desorientação, o que afetou sua atividade de forrageamento. No FIPR e CLOR houve $100 \%$ de mortalidade no final do período de 15 dias de exposição e $34,82 \%$ de mortalidade do $C$. gestroi no BIFEN, não causando dano à madeira de Pinus sp., pois os insetos vivos permaneceram isolados na primeira divisão; na segunda divisão com o solo tratado, possivelmente formou-se uma barreira química que impediu a passagem dos cupins, como já observado nas avaliações com 0, 30 e 60 DAT.

Danos causados pelo $C$. gestroi no disco de madeira foram observados somente na testemunha, onde o indice de sobrevivência foi de $98,20 \%$, semelhante aos índices obtidos nas avaliações com 0, 30 e 60 DAT. 
Tabela 9. Dados médios para cada tratamento, número de cupins $C$. gestroi vivos $(V)$ e mortos $(M)$ na $1^{\mathrm{a}} ; 2^{\mathrm{a}}$ e $3^{\mathrm{a}}$ divisões do corpo de prova e o total de mortos $(M)$, porcentagem de mortalidade (Mort. (\%)). Infestação realizada 90 dias após o tratamento do solo e avaliação realizada 15 dias após infestação

\begin{tabular}{|c|c|c|c|c|c|c|c|c|}
\hline \multirow{3}{*}{$\begin{array}{l}\text { Trata- } \\
\text { mentos }\end{array}$} & \multicolumn{7}{|c|}{ Média de cupins vivos (V) e mortos (M) } & \multirow{3}{*}{$\begin{array}{c}\text { Mort. } \\
(\%)\end{array}$} \\
\hline & \multicolumn{2}{|c|}{$1^{\mathrm{a}}$ Divisão } & \multicolumn{2}{|c|}{$2^{\text {a Divisão }}$} & \multicolumn{2}{|c|}{$3^{\mathrm{a}}$ Divisão } & \multirow{2}{*}{$\begin{array}{c}\text { Total } \\
\mathbf{M}\end{array}$} & \\
\hline & v & M & v & $\mathbf{M}$ & v & M & & \\
\hline 1. IMID & $1,40 b$ & $7,60 \mathrm{a}$ & $2,40 \mathrm{~b}$ & 74,60 a & $0,20 \mathrm{~b}$ & $13,80 \mathrm{~b}$ & $96,00 \mathrm{a}$ & 95,92 \\
\hline 2. FIPR & $0,00 \mathrm{~b}$ & $10,00 \mathrm{a}$ & $0,00 \mathrm{~b}$ & 71,00 a & $0,00 \mathrm{~b}$ & $19,00 a b$ & $100 \mathrm{a}$ & 100 \\
\hline 3. CLOR & $0,00 \mathrm{~b}$ & $10,40 \mathrm{a}$ & $0,00 \mathrm{~b}$ & $65,60 \mathrm{a}$ & $0,00 \mathrm{~b}$ & $24,00 \mathrm{a}$ & $100 \mathrm{a}$ & 100 \\
\hline 4. BIFEN & $60,00 \mathrm{a}$ & $7,40 \mathrm{a}$ & $0,00 \mathrm{~b}$ & $32,60 \mathrm{~b}$ & $0,00 \mathrm{~b}$ & $0,00 \mathrm{c}$ & $40,00 \mathrm{~b}$ & 34,82 \\
\hline 5. TEST & $6,80 \mathrm{~b}$ & $0,80 \mathrm{~b}$ & $58,80 a$ & $0,80 \mathrm{c}$ & $32,60 \mathrm{a}$ & $0,00 \mathrm{c}$ & $1,80 \mathrm{c}$ & 0,00 \\
\hline C.V. (\%) & 45,90 & 28,70 & 27,58 & 16,13 & 49,86 & 41,04 & 9,17 & $\ldots$ \\
\hline
\end{tabular}

${ }^{*} \mathrm{Na}$ coluna, médias seguidas por letras distintas diferem entre si pelo teste de Tukey em nivel de $5 \%$ de probabilidade.

\subsection{Infestação realizada 120 dias após tratamento do solo (120 DAT)}

Dados obtidos na avaliação com 120 DAT podem ser observados na Figura 14 e Tabela 10. Na avaliação com $6 \mathrm{HAl}$, os cupins presentes no FIPR e CLOR, percorreram $7,80 \pm 1,92 \mathrm{~cm}$ e $9,40 \pm 2,60 \mathrm{~cm}$ no solo da segunda divisão, não diferindo da testemunha, na qual os cupins percorreram $6,40 \pm$ $2,07 \mathrm{~cm}$, apontando estes produtos como não repelentes nesta avaliação. Ibrahim et al. (2003) trataram areia com fipronil na dose de até $0,06 \%$ e não observaram repelência ao C. formosanus; Shelton \& Grace (2003) indicaram fipronil como não repelente ao $C$. formosanus; os estudos do uso de clorpirifós para o tratamento de solo, realizados por Su et al. (1989, 1993 e 1995b) demonstraram menor repelência ao $C$. formosanus, do que o tratamento com bifentrina. No CLOR, mesmo com odor característico, mas em menor intensidade em relação às avaliações anteriores, os cupins não apresentaram 
alterações significativas de comportamento, como já observado; os cupins no IMID e BIFEN tiveram comportamento semelhante, e diferindo dos demais tratamentos, percorrendo as distâncias de 1,80 $\pm 1,64$ e $0,00 \mathrm{~cm}$ respectivamente, corroborando os resultados obtidos nas avaliações anteriores. A avaliação realizada $12 \mathrm{HAI}$, mostra que a diferenciação estatística entre os tratamentos, não deferiu dos resultados obtidos $6 \mathrm{HAl}$. Na distância percorrida pelo C. gestroi $24 \mathrm{HAI}$, os resultados no FIPR, CLOR e TEST foram semelhantes aos obtidos em 90 DAT; no IMID e BIFEN os resultados foram semelhantes às avaliações com 0,30 e 60 DAT. Observando os resultados da avaliação com $48 \mathrm{HAl}$, confirmam-se os dados obtidos $24 \mathrm{HAl}$, mantendo as mesmas diferenciações entre os tratamentos.

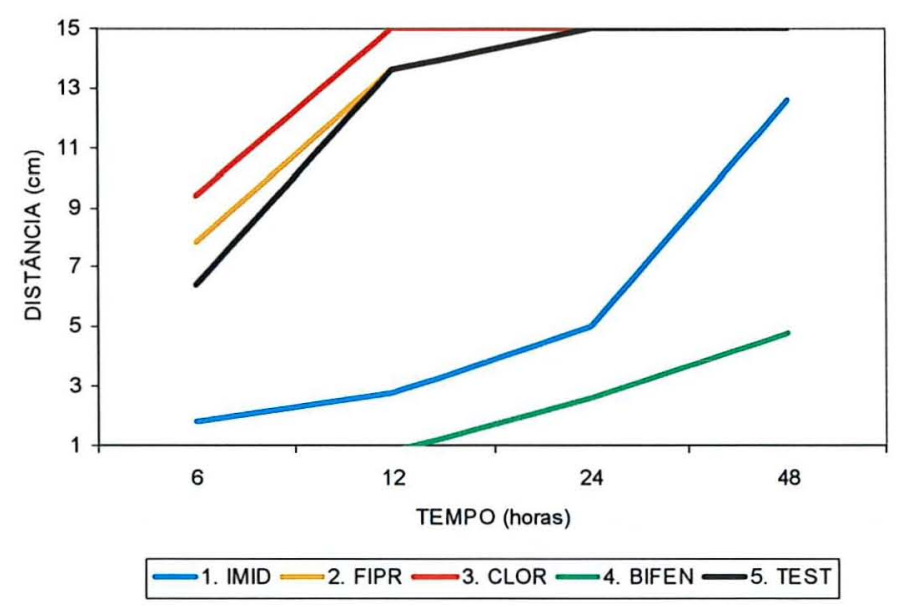

Figura 14 - Distância percorrida $(\mathrm{cm})$ pelo cupim Coptotermes gestroi na $2^{\mathrm{a}}$ divisão (solo tratado), 120 dias após o tratamento do solo com diferentes cupinicidas. Avaliações realizadas 6, 12, 24 e 48 horas após infestação 
Tabela 10. Dados médios obtidos dos diferentes tratamentos, em centimetros acumulados $(\mathrm{cm})$, percorridos pelos cupins $C$. gestroi ao longo da $2^{\mathrm{a}}$ divisão do corpo de prova (solo tratado), 120 dias após tratamento do solo, avaliando-se 6, 12, 24 e 48 horas após a infestação (HAl) e respectivos coeficientes de variação (C.V.)

\begin{tabular}{lcccc}
\hline \multirow{2}{*}{ Tratamentos } & \multicolumn{4}{c}{ Distância acumulada percorrida em solo tratado (cm) } \\
& $\mathbf{6 ~ H A l}$ & $\mathbf{1 2} \mathbf{~ H A l}$ & $\mathbf{2 4 ~ H A l}$ & $\mathbf{4 8 ~ H A l}$ \\
\hline 1. IMID & $1,80 \pm 1,64 \mathrm{~b}$ & $2,80 \pm 1,92 \mathrm{~b}$ & $5,00 \pm 1,87 \mathrm{~b}$ & $12,60 \pm 2,30 \mathrm{~b}$ \\
2. FIPR & $7,80 \pm 1,92 \mathrm{a}$ & $13,60 \pm 1,67 \mathrm{a}$ & $15,00 \pm 0,00 \mathrm{a}$ & $15,00 \pm 0,00 \mathrm{a}$ \\
3. CLOR & $9,40 \pm 2,60 \mathrm{a}$ & $15,00 \pm 0,00 \mathrm{a}$ & $15,00 \pm 0,00 \mathrm{a}$ & $15,00 \pm 0,00 \mathrm{a}$ \\
4. BIFEN & $0,00 \pm 0,00 \mathrm{~b}$ & $0,80 \pm 0,83 \mathrm{~b}$ & $2,60 \pm 1,51 \mathrm{c}$ & $4,80 \pm 1,09 \mathrm{c}$ \\
5. TEST & $6,40 \pm 2,07 \mathrm{a}$ & $13,60 \pm 1,51 \mathrm{a}$ & $15,00 \pm 0,00 \mathrm{a}$ & $15,00 \pm 0,00 \mathrm{a}$ \\
C.V. (\%) & 36,82 & 15,04 & 10,23 & 9,13 \\
\hline
\end{tabular}

* Na coluna, médias seguidas por letras distintas diferem entre si pelo teste de Tukey em nível de $5 \%$ de probabilidade.

$\mathrm{Na}$ Tabela 11, na qual estão expressos os resultados da avaliação de mortalidade dos cupins de $C$. gestroi que permaneceram 15 dias em contato com o solo tratado a 120 DAT, nota-se alta mortalidade no IMID, FIPR e CLOR com $97,70 \%, 100 \%$ e $100 \%$ respectivamente. No IMID, embora não tenha atingido $100 \%$ de mortalidade, os cupins encontrados vivos não causaram danos ao disco de madeira, como já mencionado na avaliação de 90 DAT; no BIFEN, com $54,69 \%$ de mortalidade dos cupins, houve repelência evidenciada pelo não ataque à madeira, conforme observado nas avaliações anteriores.

Apenas na testemunha, foi observado dano no disco de madeira de Pinus sp., causado pelo $C$. gestroi no final do período de 15 dias. $O$ índice de sobrevivência da testemunha foi de $95,8 \%$. 
Tabela 11. Dados médios para cada tratamento, número de cupins $C$. gestroi vivos $(V)$ e mortos $(M)$ na $1^{a} ; 2^{a}$ e $3^{a}$ divisões do corpo de prova e o total de mortos $(M)$, porcentagem de mortalidade (Mort. (\%)). Infestação realizada 120 dias após o tratamento do solo e avaliação realizada 15 dias após infestação

\begin{tabular}{|c|c|c|c|c|c|c|c|c|}
\hline \multirow{3}{*}{$\begin{array}{l}\text { Trata- } \\
\text { mentos }\end{array}$} & \multicolumn{7}{|c|}{ Média de cupins vivos (V) e mortos (M) } & \multirow{3}{*}{$\begin{array}{c}\text { Mort. } \\
(\%)\end{array}$} \\
\hline & \multicolumn{2}{|c|}{$1^{a}$ Divisão } & \multicolumn{2}{|c|}{$2^{a}$ Divisão } & \multicolumn{2}{|c|}{$3^{\mathrm{a}}$ Divisão } & \multirow{2}{*}{$\begin{array}{c}\text { Total } \\
\mathbf{M}\end{array}$} & \\
\hline & V & $\mathbf{M}$ & V & $\mathbf{M}$ & V & $\mathbf{M}$ & & \\
\hline 1. IMID & $1,00 \mathrm{~b}$ & $8,80 a$ & $1,20 \mathrm{~b}$ & $71,60 \mathrm{a}$ & $0,00 \mathrm{~b}$ & $17,40 \mathrm{a}$ & $97,80 \mathrm{a}$ & 97,70 \\
\hline 2. FIPR & $0,00 \mathrm{~b}$ & $11,00 \mathrm{a}$ & $0,00 \mathrm{~b}$ & $65,80 a b$ & $0,00 \mathrm{~b}$ & $23,20 \mathrm{a}$ & $100 a$ & 100 \\
\hline 3. CLOR & $0,00 \mathrm{~b}$ & $8,80 a$ & $0,00 \mathrm{~b}$ & $61,20 a b$ & $0,00 \mathrm{~b}$ & $30,00 \mathrm{a}$ & $100 a$ & 100 \\
\hline 4. BIFEN & $43,40 a$ & $12,60 \mathrm{a}$ & $0,00 \mathrm{~b}$ & $46,00 \mathrm{~b}$ & $0,00 \mathrm{~b}$ & $0,40 \mathrm{~b}$ & $58,60 \mathrm{~b}$ & 54,69 \\
\hline 5. TEST & $11,00 \mathrm{~b}$ & $1,60 \mathrm{~b}$ & $64,20 \mathrm{a}$ & $2,00 \mathrm{c}$ & $20,60 a$ & $0,00 \mathrm{~b}$ & $4,20 \mathrm{c}$ & 0,00 \\
\hline C.V. $(\%)$ & 92,37 & 36,19 & 25,21 & 22,06 & 63,50 & 47,27 & 15,92 & -- \\
\hline
\end{tabular}

${ }^{*} \mathrm{Na}$ coluna, médias seguidas por letras distintas diferem entre si pelo teste de Tukey em nivel de $5 \%$ de probabilidade.

\subsection{Infestação realizada 150 dias após tratamento do solo (150 DAT)}

$\mathrm{Na}$ avaliação com 150 DAT (Figura 15 e Tabela 12), com $6 \mathrm{HAI}$, a distância percorrida pelos cupins no FIPR não diferiu estatisticamente da testemunha; a distância percorrida pelos cupins no CLOR condiz com as avaliações de 0, 30, 60, 90 e 120 DAT; o resultado do IMID é semelhante aos obtidos com 90 e 120 DAT e, no BIFEN, os dados são semelhantes aos das avaliações anteriores. Na avaliação com $12 \mathrm{HAI}$, os tratamentos IMID, FIPR, CLOR e TEST não diferiram estatisticamente entre si. O C. gestroi apresenta certa tendência à inibição de penetrar no solo tratado com imidacloprid, como observado anteriormente, tendência esta que se reduziu consideravelmente nesta avaliação. Pode-se observar que houve redução da concentração de imidacloprid no solo, chegando a $2,30 \mathrm{mg} / \mathrm{kg}$ (Figura 17). Acredita-se que, devido a isso, ocorra menor percepção do imidacloprid pelo C. gestroi. Tal 
percepção já foi indicada nas avaliações que antecedem; o BIFEN diferiu dos demais, pois, neste período, os cupins não penetraram na $2^{\mathrm{a}}$ divisão. Os resultados obtidos nas avaliações com 24 e $48 \mathrm{HAl}$ assemelharam-se aos de 12 HAI.

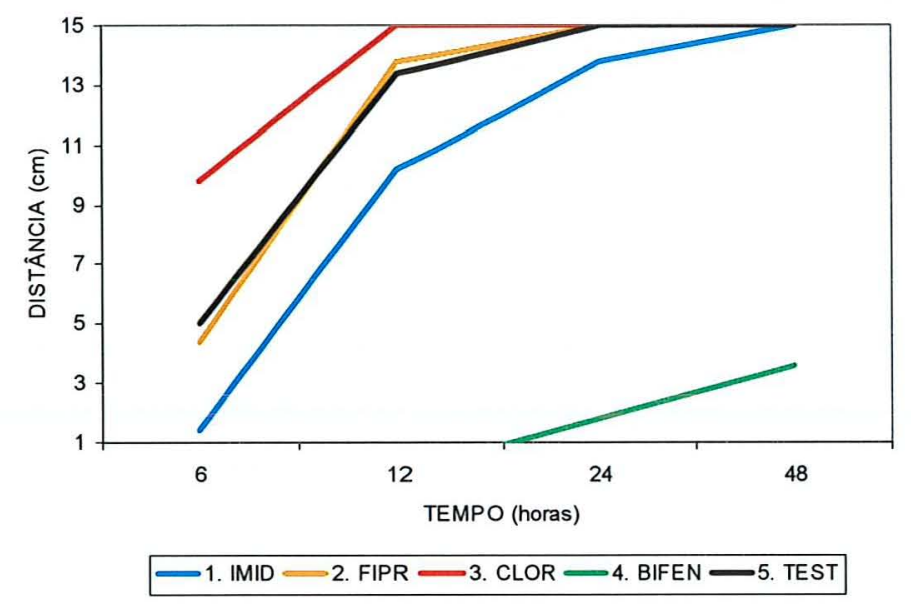

Figura 15 - Distância percorrida $(\mathrm{cm})$ pelo cupim Coptotermes gestroi na $2^{\mathrm{a}}$ divisão (solo tratado), 150 dias após o tratamento do solo com diferentes cupinicidas Avaliações realizadas 6, 12, 24 e 48 horas após infestação 
Tabela 12. Dados médios obtidos dos diferentes tratamentos, em centímetros acumulados $(\mathrm{cm})$, percorridos pelos cupins $C$. gestroi ao longo da $2^{\mathrm{a}}$ divisão do corpo de prova (solo tratado), 150 dias após tratamento do solo, avaliando-se 6, 12, 24 e 48 horas após a infestação (HAl) e respectivos coeficientes de variação (C.V.)

\begin{tabular}{lcccc}
\hline \multirow{2}{*}{ Tratamentos } & \multicolumn{4}{c}{ Distância acumulada percorrida em solo tratado (cm) } \\
& $\mathbf{6 ~ H A l}$ & $\mathbf{1 2} \mathbf{~ H A l}$ & $\mathbf{2 4} \mathbf{~ H A l}$ & $\mathbf{4 8} \mathbf{~ H A l}$ \\
\hline 1. IMID & $1,40 \pm 2,07 \mathrm{~cd}$ & $10,20 \pm 2,58 \mathrm{a}$ & $13,80 \pm 1,30 \mathrm{a}$ & $15,00 \pm 0,00 \mathrm{a}$ \\
2. FIPR & $4,40 \pm 2,07 \mathrm{bc}$ & $13,80 \pm 1,30 \mathrm{a}$ & $15,00 \pm 0,00 \mathrm{a}$ & $15,00 \pm 0,00 \mathrm{a}$ \\
3. CLOR & $9,80 \pm 1,92 \mathrm{a}$ & $15,00 \pm 0,00 \mathrm{a}$ & $15,00 \pm 0,00 \mathrm{a}$ & $15,00 \pm 0,00 \mathrm{a}$ \\
4. BIFEN & $0,00 \pm 0,00 \mathrm{~d}$ & $0,00 \pm 0,00 \mathrm{~b}$ & $1,80 \pm 2,16 \mathrm{~b}$ & $3,60 \pm 1,34 \mathrm{~b}$ \\
5. TEST & $5,00 \pm 1,58 \mathrm{~b}$ & $13,40 \pm 1,51 \mathrm{a}$ & $15,00 \pm 0,00 \mathrm{a}$ & $15,00 \pm 0,00 \mathrm{a}$ \\
C.V. (\%) & 41,75 & 13,95 & 9,33 & 4,71 \\
\hline *Na coluna, médias seguidas por letras distintas diferem entre si pelo teste de Tukey em nivel \\
de $5 \%$ de probabilidade.
\end{tabular}

Nos resultados da porcentagem de mortalidade (Mort. (\%)) do C. gestroi infestado no solo 150 DAT (Tabela 13), observa-se que no FIPR e CLOR a mortalidade se manteve em $100 \%$ e no IMID, $92,35 \%$. Embora o número de cupins vivos tenha aumentado, os encontrados na segunda e terceira divisões não causaram danos ao disco de madeira, como mencionado na avaliação com 90 DAT; no BIFEN, houve $76,85 \%$ de mortalidade. Os sobreviventes não chegaram à terceira divisão, não causando dano à madeira.

$\mathrm{Na}$ testemunha, ocorreu ataque do disco de madeira pelo C. gestroi, o que não foi observado nos demais tratamentos. $O$ índice de sobrevivência do tratamento testemunha foi de $96,8 \%$. 
Tabela 13. Dados médios para cada tratamento, número de cupins $C$. gestroi vivos $(V)$ e mortos $(M)$ na $1^{\mathrm{a}} ; 2^{\mathrm{a}}$ e $3^{\mathrm{a}}$ divisões do corpo de prova e o total de mortos (M), porcentagem de mortalidade (Mort. (\%)). Infestação realizada 150 dias após o tratamento do solo e avaliação realizada 15 dias após infestação

\begin{tabular}{|c|c|c|c|c|c|c|c|c|}
\hline \multirow{3}{*}{$\begin{array}{l}\text { Trata- } \\
\text { mentos }\end{array}$} & \multicolumn{7}{|c|}{ Média de cupins vivos (V) e mortos (M) } & \multirow{3}{*}{$\begin{array}{l}\text { Mort. } \\
(\%)\end{array}$} \\
\hline & \multicolumn{2}{|c|}{$1^{\mathrm{a}}$ Divisão } & \multicolumn{2}{|c|}{$2^{\mathrm{a}}$ Divisão } & \multicolumn{2}{|c|}{$3^{\mathrm{a}}$ Divisão } & \multirow{2}{*}{$\begin{array}{c}\text { Total } \\
\mathbf{M}\end{array}$} & \\
\hline & $\mathbf{v}$ & M & $\mathbf{v}$ & $\mathbf{M}$ & v & M & & \\
\hline 1. IMID & $4,60 \mathrm{bc}$ & $9,00 \mathrm{~b}$ & $2,40 \mathrm{~b}$ & $67,00 \mathrm{a}$ & $0,40 \mathrm{~b}$ & $16,60 \mathrm{a}$ & $92,60 \mathrm{~b}$ & 92,35 \\
\hline 2. FIPR & $0,00 \mathrm{c}$ & $11,20 \mathrm{ab}$ & $0,00 \mathrm{~b}$ & $64,00 \mathrm{a}$ & $0,00 \mathrm{~b}$ & $24,80 \mathrm{a}$ & $100 \mathrm{a}$ & 100 \\
\hline 3. CLOR & $0,00 \mathrm{c}$ & $11,60 \mathrm{ab}$ & $0,00 \mathrm{~b}$ & $61,80 a$ & $0,00 \mathrm{~b}$ & $26,60 \mathrm{a}$ & $100 \mathrm{a}$ & 100 \\
\hline 4. BIFEN & $22,40 \mathrm{a}$ & $17,60 \mathrm{a}$ & $0,00 \mathrm{~b}$ & $60,00 \mathrm{a}$ & $0,00 \mathrm{~b}$ & $0,00 \mathrm{~b}$ & $77,60 \mathrm{c}$ & 76,85 \\
\hline 5. TEST & $10,60 \mathrm{~b}$ & $1,80 \mathrm{c}$ & $65,20 \mathrm{a}$ & $0,80 \mathrm{~b}$ & $21,00 \mathrm{a}$ & $0,60 \mathrm{~b}$ & $3,20 d$ & 0,00 \\
\hline C.V. $(\%)$ & 47,72 & 33,68 & 19,14 & 11,09 & 104,12 & 47,30 & 4,33 & -- \\
\hline
\end{tabular}

* Na coluna, médias seguidas por letras distintas diferem entre si pelo teste de Tukey em nivel de $5 \%$ de probabilidade.

\subsection{Infestação realizada 180 dias após tratamento do solo (180 DAT)}

De acordo com os resultados obtidos das distâncias percorridas pelo $C$. gestroi 180 DAT (Figura 16 e Tabela 14), pode-se observar que o FIPR $6 \mathrm{HAl}$ não diferiu da testemunha, confirmando a não repelência ao fipronil e condizendo com os resultados obtidos nas avaliações; o IMID e BIFEN não diferiram entre si e diferiram da testemunha; os resultados obtidos com imidacloprid coincidem com os obtidos por Wei et al. (2000), que observaram que o $C$. formosanus não penetra em solo tratado com imidacloprid logo após o tratamento; os resultados indicam repelência à bifentrina do C. gestroi, já previstos em razão da característica padrão de um piretróide e, como observado em todas as avaliações de 0 a 180 DAT, no tratamento com CLOR, 
com $12,00 \pm 2,23 \mathrm{~cm}$, o resultado diferiu dos demais. O efeito observado nos cupins agitados, com tentativa de fuga aparente, possivelmente ocorreu devido ao odor característico do clorpirifós que ainda se fez perceptivel nas amostras de solo coletadas. Os resultados obtidos na avaliação com 12 HAl o FIPR e o CLOR não diferiram estatisticamente da testemunha; no IMID, os cupins percorreram $10,00 \pm 1,58 \mathrm{~cm}$, o que indica percepção do imidacloprid pelo $C$. gestroi, mas em menor intensidade a 0,30,60, 90 e 120 DAT. Na figura 17, pode-se observar menor concentração da molécula no solo em relação às avaliações citadas, diminuindo, assim, a percepção aparente do imidacloprid. No BIFEN os cupins permaneceram na primeira divisão, não chegando à segunda divisão, como observado em 150 DAT. Na avaliação com $24 \mathrm{HAl}$, os cupins de todos os tratamentos tiveram comportamento semelhante a 150 DAT Nos resultados obtidos na avaliação com $48 \mathrm{HAl}$, nota-se que os cupins presentes no IMID percorreram os $15,00 \mathrm{~cm}$ da segunda divisão, comportamento já observado $24 \mathrm{HAI}$ com 150 DAT. Os cupins dos tratamentos FIPR, CLOR e da testemunha também percorreram os $15,00 \mathrm{~cm}$ do solo da segunda divisão, não diferindo entre si. No tratamento BIFEN, os cupins penetraram a distância de $4,80 \pm 0,83 \mathrm{~cm}$ na segunda divisão, apresentando maior repelência aparente em relação aos cupinicidas testados, como foi indicado anteriormente. 


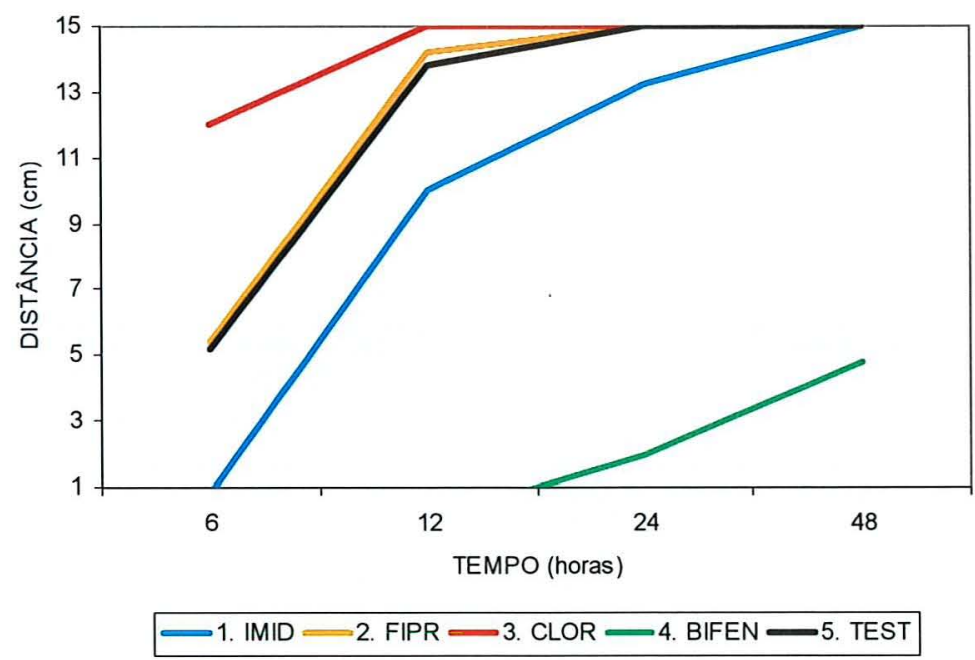

Figura 16 - Distância percorrida $(\mathrm{cm})$ pelo cupim Coptotermes gestroi na $2^{\mathrm{a}}$ divisão (solo tratado), 180 dias após o tratamento do solo com diferentes cupinicidas. Avaliações realizadas 6, 12, 24 e 48 horas após infestação

Tabela 14. Dados médios obtidos dos diferentes tratamentos, em centímetros acumulados $(\mathrm{cm})$, percorridos pelos cupins $C$. gestroi ao longo da $2^{\mathrm{a}}$ divisão do corpo de prova (solo tratado), 180 dias após tratamento do solo, avaliando-se 6, 12, 24 e 48 horas após a infestação (HAI) e respectivos coeficientes de variação (C.V.)

\begin{tabular}{lcccc}
\hline \multirow{2}{*}{ Tratamentos } & \multicolumn{4}{c}{ Distância acumulada percorrida em solo tratado (cm) } \\
& 6 HAl & 12 HAl & 24 HAl & 48 HAI \\
\hline 1. IMID & $0,80 \pm 0,83 \mathrm{c}$ & $10,00 \pm 1,58 \mathrm{~b}$ & $13,20 \pm 1,78 \mathrm{a}$ & $15,00 \pm 0,00 \mathrm{a}$ \\
2. FIPR & $5,40 \pm 1,14 \mathrm{~b}$ & $14,20 \pm 0,83 \mathrm{a}$ & $15,00 \pm 0,00 \mathrm{a}$ & $15,00 \pm 0,00 \mathrm{a}$ \\
3. CLOR & $12,00 \pm 2,23 \mathrm{a}$ & $15,00 \pm 0,00 \mathrm{a}$ & $15,00 \pm 0,00 \mathrm{a}$ & $15,00 \pm 0,00 \mathrm{a}$ \\
4. BIFEN & $0,00 \pm 0,00 \mathrm{c}$ & $0,00 \pm 0,00 \mathrm{c}$ & $2,00 \pm 1,58 \mathrm{~b}$ & $4,80 \pm 0,83 \mathrm{~b}$ \\
5. TEST & $5,20 \pm 1,48 \mathrm{~b}$ & $13,80 \pm 1,64 \mathrm{a}$ & $15,00 \pm 0,00 \mathrm{a}$ & $15,00 \pm 0,00 \mathrm{a}$ \\
C.V. (\%) & 28,98 & 10,24 & 8,86 & 2,88 \\
\hline
\end{tabular}

${ }^{*} \mathrm{Na}$ coluna, médias seguidas por letras distintas diferem entre si pelo teste de Tukey em nível de $5 \%$ de probabilidade. 
$\mathrm{Na}$ Tabela 15, estão expressos os resultados da avaliação de porcentagem da mortalidade do C. gestroi após 180 dias da aplicação dos cupinicidas no solo. O FIPR e o CLOR permaneceram inalterados, da primeira à última avaliação, com $100 \%$ de mortalidade do C. gestroi, estando de acordo com as conclusões obtidas por Waite (2003), que observou que quando o tratamento de solo é realizado de maneira uniforme com fipronil, os resultados são satisfatórios no controle da espécie $C$. formosanus avaliado 180 DAT. Em solo tratado com clorpirifós, Su et al. (1999) obtiveram o controle de $R$. flavipes em $96,7 \%$ de mortalidade, mesmo com 360 DAT; o IMID causou $86,28 \%$ de mortalidade do $C$. gestroi. Embora não tenha reduzido a concentração do imidacloprid no solo, houve uma pequena redução da porcentagem de mortalidade comparando com a avaliação de 150 DAT. Em todas as divisões, foram encontrados cupins vivos, mas não foi verificado dano no disco de madeira, como discutido nas avaliações de 90,120 e 150 DAT. O residual do imidacloprid pode ser comparado aos resultados de Osbrink \& Lax (2003), que observaram que, em árvores infestadas pelo $C$. formosanus tratadas com imidacloprid $0,1 \%, 180 \mathrm{DAT}$, parte das colônias voltaram à atividade. No BIFEN, houve $67,93 \%$ de mortalidade do $C$. gestroi e, em razão de os cupins não chegarem até o disco de madeira, morrendo na segunda divisão, também não foi observado dano no disco de madeira. Esses resultados sugerem que ocorreu a formação de uma barreira química que impediu a passagem dos cupins.

Apenas na testemunha, foi observado dano no disco de madeira causado pelo C. gestroi. O índice de sobrevivência foi de $94,8 \%$. 
Tabela 15. Dados médios para cada tratamento, número de cupins $C$. gestroi vivos $(V)$ e mortos $(M)$ na $1^{a} ; 2^{a}$ e $3^{a}$ divisões do corpo de prova e o total de mortos $(M)$, porcentagem de mortalidade (Mort. (\%)). Infestação realizada 180 dias após o tratamento do solo e avaliação realizada 15 dias após infestação

\begin{tabular}{|c|c|c|c|c|c|c|c|c|}
\hline \multirow{3}{*}{$\begin{array}{l}\text { Trata- } \\
\text { mentos }\end{array}$} & \multicolumn{7}{|c|}{ Média de cupins vivos (V) e mortos (M) } & \multirow{3}{*}{$\begin{array}{c}\text { Mort. } \\
(\%)\end{array}$} \\
\hline & \multicolumn{2}{|c|}{$1^{\text {a }}$ Divisão } & \multicolumn{2}{|c|}{$2^{\mathrm{a}}$ Divisão } & \multicolumn{2}{|c|}{$3^{\mathrm{a}}$ Divisão } & \multirow{2}{*}{$\begin{array}{c}\text { Total } \\
\text { M }\end{array}$} & \\
\hline & v & M & v & $\mathbf{M}$ & v & $\mathbf{M}$ & & \\
\hline 1. IMID & $2,20 b$ & $5,40 \mathrm{c}$ & $5,80 \mathrm{~b}$ & $57,00 \mathrm{a}$ & $5,00 \mathrm{~b}$ & $24,60 \mathrm{a}$ & $87,0 \mathrm{~b}$ & 86,28 \\
\hline 2. FIPR & $0,00 \mathrm{~b}$ & $10,80 \mathrm{ab}$ & $0,00 \mathrm{~b}$ & $65,40 \mathrm{a}$ & $0,00 \mathrm{~b}$ & $23,80 a$ & $100 \mathrm{a}$ & 100 \\
\hline 3. CLOR & $0,00 \mathrm{~b}$ & $12,00 \mathrm{a}$ & $0,00 \mathrm{~b}$ & $55,00 a$ & $0,00 \mathrm{~b}$ & 33,00 a & $100 \mathrm{a}$ & 100 \\
\hline 4. BIFEN & $30,40 a$ & $8,00 \mathrm{bc}$ & $0,00 \mathrm{~b}$ & $61,60 \mathrm{a}$ & $0,00 \mathrm{~b}$ & $0,00 \mathrm{~b}$ & $69,60 \mathrm{c}$ & 67,93 \\
\hline 5. TEST & $9,00 \mathrm{~b}$ & $1,20 \mathrm{~d}$ & $57,00 \mathrm{a}$ & $3,40 \mathrm{~b}$ & $28,80 a$ & $0,60 \mathrm{~b}$ & $5,20 \mathrm{~d}$ & 0,00 \\
\hline C.V. (\%) & 76,86 & 26,19 & 25,72 & 15,84 & 58,87 & 34,57 & 8,48 & $\ldots$ \\
\hline
\end{tabular}

* Na coluna, médias seguidas por letras distintas diferem entre si pelo teste de Tukey em nivel de $5 \%$ de probabilidade.

\subsection{Análise de resíduo do solo}

As concentrações dos cupinicidas aplicados no solo obtidas por meio da análise química, durante o decorrer do mesmo periodo das avaliações biológicas, são representadas graficamente na Figura 17.

Nas análises realizadas não foi constatada contaminação cruzada nas amostras coletadas.

Nos resultados dessas análises, expressos na Figura 17, pode-se observar que, no tratamento IMID, aplicada uma solução de $0,1 \%$ de imidacloprid, houve concentração no solo de $8,80 \mathrm{mg} / \mathrm{kg}$; com 30 DAT, reduziuse para 3,09 mg/kg; com 60 DAT, houve pequena elevação, chegando a 3,60 $\mathrm{mg} / \mathrm{kg}$; com $90 \mathrm{DAT}$, para $3,02 \mathrm{mg} / \mathrm{kg}$; na avaliação com 120 DAT, verificou-se $2,87 \mathrm{mg} / \mathrm{kg}$; com 150 DAT 2,30 mg/kg. Na última avaliação, com 180 DAT, a concentração foi de $2,39 \mathrm{mg} / \mathrm{kg}$. Com alta redução da concentração do produto no solo com 30 DAT, não foram coerentes com os resultados obtidos nos 
estudos de Baskaran et al. (1999), que, em condições de laboratório, observaram baixa degradação de imidacloprid com a meia vida estimada em 1230 dias. A análise dos resultados obtidos por Osbrink \& Lax (2003) mostram que a maioria das infestações de $C$. formosanus tratadas com imidacloprid $0,1 \%$ voltaram à atividade após 6 meses do tratamento, sugerindo que houve redução da concentração do cupinicida. No presente estudo, o solo foi tratado em condições de campo, e o estudo realizado por Osbrink \& Lax (2003) também ficou sujeito às condições climáticas. Levando em consideração que a solubilidade do imidacloprid é de $510 \mathrm{mg} / \mathrm{L}$ de água (Tomlin, 1994), o que é considerado alto, ela pode favorecer a mobilidade no solo e conseqüentemente a redução da concentração no solo.

No FIPR, onde foi aplicada uma solução de $0,037 \%$ de fipronil, na análise realizada com 0 DAT o solo estava com $0,809 \mathrm{mg} / \mathrm{kg}$. Registrou-se pequena elevação na avaliação, com 30 DAT, para $0,960 \mathrm{mg} / \mathrm{kg}$. Houve discrepância na avaliação com 60 DAT, com 1,585 mg/kg; no entanto, nas avaliações seguintes, com 90,120,150 e 180 DAT, houve redução gradativa de $0,755 \mathrm{mg} / \mathrm{kg}$ para $0,620 \mathrm{mg} / \mathrm{kg}$, havendo estabilidade no solo, como observado por Bobe et al. (1998) que calcularam a meia vida em 1390 dias em solo com $\mathrm{pH} 7,1$ e protegido da luz. A solubilidade do fipronil segundo Tomlin (1994) é de $2 \mathrm{mg} / \mathrm{L}$ de água, o que deve dificultar sua mobilidade no solo. Com isso, possivelmente, tenha acumulado maior concentração na faixa da aplicação.

As análises de residuo do solo tratado com clorpirifós apresentaram resultados desuniformes; logo após aplicação, a concentração foi de 125,42 $\mathrm{mg} / \mathrm{kg}$. O menor resultado foi com 30 DAT com $113,00 \mathrm{mg} / \mathrm{kg}$ e, a maior concentração foi com 150 DAT chegando a $203,64 \mathrm{mg} / \mathrm{kg}$, finalizando com $157,46 \mathrm{mg} / \mathrm{kg}$ em $180 \mathrm{DAT}$; como a amostragem do solo foi realizada aleatoriamente, existe a hipótese de que as amostras teriam sido coletadas em locais com maior ou menor concentração do clorpirifós ocorrendo, assim, desuniformidade das amostras; isso também gerou a hipótese de que tenha ocorrido a mesma desuniformidade na faixa de solo tratado e para melhor 
avaliar, deve-se rever a metodologia de amostragem de solo. Os dados de Ambrus (1999) indicam que o coeficiente de variação de resíduos no solo é de $36,3 \%$, quando realizadas 5 amostragens, e de $24,7 \%$ em 10 amostragens; como no presente trabalho, foram realizadas 8 amostragens, elas podem ter contribuido para a desuniformidade das análises, pela alta variação obtida. $O$ clorpirifós é considerado estável no solo, pois, segundo Tomlin (1994), a baixa solubilidade de 1,4 mg/L de água diminui sua mobilidade no solo; o experimento de laboratório de Baskaran et al. (1999) indicou alta degradação do clorpirifós no solo, mas o solo utilizado apresentava $\mathrm{pH} \mathrm{9,6} \mathrm{ocorrendo} \mathrm{hidrolise} \mathrm{alcalina.} \mathrm{O}$ solo utilizado neste estudo apresentava pH 4,8 e Pearce (1997) menciona, em seu trabalho, que o residual do clorpirifós no solo pode variar muito em relação ao clima e tipo de solo, e que, em clima tropical, ele pode variar entre 1 a 5 anos. Aplicando clorpirifós em solo arenoso, Su et al. (1999) avaliaram inicialmente $744,7 \mathrm{mg} / \mathrm{kg}$ e, após um ano, $225,6 \mathrm{mg} / \mathrm{kg}$.

Os resultados das análises de resíduos obtidos do solo tratado com bifentrina variaram de 6,10 a $24,19 \mathrm{mg} / \mathrm{kg}$, embora não houvesse degradação uniforme em relação aos períodos das avaliações, pois com 0 DAT foi de 9,65 $\mathrm{mg} / \mathrm{kg}$; com 30 DAT, foi de $24,19 \mathrm{mg} / \mathrm{kg}$; mas a menor concentração foi obtida com 150 DAT, chegando a $6,10 \mathrm{mg} / \mathrm{kg}$, finalizando com $9,24 \mathrm{mg} / \mathrm{kg}$ aos 180 DAT. Dentre os cupinicidas utilizados no presente trabalho, a bifentrina é a de menor solubilidade, sendo $0,1 \mathrm{mg} / \mathrm{L}$ de água (Tomlin, 1994), possivelmente com menor mobilidade no solo; em estudo de laboratório, Baskaran et al. (1999) calcularam a meia vida da bifentrina em 1332 dias, e no estudo de Su et al. (1999), aplicando bifentrina em solo arenoso, inicialmente foram obtidas 10,9 $\mathrm{mg} / \mathrm{kg}$ e, após 1 ano, $2,1 \mathrm{mg} / \mathrm{kg}$.

Em todas as avaliações, na testemunha não foram detectados resíduos no solo dos cupinicidas testados, indicando que não houve contaminação.

Como o solo é fator importante na avaliação desses resultados, o trabalho foi realizado em solo de textura média argiloso. Possivelmente, tais dados, em outros tipos de solo seriam diferentes; Grace et al. (2002) avaliaram 
a porcentagem de mortalidade do $C$. formosanus tratando solo arenoso e argiloso com cipermetrina após 3 anos da aplicação e obtiveram $80 \%$ de mortalidade em solo argiloso e $40 \%$ em solo arenoso.

O residual de solo coberto com proteção à luminosidade e águas pluviais sofrerá menor alteração no tempo de degradação dos cupinicidas; no estudo realizado por Lenz et al. (1988), realizado na região dos trópicos, concluiu-se que, no solo protegido tratado com clorpirifós, o residual foi de 7 anos e, em solo descoberto, o residual foi de 4 anos.

Assim sendo, na avaliação dos resultados da presente pesquisa, esse procedimento deve ser levado em consideração, quando se deseja fazer comparações das aplicações dos produtos em condições naturais. 

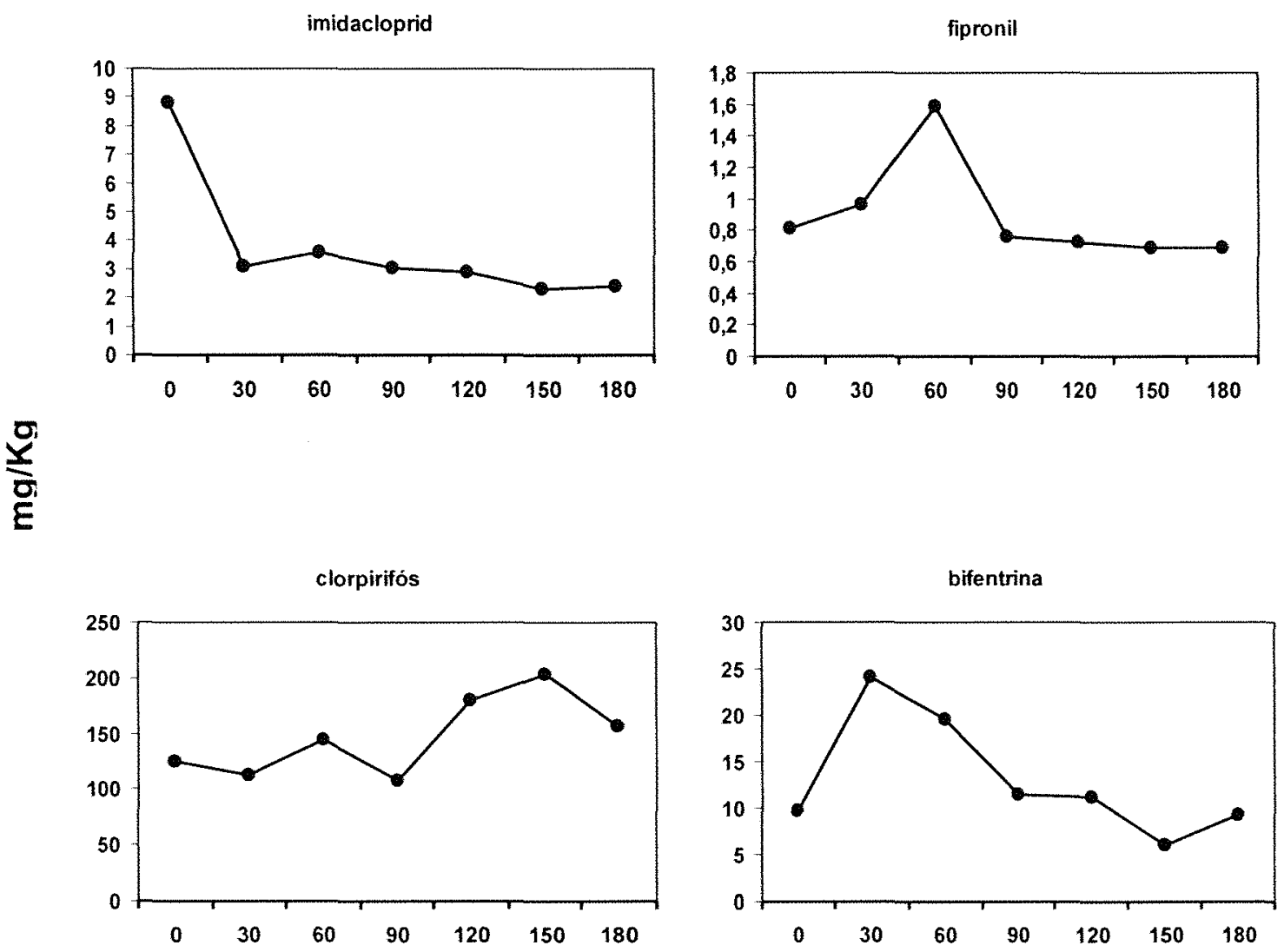

dias após tratamento do solo

Figura 17 - Concentração de imidacloprid, fipronil, clorpirifós e bifentrina no solo tratado nos diferentes períodos de coleta após o tratamento 


\section{CONCLUSÕES}

Os resultados obtidos permitiram concluir que:

a) os inseticidas imidacloprid, fipronil, clorpirifós e bifentrina, mostram resultados satisfatórios para o controle do $C$. gestroi no tratamento de solo;

b) o solo tratado com imidacloprid apresenta inibição à penetração do $C$. gestroi;

c) no solo tratado com fipronil, não há repelência do C. gestroi, não formando barreira;

d) solo tratado com clorpirifós causa aparente irritabilidade e desorientação ao C. gestroi;

e) a bifentrina, quando no solo, forma uma barreira química impedindo a passagem do C. gestroi; 


\section{REFERÊNCIAS BIBLIOGRÁFICAS}

ABBOTT, W.S. A method of computing the effectiveness of insecticides. Journal of Economic Entomology, v.18, p.265-267, 1925.

ALMEIDA, J.E.M.; ALVES, S.B. Mortalidade de Heterotermes tenuis (Hagen) atraídos por armadilhas com Beauveria bassiana (Bals.) Vuill e imidacloprid. Anais da Sociedade Entomológica do Brasil, v.25, n.3, p.507-512, 1996.

ALMEIDA, J.E.M.; ALVES, S.B.; MOINO JUNIOR., A.; LOPES, R.B. Controle do cupim subterrâneo Heterotermes tenuis (Hagen) com iscas termitrap impregnadas com inseticidas e associadas ao fungo entomopatogênico Beauveria bassiana (Bals.) Vuill. Anais da Sociedade Entomológica do Brasil, v.27, n.4, p.639-644, 1998.

ALVES, S.B.; MOINO JUNIOR., A.; ALMEIDA, J.E.M. Produtos fitossanitários e entomopatógenos. In: ALVES, S.B. (Ed.). Controle microbiano de insetos. 2.ed. Piracicaba: FEALQ, 1998. cap.8, p.217-238.

AMARAL, R.D.A.M. Diagnóstico da ocorrência de cupins xilófagos em árvores urbanas do bairro de Higienópolis, na cidade de São Paulo. Piracicaba, 2002. 71p. Dissertação (Mestrado) - Escola Superior de Agricultura "Luiz de Queiroz", Universidade de São Paulo. 
AMBRUS, A. Quality of Residue Data. In: BROOKS, G. T; ROBERTS R, T. (Org.). Pesticide chemistey and bioscience the food-Environment Challenge. Cammidge: Royal Society of Chemistry, 1999. 438p.

ANDREI, E. Compêndio de defensivos agrícolas. São Paulo, SP: Organização Andrei Editora, 1999. 672p.

ARAUJO, R.L. Contribuição à biogeografia dos térmitas de São Paulo, Brasil (Insecta, Isoptera). Arquivo Instituto Biológico, v.25, p.187-217, 1958.

ARAUJO, R.L. Catálogo dos isoptera do novo mundo. de Ciências, Rio de Janeiro: Academia Brasileira, 1977. 92p.

ARAUJO, R.L. Térmitas prejudiciais às madeiras. In: MARICONI, F.A.M.; ZAMITH, A.P.L.; ARAUJO, R.L. (Ed.). Inseticidas e seu emprego no combate às pragas. São Paulo: Nobel, 1980. p.100-123.

BASKARAN, S.; KOOKANA, R.S.; NAIDU, R. Degradation of bifentrin, chlorpyrifos and imidacloprid in soil and bedding materials at termiticidal application rates. Pesticide Science, v.55, p.1222-1228, 1999.

BEAL, R.H. The use of chemicals for termite control: methods and techiques used worlwide. Sociobiology, v.5, p.163-169, 1980.

BENNETT, G.W.; OWENS, J.M.; CORRIGAN, R.M. Guia cientifica de Truman: para operaciones de control de plagas., West Lafayette, Indiana: Purdue University, 1988. p.149-164. 
BERTI FILHO, E.; MARICONI, F.A.M.; WILCKEN, C.F.; DIETRICH, C.R.R.C.; COSTA, V.A.; CHAVES, L.E.L.; CERIGNONI, J.A. Cupins ou Térmitas., Piracicaba, SP: IPEF/SIF, 1993. 56p.

BOBE, A.; COOPER, J.; COSTE, C.M.; MULLER, M.-A. Behavior of fipronil in soil under sahelian plain field conditions. Pesticide Science, v.52, p.275281, 1998.

BORROR, D.J.; DELONG, D.M. Estudo dos insetos. 3.ed. São Paulo: Edusp, 1969. $653 \mathrm{p}$.

CAMARGO-DIETRICH， C.R.R.; COSTA-LEONARDO, A.M. População e território de forrageamento de uma colônia de Heterotermes tenuis (Hagen) (Isoptera, Rhinotermitidae). Revista Brasileira de Zoologia, v.20, n.3, p.397-399, 2003 .

CHEN, K.; OHMURA, W.; DOI, S.; AOYAMA, M. Termite feeding deterrent from Japanese larch wood. Bioresource Technology, v.95, p.129-134, 2004.

CONSTANTINO, R. Catalog of the termites of the New World (Insecta: Isoptera). Arquivos de Zoologia, v.35, n.2, p.135-230, 1998.

CONSTANTINO, R. Chave ilustrada para identificação dos gêneros de cupins (Insecta: Isoptera) que ocorrem no Brasil. Papéis Avulsos de Zoologia, v.40, n.25, p.387-448, 1999.

CONSTANTINO, R. The pest termites of South America: taxonomy, distribution and status. Journal of Applied Entomology, v. 126, n.7/8, p.355-365, 2002. 
CONSTANTINO, R. O catálogo dos cupins do novo mundo. http://www.unb.br/ib/zoo/docente/constant/catl/catnew.html (05 Maio 2005).

COSTA-LEONARDO, A.M. A metodologia de iscas para controle de cupins subterrâneos. Revista Agricultura, v.71, n.3, p.337-345, 1996.

COSTA-LEONARDO, A.M. Cupins-Praga: Morfologia, biologia e controle. Rio Claro, SP, 2002. 128p.

COSTA-LEONARDO, A.M.; THORNE, B.L. Iscas e outras metodologias alternativas para o controle de cupins. In: BERTI FILHO, E; FONTES, L.R. (Ed.). Alguns aspectos atuais da biologia e controle de cupins, Piracicaba: FEALQ, 1995. p.89-94.

COSTA-LEONARDO, A.M.; BARSOTTI, R.C. Estudo morfológico do macho alado do cupim Coptotermes havilandi (Isoptera, Rhinotermitidae). In: CONGRESSO BRASILEIRO DE ENTOMOLOGIA, 17., Rio de Janeiro, 1998. Resumos. Rio de Janeiro, 1998. v.2, p.800.

COSTA-LEONARDO, A.M.; CAMARGO-DIETRICH, C.R.R. Território e população de forrageio de uma colônia de Coptotermes havilandi (Isoptera: Rhinotermitidae) em meio urbano. Arquivos do Instituto Biológico, São Paulo, v.66, n.2, p.99-105, 1999.

COSTA-LEONARDO, A.M.; BARSOTTI, R.C.; CAMARGO-DIETRICH, C.R.R. Review and update on the biology of Coptotermes havilandi (Isoptera, Rhinotermitidae). Sociobiology, v.33, n.3, p.339-356, 1999. 
COSTA-LEONARDO, A.M.; BLANCO, Y.C.; ARAB, A.; TELES, C.D.M. Consumo de madeira e sobrevivência de Coptotermes havilandi (Isoptera, Rhinotermitidae) no laboratório. O Biológico, v.64, n.1, p.106, 2002.

CULLENY, T.W.; GRACE, J.K. Prospects for the biological control of subterranean termites (Isoptera: Rhinotermitidae), with special reference to Coptotermes formosanus. Bulletin of Entomological Research, v.90, p.9$21,2000$.

DESIGNATION D 3345-74. Metodo estandard para la evaluación en laboratorio de madera y otros materiales celulósicos para resistencia a termitas. Annual Book of ASTM Standards, v.04, n.10, 1992.

DIOGO, A.S.; CONCEIÇÃO, R.G.; SOUZA, J.H.; PATERNOSTRO, H.G.; BIGALHO, A.C.; MENEZES, E.B.; AGUIAR-MENEZES, E.L.; CONSTANTINO, R. Freqüência de ninhos policálicos de Coptotermes havilandi (Isoptera: Rhinotermitidae) em diferentes tipos de edificações na cidade do Rio de Janeiro e vizinhanças. O Biológico, v.64, n.1, p.108, 2002.

EDWARDS, R.; MILL, A.E. Termites in buildings. Their biology and control. England: Rentokill, 1986. 261p.

ELEOTERIO, E.S.R.; BERTI FILHO, E. Levantamento e identificação de cupins (Insecta: Isoptera) em área urbana de Piracicaba - SP. Ciência Florestal, v.10, n.1, p.125-139, 2000.

EWART, D. McG. Termite barriers for new construction in Australia (Isoptera). Sociobiology, v.37, n.2, p.379-388, 2001. 
FONTES, L.R. Key to the genera of New World Apicotermitinae (Isoptera:Termitidae). In: QUINTERO, D.; AIELLO, A. (Ed.). Insects of Panama and Mesoamerica. Oxfford: Oxford University Press, p.242-248, 1992.

FONTES, L.R. Cupins em áreas urbanas. In: BERTI FILHO, E.; FONTES, L.R. Ed.). Alguns aspectos atuais da biologia e controle de cupins, Piracicaba: FEALQ, 1995, p.57-75.

FONTES, L.R. Infestação urbana por cupins no Brasil. In: CONGRESSO BRASILEIRO DE ENTOMOLOGIA, 20, Gramado, 2004. Resumos. Gramado: SBPC, 2004. p.102.

FONTES, L.R.; VEIGA, A.V.S.L. Registro do cupim subterrâneo, Coptotermes havilandi (Isoptera: Rhinotermitidae), na área metropolitana de Recife, PE. In: CONGRESSO BRASILEIRO DE ENTOMOLOGIA, 17., Rio de Janeiro, 1998. Resumos. Rio de Janeiro: SBPC, 1998a. p.1005.

FONTES, L. R.; BERTI FILHO, E. Cupins: O desafio do conhecimento. Piracicaba: FEALQ, 1998b. 512p.

FONTES, L.R.; MILANO, S. Termites as an urban problem in South America. Sociobiology, v.40, n.1, p.103-151, 2002. 
FORSCHLER, B.T. Biology and control. In: MANDO, A.; FASO, B; CONSTANTINO, R.; RIPA, R.S.; ZHONG, J.; KONATE, S.; MOEIN, S.I.M.; ABDULAHI, A.; KAIB, M.; TSUMODA, K.; KIRTON, L.G.; SUNDENBYLEHN, A.; THORNE, B.L.; DWINELL, S.E.; SU, N.-Y.;LEWIS, V.R.; FORSCHLER, B.T.; HAVERTY, M. (Ed.). Finding alternatives to persistent organic pollutants (POPs) for termite management. http://www.chem.unep.ch/pops/termites/termitefulldocument.doc. (17 março 2005).

FORSCHLER, B.T.; TOWNSEND, M.L. Mortality of eastern subterranean termites (Isoptera: Rhinotermitidae) exposed to four soils treated with termiticides. Journal of Economic Entomology, v.89, n.3, p.678-681, 1996.

FRENCH, J.R.J. Physical barriers and bait toxicants in future termite control strategies. Annals of Entomology, v.9, p.1-5, 1993.

GATTI, -S.-S; HENDERSON, -G. Differential response of formosan subterranean termite castes (Isoptera: Rhinotermitidae) to selected termiticides. Sociobiology, v.28, n.1, p.23-32, 1996.

GAY, F.J.; GREAVES, T.; HOLDAWAY F.G.; WETHERLY, A.H. The development and use of field testing techniques with termites in Australia. Australian Bulletin, n.280, p.1-31, 1957. 
GOLD, R.E.; HOWELL, J.R.H.N.; PAWSON, B.M.; WRIGHT, M.S.; LUTZ J.C. Evaluation of termiticyde residues and bioavailability from five soil types and locations in Texas. In: WILDEY, K.B. (Ed.). In: INTERNATIONAL CONFERENCE ON INSECT PESTS IN THE URBAN ENVIRONMENT. Proceedings. Edinburgh: Insect Pest Eradication Publications, 1996. p. 467484.

GRACE, J.K.; YATES, J.R. Behaviaoural effects of neem insecticide on Coptotermes formosanus (Isoptera: Rhinotermitidae). Tropical Pest Management., v.38, p.176-180, 1992.

GRACE, J.K.; YAMAMOTO, T. Diatomaceous earth is not a barrier to formosan subterranean termites (Isoptera: Rhinotermitidae). Sociobiology, v.23, p.2530,1993

GRACE, J.K.; WOODROW, R.J.; YATES, J.R. Distribution and management of termites in Hawaii. Sociobiology, n. 40, p.87-93, 2002.

GRASSÉ, P.P. Termitologia. Comportement, socialité, écologie, evolution, systematique, Paris: Masson, 1986. 715p.

HERDERSON, G; FORSCHLER, B.T. Termite baits tests. Louisiana Agriculture, v.40, n.3, p.9-11, 1997.

IBRAHIM, S.A.; HENDRESON, G.; FEI, H. Toxicity, repellency, and horizontal transmission of Fipronil in the formosan subterranean termite (Isoptera: Rhinotermitidae). Journal Economic Entomology, v.96, n.2, p.461-467, 2003. 
JOHNSTON, H.R.; SMITH, V.K.; BEAL, R.H. Subterranean termites: their prevention and control in buildings. U. S. Dept. Agric., Home and Gard Bulletin, v.64, p.30, 1979.

KIRTON, L.G.; BROWN, V.K. The taxonomic status of pest species of Coptotermes in Southeast Asia: Resolving the paradox in the pest status of the termites, Coptotermes gestroi, C. havilandi and C. travians (Isoptera: Rhinotermitidae). Sociobiology, n.42, p.43-83, 2003.

LELIS, A. T. Termite problems in São Paulo city - Brazil. LENOIR, A.; ARNOLD, G.; LEPAGE, M. (Ed.). Les Insectes Sociaux. In: CONGRESS OF THE INTERNARIONAL UNION FOR THE STUDY OF SOCIAL INSECTS (IUSSI), 12., Paris, 1994. Anais. Paris: Sorbonne, 1994. 253p.

LELIS, A.T. Anest of Coptotermes havilandi (Isoptera, Rhinotermitidae) off ground level, found in the $20^{\text {th }}$ story of a building in the city of São Paulo, Brazil. Sociobiology, n.26, v.1, p.1-5, 1995.

LELIS, A.T. Primeiro registro no Brasil de rainha de substituição de Coptotermes havilandi e sua implicação no controle desse cupim. Vetores \& pragas, n.4, p.19-23, 1999.

LENZ, M.; MARROW, P.; RUNKO, S. A novel chemical barrier system, Kordon $₫ T M B$, for the protetion of buildings against subterranean termites using a synthetic matrix as carrier for the chemical. In: ANNUAL MEETING INTERNATIONAL RESEARCH GROUP ON WOOD PRESERVATION, 29., (Document N IRGMP98-10264). Sweden, 1998. Abstracts. Sweden: IRG Secretariat, 1998. p.8. 
LENZ, M.; WATSON, J.A.L.; BARRETT, R.A. Australian efficacy data for chemicals used in soil barreiers against subterranean termites. Camberra, Australian: CSIRO Entomology, 1988. p.57-81.

LOECK, A.E. Atividade biológica de dois inseticidas piretróides e sua persistência em solo barro-areno-argiloso em condições de campo. Piracicaba, 1985. 101p. Tese (Doutorado) Escola Superior de Agricultura "Luiz de Queiroz", Universidade de São Paulo.

LOGON, J.W.M.; ABOOD, F. Laboratory trials on the toxicity of hydramethylnon (Amdro; AC 217,300) to Reticulitermes flavipes Feytaud (Isoptera: Rhinotermitidae) and Microtermes lepitus Sjöstedt (Isoptera: Termitidae). Bulletin of Entomological Research, v.80 p.19-26, 1990.

LOGON, J.W.M.; COWIE, R.H.; WOOD, T.G. Termite (Isoptera) control in agriculture and florestry by non-chemical methods: a review. Bulletin of Entomological Research, v.80, n.3, p.309-330, 1990.

MARICONI, F.A.M.; FONTES, L.R.; ARAUJO, R.L.; ZAMITH, A.P.L.; CARVALHO NETO, C.; BUENO, O.C.; CAMPOS-FARINHA, A.E.C.; MATTHIESEN, F.A.; TADDEI, V.A.; OLIVEIRA FILHO, A.M.; FERREIRA, W.L.B. Insetos e outros invasores de residências. Piracicaba: FEALQ, 1999. v.6, p. 35-91.

MENEZES, E.B. Importância, diversidade e controle de cupins da família Rhinotermitidae (Isoptera) em áreas urbanas e rurais. In: CONGRESSO BRASILEIRO DE ENTOMOLOGIA, 20. Gramado, 2004. Resumos. Gramado: SBPC. 2004. p.110. 
MILANO, S.; FONTES, L.R. Cupim e Cidade: Implicações ecológicas e controle, São Paulo: Conquistas Arte Gráfica, 2002. 141p.

MILANO, S.; FONTES, L.R.; LELIS, A. T. Cupins Urbanos: os caminhos para o controle. Boletim Técnico APRAG, n. 2, 45p., 1996.

MOEIN, S.I. Methods of controlling the structural termites in Egypt Conventional and prospect of the future management. In: REPORT OF THE UNEP/FAO/Global IPM Facility Termite Biology and Management, Geneva, 2000. Report. Geneva: UNEP/FAO/Global IPM, 2000. p. 41-42.

NUNES, A.L.O.S.; LEAL, M.R.; GONÇALVES, M.P.; ARAÚJO, G.T.; DIAS, I.S.; MENEZES, E.B.; AGUIAR-MENEZES, E.L. Teste de eficácia com piretróide bifentrina no controle de Coptotermes havilandi (Isoptera: Rhinotermitidae) em condições de laboratório. O Biológico. v.64, n.1, p.107, 2002.

OSBRINK, W.L.A.; LAX, A.R. Effect of tolerance to insecticides on substrate penetration by formosan subterranean termites (Isoptera: Rhinotermitidae). Journal of Economic Entomology, v.95, n.5, p.989-1000, 2002.

OSBRINK, W.L.A.; LAX, A.R. Effect of Imidacloprid tree treatments on the occurrence of formosan subterranean termites, Coptotermes formosanus Shiraki (Isoptera: Rhinotermitidae), in independent monitors. Journal of Economic Entomology, v.96, n.1, p.117-125, 2003.

OSBRINK, W.L.A.; LAX, A.R.; BRENNER, R.J. Insecticide susceptibility in Coptotermes formosanus and Reticulitermes virginicus (Isoptera: Rhinotermitidae). Journal of Economic Entomology, v.94, n.5, p.12171228, 2001. 
PAIVA, C.L. Construções rurais coloniais no quadrilátero do açúcar, Estado de São Paulo. Revista do Instituto Histórico e Geográfico de Piracicaba, v.5, p.37-46, 1997.

PEARCE, M.J. Termites: Biology and pest management. New York: CAB Iternational, 1997. 172p.

PERALTA, R.C.G.; MENEZES, E.B.; CARVALHO, A.G.; AGUIAR-MENEZES, E.L. Wood consumption rates if forest species by subterranean termites (Isoptera) under field conditions. Revista Árvore, v.28, n.2, p.283-289, 2004.

PETER, B.C.; KING, J.; WYLIE, F.R. Treating subterranean termite attacks in buildings. Queensland: Forestry Research Institute, 2001. 6p. (Timber Note, 10).

POTENZA, M.R.; CAMPOS, T.B.; ZORZENON, F.J.; CANCELLO, E.M. Métodos de controle. In: ZORZENON, F.J.;POTENZA, M.R. (Ed.). Cupins: Pragas em áreas urbanas. Boletim Técnico do Instituto Biológico, n.10, p.5-40, 1998.

ROMAGNANO, L. F. T. Ocorrência de cupim subterrâneo Coptotermes havilandi em embarcações no Guarujá, SP. O Biológico. v.64, n.1, p.105, 2002.

SHELLMAN-REEVE, J.S. The spectrum of eusociality in termites. In: CHOE, J.C. (Ed.). The Evolution of social behavior in insects and arachnids. Cambridge University Press, 1997, p.52-93. 
SHELTON, T.G.; GRACE, J.K. Effects of exposure duration on transfer of nonrepellent termiticides among workers of Coptotrmes formosanus Shiraki (Isoptera: Rhinotermitidae). Journal of Economic Entomology, v.96, n.2, p.456-460, 2003.

SU, N.-Y. Field evaluation of a hexaflumuron bait for population suppression of subterranean termites (Isoptera: Rhinotermitidae). Journal of Economic Entomology, v.87, n.2, p.389-397, 1994.

SU, N-Y. Pesquisa e desenvolvimento de tecnologias para o controle de cupins subterrâneos. In: CONGRESSO INTERNACIONAL DE CONTROLE DE VETORES E PRAGAS 4., São Paulo, 2002. Anais. São Paulo: APRAG. 2002. p.51.

SU, N.-Y.; FAGE, J.P.L.A. Effects of starvation on survival and maintenance of soldier proportion in laboratory groups of the formosan subterranean termite, Coptotermes formosanus (Isoptera: Rhinotermitidae). Annals of the Entomological Society of America, v.79, n.2, p.312-316, 1986.

SU, N.-Y.; SCHEFFRHAN, R.H. Comparison of eleven soil termiticides against the formosan subterranean termite and eastern subterranean termite (Isoptera: Rhinotermitidae). Journal of Economic Entomology, v.83, n.5, p.1918-1924, 1989.

SU, N.-Y.; SCHEFFRHAN, R.H. Potential of insect growth regulators as termiticides: a review. Sociobiology, v.17, p. 313-328, 1990.

SU, N.-Y.; SCHEFFRAHN, R.H. Penetration of sized particle barriers by field populations of subterranean termites (Isoptera: Rhinotermitadae. Journal of Economic Entomology, v.85, p.2275-2278, 1992. 
SU, N.-Y.; SCHEFFRHAN, R.H. Laboratory evaluation of two chitin synthesis inhibitors, hexaflumuron and diflubenzuron, as bait toxicants against the Formosan subterranean termite and easten subterranean termite (Isoptera: Rhinotermitidae). Journal of Economic Entomology, v. 86, p.1453-1457, 1993.

SU, N.-Y; SCHEFFRAHN, R.H. Comparative effects of two chitin sysnthesis inhibitors, hexaflumuron and lufenuron, in a bait matrix against subterranean termites (Isoptera: Rhinotermitidae). Journal of Economic Entomology, v.89, p.1156-1160, 1996.

SU, N.-Y; SHEFFRAHN, R.H. A review of subterranean termite control practices and prospects for integrated pest management programs. Integrated Pest Management Review, v.3 p.1-13, 1998.

SU, N.-Y.; SCHEFFRAHN, R.H. Longevity and efficacy of pyrethroid and organophosphate termiticides in field degradation studies using miniature slabs. Journal Economic Entomology, v.92, n.4, p.890-898, 1999.

SU, N.-Y.; SCHEEFRAHN, R. H. Termites as pests of building. In: ABE, T.; BIGNELL, D. E.; HIGASHI, M. (Ed.). Termites: Evolution, Sociality, Symbioses, Ecology, Kluwer Academic Publishers, Boston, p.437-453, 2000.

SU, N.-Y.; SCHEFFRAHN, R.H. Formosan Subterranean termite, Coptotermes formosanus Shiraki (Insecta: Isoptera: Rhinotermitidae). http://edis.ifas.ufl.edu/IN278. (17 março 2005). 
SU, N.-Y.; SCHEEFRAHN, R.H.; BAN, P.M. Barrier efficacy of pyrethroid and organophosphate formulations against subterranean termites (Isoptera: Rhinotermitidae). Journal of Economic Entomology, v.86, n.3, p.772-776, 1993.

SU, N.-Y.; SCHEEFRAHN, R.H.; BAN, P.M. Effects of sulfluramid treated bait blocks on field colonies of the Formosan subterranean termite (Isoptera: Rhinotermitidae). Journal of Economic Entomology, v.88, p.1343-1348, 1995a.

SU, N.-Y.; SCHEFFRAHN, R.H.; WEISSLING, T. Termite species migrantes to Florida. Pest Control, n.2, p.27-29, 1997.

SU, N.-Y.; BAN, P.M.; SCHEFFRAHN, R.H. Control of Coptotermes havilandi (Isoptera: Rhinotermitidae) with hexaflumuron baits and a sensor incorporated into a monitoring and baiting program. Journal of Economic Entomology, v.93, n.2, p.415-421, 2000.

SU, N.-Y.; BAN, P.M.; SCHEFFRAHN, R.H. Control of subterranean termite population at San Cristóbal and El Morro, San Juan National Historic Site. Journal of Cultural Heritage, v.3, p.217-225, 2002.

SU, N.-Y.; CHEW, V.; WHEELER, G.S.; SCHEFFRAHN, R.H. Comparison of tunneling responses into inseticide-treated soil by field populations and laboratory groups of subterranean termites (Isoptera: Rhinotermitidae). Journal of Economic Entomology, v.90, n.2, p.503-509, 1997.

SU, N.-Y; BAN, P.M.; CHEW, V.; SCHEFFRAHN, R.H. Size and edge effects of concrete plots on chlorpyrifos degradation in sub-slab sand. Journal of Economic Entomology. v.92, p.409-415, 1999. 
SU, N.-Y; CHEW, V.; WHEELER, G.S.; SCHEFFRAHN, R.H. Subterranean termite (Isoptera: Rhinotermitidae) penetration into sand treated at various thicknesses with termiticides. Journal of Economic Entomology, v.88, n.6, p.1690-1694, 1995b.

TAMASHIRO, M. YATES, J.R.; YAMAMOTO, R.T. EBEUS, R. Tunneling behaviour of the Formosan subterranean termite and basalt barriers. Sociobiology, v.19, p.163-170, 1991.

THOMAS, C.R.; ROBINSON, W.H. Termiticide distribution after subslab injection. Pest Control Techonology, v.19, n.10, p. 60-66, 1991.

THORNE, B.L.; BREISCH, N.L. Effects of sublthal exposure to imidacloprid on subsequent behavior of subterranean termite Reticulitermes virginicus (Isoptera: Rhinotermitidae). Journal of Economic Entomology, v.94, n.2, p.492-498, 2001.

TOMLIN, C. A World compendium: The pesticide manual. 10.ed. British: Crop Protection Publications, 1994. 1341p.

TORALES, G.J. Rol de los isopteros en la Argentina. In: FONTES, L.R.; BERTI FILHO, E. (Ed.). Cupins: O desafio do conhecimento. Piracicaba: FEALQ, 1998. p.413-135.

USEPA 3545. http://www.epa.gov/epaoswer/hazwaste/test/pdfs/3545.dpf. (17 maio 2005). 
WAITE, T.D. Field studies of exterior-only applications with fipronil (Termidor® $\mathrm{SC})$ for the post-construction control of interior populations of subterranean termites (Isoptera: Rhinotermitidae). Texas, 2003. 88p. Thesis (Master of Science) - Texas A\&M University.

WALLER, D.A.; LA FAGE, J.P. Nutritional ecology of termites. In: SLANSKY JR., F.; RODRIGUEZ, J.C. (Ed.). Nutritional ecology of insects, mites, spiders and related invertebrates. Wiley-Interscience Publication, New York, cap.16, p.487-532, 1986.

WANG, C.; POWELL, J.E. Cellulose bait improves the effectiveness of Matarhizium anisopliae as a microbial control of termites (Isoptera: Rhinotermitidae). Biological Control, v.30, p.523-529, 2004.

WEI, C.-H; LU,C.-C; YI, Y.-H. Preliminary study on the control of Coptotermes formosanus Shiraki by imidacloprid. Journal of South China Agricultural University, v.21, n.4, p. 33-35, 2000.

WISEMAN, S.; EGGLETON, P. The termicide market (D588). Richmond, Surrey: Agrow PJB Publications, 1994, p.21-27.

YOSHIMURA, Y.; TSUMODA, K. Alternative protetion of Japanese houses from subterranean termite invasion. In: LENOIR, A..; ARNOLD, G.; LEPAGE, M. (Ed.). Termites in Urban Areas. Les Insectes Sociaux, Paris, 1994. In: INTERNATIONAL CONGRESS INTERNATIONAL UNION FOR THE STUDY OF SOCIAL INSECTS, 12., Paris, 1994. Abstracts. Paris: Sorbone, 1994. p.259.

ZONTA, E.P.; MACHADO, A.A. SANEST: Sistema de análise estatística para microcomputadores. Piracicaba: CIAGRI, ESALQ/USP, 1993. 138p. 
ZORZENON, F.J.; POTENZA, M.R.Cupins: pragas em áreas urbanas. Boletim Técnico do Instituto Biológico, n.10, p.5-40, 1998. 